\title{
EFFECT OF SUBSURFACE CONDITIONS ON EARTHQUAKE GROUND MOTIONS
}

Felix Y. Yokel

Building and Fire Research Laboratory

Gaithersburg, Maryland 20899

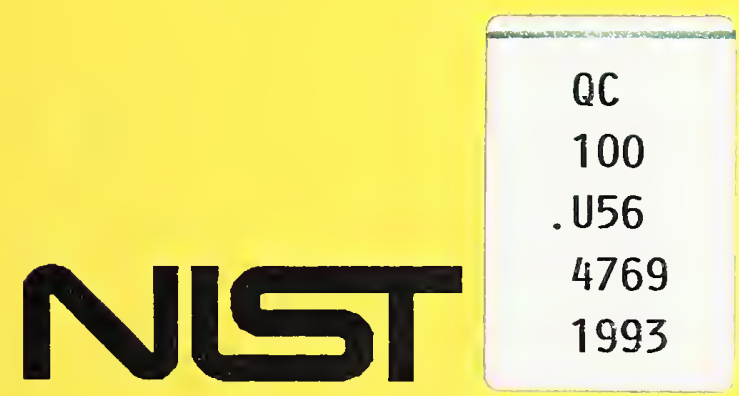

United States Department of Commerce Technology Administration

National Institute of Standards and Technology 



\section{EFFECT OF SUBSURFACE CONDITIONS ON EARTHQUAKE GROUND MOTIONS}

Felix Y. Yokel

January 1993

Building and Fire Research Laboratory

National Institute of Standards and Technology

Gaithersburg, MD 20899

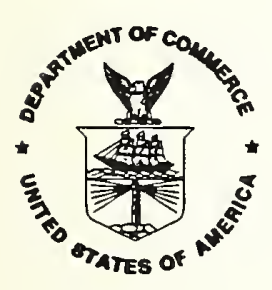

\section{U.S. DEPARTMENT OF COMMERCE}

Ronald H. Brown, Secretary

National Institute of Standards and Technology

John W. Lyons, Director 



\section{ABSTRACT}

A revised version of the SHAKE program was prepared and used to study the effects of subsurface conditions on the earthquake ground motion in the Loma Prieta earthquake. Preliminary soil profile data from the sites of the Oakland Outer Harbor Wharf and Apeel 2 strong motion stations are used to calculate ground motions, which are then compared with the recorded ground motions using response spectra calculated for a $5 \%$ damping ratio. Parameters affecting the amplitude of the calculated ground motion are examined. Response Spectra for recorded and calculated ground motions are compared with recommended design spectra (NEHRP, 1988). It is shown that for periods less than $1.4 \mathrm{~s}$ the response spectra for recorded far source earthquake motions at Oakland Wharf and Apeel 2 fall outside the envelope of the applicable design spectra, and that response spectra for deeper soil profiles calculated for near source conditions exceed the design spectra by a considerable margin. Design spectra for the San Francisco Bay region, recently proposed in a USGS study, are reasonably close to the calculated near source spectra for deeper soil profiles for periods less than $1 \mathrm{~s}$, but they are conservative for the bedrock motion, and extremely conservative for longer period structures.

Key Words: dynamic soil properties; earthquake engineering; ground motion; shear wave propagation; response spectra; soil dynamics; wave mechanics 


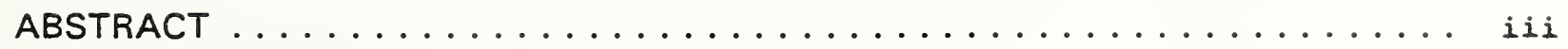

TABLE OF CONTENTS $\ldots \ldots \ldots \ldots \ldots \ldots \ldots \ldots \ldots \ldots \ldots \ldots$

LIST OF SYMBOLS $\ldots \ldots \ldots \ldots \ldots \ldots \ldots \ldots \ldots \ldots \ldots \ldots \ldots \ldots \ldots$

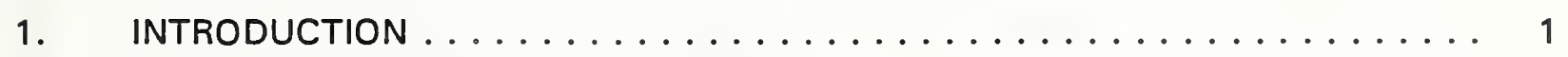

2: MODELING THE PROPAGATION OF THE BEDROCK MOTION TO THE GROUND

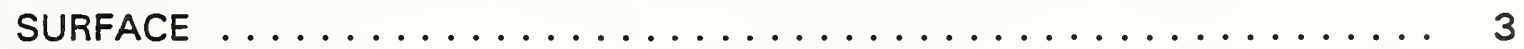

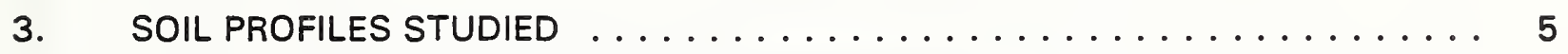

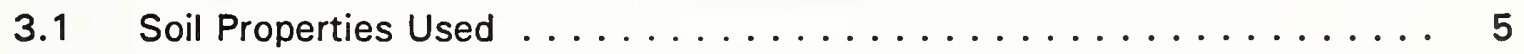

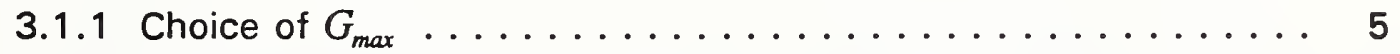

3.1.2 Relationship between $G_{\max }$ and $\beta$ and cyclic shear strain ..... 6

3.2 Soil Profiles Studied $\ldots \ldots \ldots \ldots \ldots \ldots \ldots \ldots$

4. RESULT OBTAINED WITH MODIFIED SHAKE PROGRAM . . . . . . . . 13

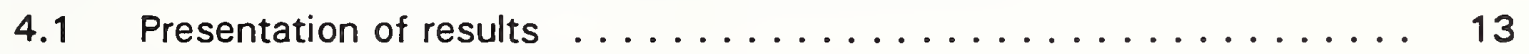

4.2 Discussion of Results $\ldots \ldots \ldots \ldots \ldots \ldots \ldots \ldots \ldots$

4.2.1 Oakland Outer Harbor Wharf Motion. . . . . . . . . . . . . . 14

4.2.2 Profiles with New Bay Mud (Cases 1 through 4) . . . . . . . . 25

4.2.2.1 Profiles Studied ................ 25

4.2.2.2 Effect of New Bay Mud depth ........... 25

4.2.2.3 Effect of Layer Thickness used in Analysis .... 26

4.2.3 Effect of Alluvium (Cases 5 to 7 ) .............. 27

4.2 .4 Composite Profiles ..................... 27

4.2.4.1 New Bay Mud Over Alluvium . . . . . . . . . . 27

4.2.4.2 Old Bay Mud, Alluvium and New Bay Mud ...... 28

4.2.5 Comparison of New Bay Mud, Alluvium, and Old Bay Mud .... 28 
5. COMPARISON OF CALCULATED RESPONSE SPECTRA WITH NEHRP DESIGN

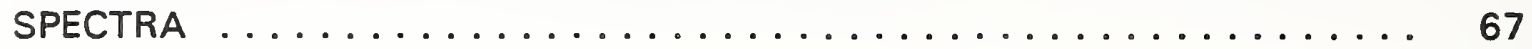

5.1 Design Spectra Considered ................... 67

5.2 Comparison of the NEHRP design Spectra with Response Spectra for Calculated and Observed Ground Motions ................ 68

5.3 Spectral Maps Prepared by USGS $\ldots \ldots \ldots \ldots \ldots \ldots \ldots \ldots$

6. SUMMARY OF FINDINGS $\ldots \ldots \ldots \ldots \ldots \ldots \ldots \ldots \ldots \ldots \ldots \ldots$

6.1 Modeling of the Ground Motion . . . . . . . . . . . . 81

6.2 Effect of Soil Profile Characteristics $\ldots \ldots \ldots \ldots \ldots \ldots \ldots$

6.3 Comparison With Recommended Design Spectra ............ 82

7. ACKNOWLEDGEMENT $\ldots \ldots \ldots \ldots \ldots \ldots \ldots \ldots \ldots \ldots \ldots \ldots \ldots$

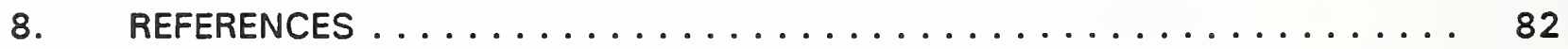

APPENDIX: EQUATIONS USED IN THE SHAKE PROGRAM ........... 84 


\section{LIST OF SYMBOLS}

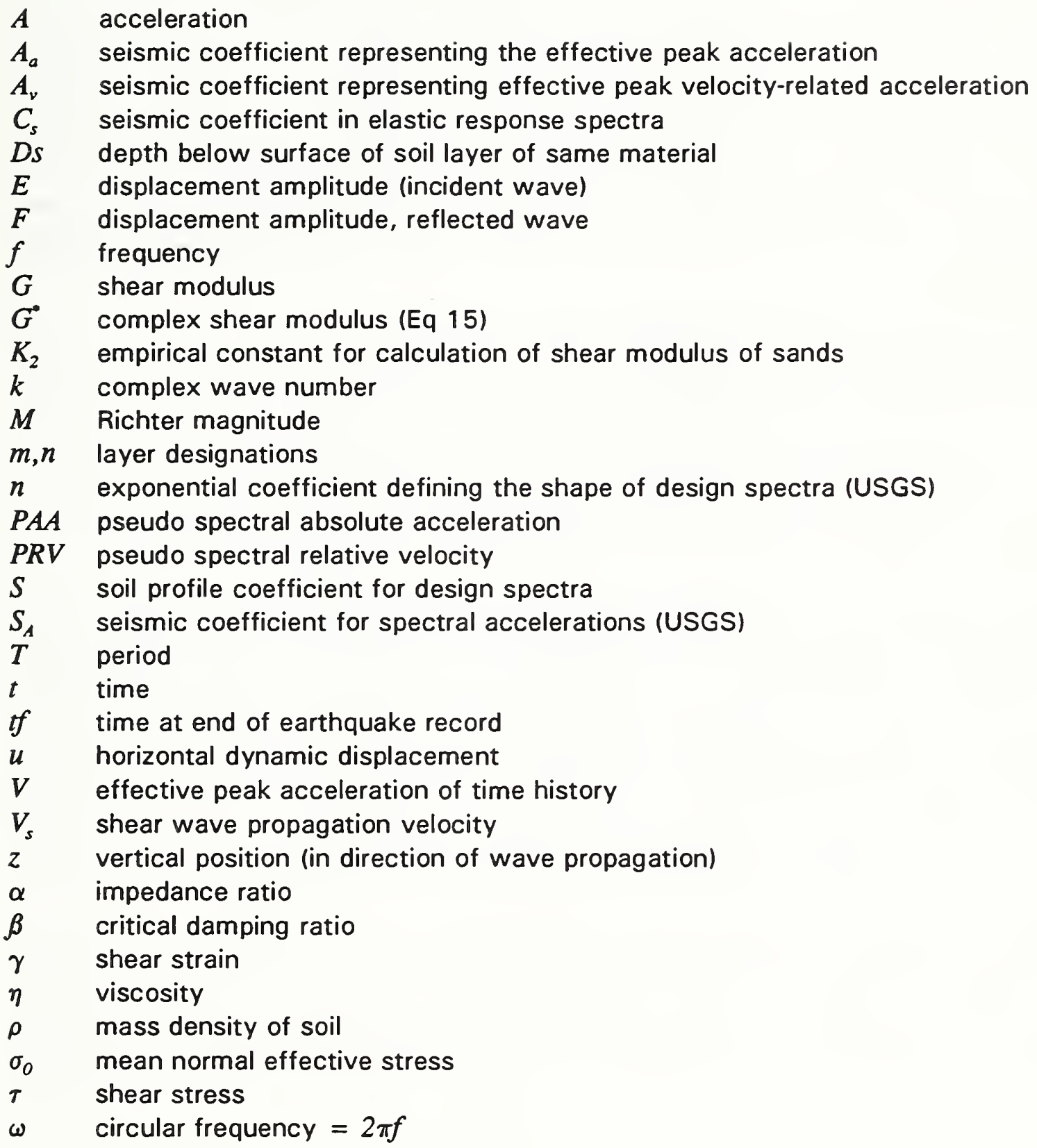


viii 


\section{INTRODUCTION}

One of the prominent features of the October 17,1989 Loma Prieta Earthquake was the close correlation between the subsurface conditions and the damage pattern. While this is not a new observation (re: Mexico City, Caracas, etc.), it appears in this instance that even very stiff structures were damaged on sites with relatively deep soil deposits, while similar structures in the vicinity, resting on shallow, competent soil or rock, suffered no damage. Substantial amplification of the earthquake motion was observed in areas of Bay Mud deposits (average amplification of maximum vertical and horizontal accelerations by factors of 1.8 and 2.6, respectively) and on sites of deep alluvial deposits (average amplification of maximum vertical and horizontal accelerations by factors of 1.9 and 1.8 , respectively) (EERI, 1989). Coupled with the longer dominant period of the horizontal ground motion of most deep soil deposits, the horizontal acceleration amplifications result in much larger amplifications of velocities and displacements.

After the Loma Prieta earthquake, the National Institute of Standards and Technology (NIST) initiated a research effort which was designed to address gaps in the state of the art of earthquake engineering and deficiencies in design standards which became apparent as a result of the earthquake damage. One of the topics identified as requiring further study is the effect of subsurface conditions on the earthquake ground motion. The research undertaken by NIST focussed on the prediction of the effect of the intervening unconsolidated deposits on the propagation of earthquake ground motions from the underlying bedrock to the ground surface, as well as on the selection of bedrock motions for seismic design.

Strong motion data collected during the earthquake, coupled with information acquired in subsequent subsurface investigations, afford the opportunity to test the validity of present mathematical models, dealing with the propagation of the earthquake motion from the underlying bedrock to the ground surface. In one phase of the NIST research, which is carried out at the University of California, Davis, subsurface data from the site of the strong motion recording on Treasure Island are utilized to examine mathematical models for predicting the ground motion. In this latter project strong motion records from rock outcrop motions at Yorba Buena and Rincon Hill were utilized to generate a ground surface motion, which then could be compared with the strong motion record from Treasure Island.

In this report, a revised version of the SHAKE program (Schnabel et al., 1972), prepared as part of the NIST research, is used to study the effect of various soil conditions encountered in the San Francisco Bay area on the horizontal components of the ground motion. Vertical ground motions are not studied in this NIST project. A user manual for the revised SHAKE program will be published at a later date. Some of the revisions are discussed in the following section. 


\section{MODELING THE PROPAGATION OF THE BEDROCK MOTION TO THE GROUND SURFACE}

Plots of dynamic stress-strain properties, used in this study for Bay Mud, alluvium, and sand under small confining pressures are shown in Figure 2.1. The shear modulus is plotted as a function of $G_{\max }$, the shear modulus at very small strains, such as those associated with shearwave propagation velocity measurements in a geophysical soil explorations. Damping is given as a percentage of critical damping. It can be seen that the dynamic shear modulus decreases, and the damping ratio increases with increasing strains.

Many different methods can be used to model the propagation of the bedrock motion to the ground surface, such as modeling of wave propagation, lumped mass models, and finite element models. An important aspect of a numerical model is whether or not it can reasonably represent the non linear behavior of soils under cyclic loading conditions. From this viewpoint the models fall into two categories: equivalent linear, and non linear models. In the equivalent linear models, the dynamic shear modulus and the damping ratio for the entire time history of the motion are fixed for each soil layer for a specific strain level which is defined as a fraction of the maximum strain experienced. This approach does not permit consideration of cyclic degradation effects on stiffness and damping. It is therefore not sensitive to the number of strain cycles applied, although allowance for the magnitude of the earthquake can be made by the setting of the user defined strain level for which the equivalent linear properties are determined. The equivalent linear approach can also not be used to predict the ground motion for sites which experience cyclic mobility or liquefaction. However, it is extensively used to predict the liquefaction potential of sites in terms of the cyclic stress or strain level before liquefaction occurs. Another limitation to the use of equivalent linear models is the magnitude of cyclic strains experienced in the earthquake. If these strains are very large, most soils will experience cyclic degradation and the use of an equivalent linear model is therefore inappropriate.

In this study the SHAKE program (Schnabel et al., 1972) was used, which is an equivalent linear program, based on one-dimensional wave propagation theory. The 1-D wave equation is used on the basis of the assumption that the soil deposit is horizontally layered (orthotropic). The ground motion is idealized as in-plane horizontal displacements, propagated upward from an isotropic halfspace of bedrock with a horizontal surface. This idealization is reasonably applicable to many situations, particularly in sedimentary deposits. Equations used in the SHAKE program, which were derived by Schnabel et al., 1972, and amended by Udaka and Lysmer, 1973, are reviewed in the appendix. Since it was authored in 1972, the SHAKE program has undergone successive revisions. The last version published before initiation of the NIST ground motion study was by Sun and Galesorkhi, 1988. In this latter version, the number of soil types for which dynamic properties can be specified was increased from 4 to 13, and specific dynamic properties for clays and sands were proposed. In the current revision the number of soil layers in the profile for which the calculations can be performed was increased from 20 to 50 . This not only enables us to better represent complex subsurface conditions, but also permits the use of thinner layers. It was reasoned, that in order to properly represent the higher frequency range of the ground motion, layer thicknesses should not exceed $1 / 4$ of the wave length. Other revisions in the program are discussed in more detail in the user manual for the revised program (Idriss et al.,1992). 
It was reasoned, that in order to properly represent the higher frequency range of the ground motion, layer thicknesses should not exceed $1 / 4$ of the wave length.

Other revisions in the program are discussed in more detail in the user manual for the revised program (Idriss et al.,1992).

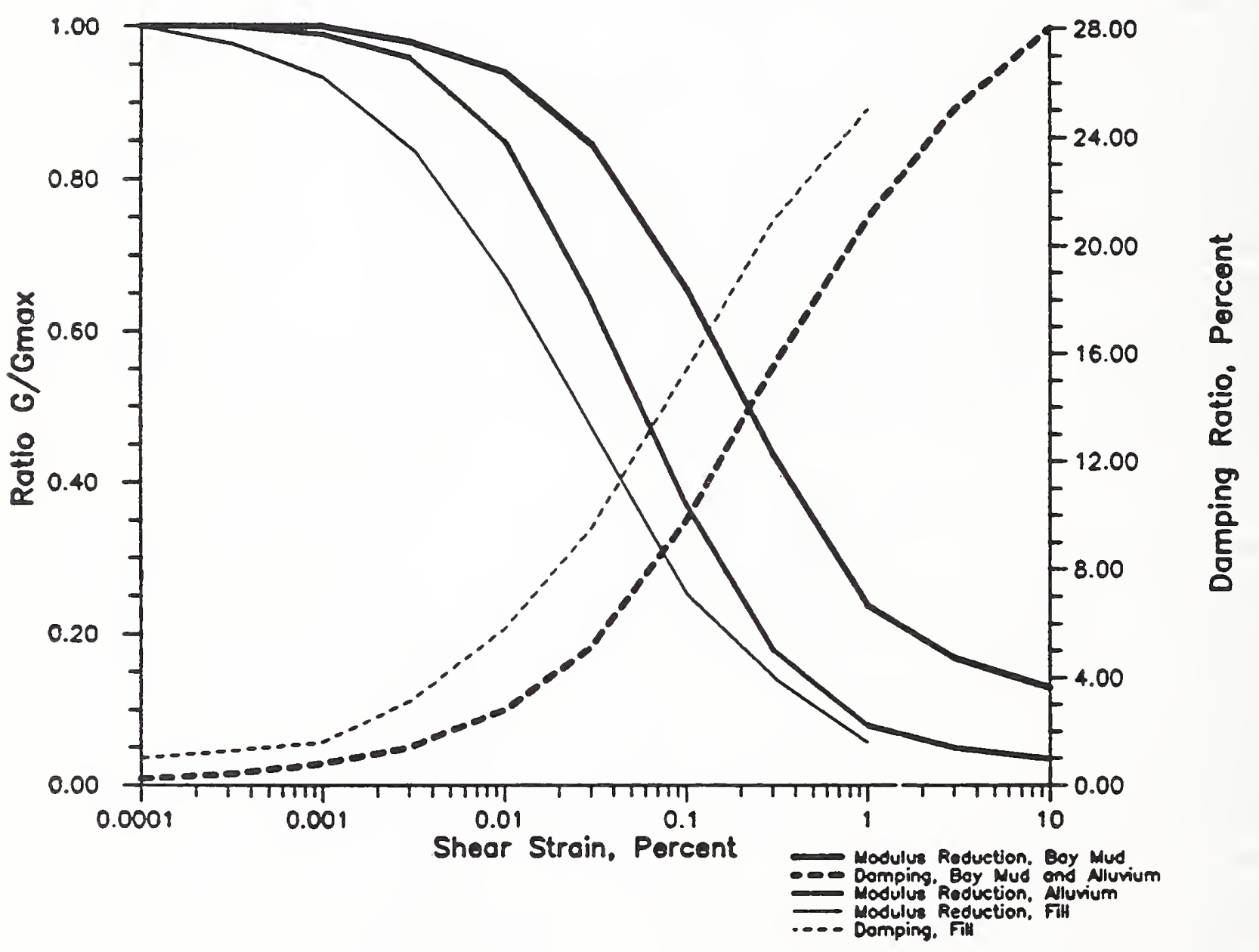

Figure 2.1: Dynamic Stress-Strain Properties of Soils Used in this Study 


\section{SOIL. PROFILES STUDIED}

\subsection{Soil Properties Used}

\subsubsection{Choice of $G_{\max }$}

Figure 1 shows the dynamic shear modulus reduction $G / G_{\max }$ as a function of strain, relative to the dynamic shear modulus at very small strains, $G_{\max }$. This still leaves the problem of determining a value for $G_{\max }$. In practice this is usually accomplished in situ by measuring the shear wave velocity. The shear wave velocity is related to $G_{\max }$ by the following relationship:

$$
G_{\max }=\rho V_{s}^{2}
$$

where: $\quad \rho=$ mass density of soil

$$
V_{s}=\text { shear wave propagation velocity }
$$

In sands, the shear modulus has been found to be approximately proportional to the square root of the mean normal effective stress (Seed \& Idriss, 1970):

$$
\begin{aligned}
& G_{(p s f)}=1000 K_{2}\left(\sigma_{0(p s f)}\right)^{0.5}, \\
& G_{(k s f)}=K_{2}\left(1000 \sigma_{0(K s f)}\right)^{0.5}
\end{aligned}
$$

where: $\quad \sigma_{0}=$ mean normal effective stress

$K_{2}=$ empirical constant

$G=$ shear modulus

These values can be converted to SI units as follows:

$$
G_{(M P a)}=K_{2 m}\left(\sigma_{0}\right)^{0.5}
$$

where: $\quad \sigma_{0}=$ mean normal stress in $\mathrm{MPa}$

$$
K_{2 m}(k P a)^{0.5}=.2188 \cdot K_{2}(p s f)^{0.5}=\text { empirical constant }
$$


The following soil properties were used in the analysis of the San Francisco area profiles. These properties represent an estimate of average values. For example, shear wave velocity values as low as $55 \mathrm{~m} / \mathrm{s}(180 \mathrm{ft} / \mathrm{s})$ have been reported for some New Bay Mud deposits.

For fill:

$K_{2(\max )}=50(p s f)^{0.5} ;$ or $K_{2 m(\max )}=10.94(\mathrm{kPa})^{0.5}$

Unit Weight: $.1 \mathrm{Kcf}=1.6 \mathrm{Mg} / \mathrm{m}^{3}$

For Alluvium:

$K_{2(\max )}=60$ to $90(p s f)^{0.5} ;$ or $K_{2 \max )}=13$ to $20(\mathrm{kPa})^{0.5}$

Unit Weight $=.13$ to $.14 \mathrm{Kcf}=2$ to $2.2 \mathrm{Mg} / \mathrm{m}^{3}$

For New Bay Mud:

$V_{s}=300$ to $600 \mathrm{ft} / \mathrm{s}=90$ to $180 \mathrm{~m} / \mathrm{s}$

Unit Weight: . 11 to $.13 \mathrm{Kcf}=1.76$ to $2.1 \mathrm{Mg} / \mathrm{m}^{3}$

For Old Bay Mud:

$V_{s}=1200$ to $2500 \mathrm{ft} / \mathrm{s}$ (for $600 \mathrm{ft}$ deep deposit) $=365$ to $762 \mathrm{~m} / \mathrm{s}$

Unit weight $=.13 \mathrm{Kcf}=2.08 \mathrm{Mg} / \mathrm{m}^{3}$

For the study of the generic soil profiles, representing generic soil profile types specified in the National Earthquake Hazard Reduction Program (NEHRP) recommended provisions (NEHRP, 1988), shear wave velocities of soft soil deposits were assumed to vary from 200 to $400 \mathrm{ft} / \mathrm{s}$ (60 to $120 \mathrm{~m} / \mathrm{s}$ ).

3.1.2 Relationship between $G_{\max }$ and $\beta$ and cyclic shear strain

The variations of modulus reduction $\left(G / G_{\max }\right)$ and damping ratio $(\beta)$ with cyclic strains used in this study are shown in figure 2.1. The following data were used in the analysis: 
Curves NO 1 and 2 were used for modulus and damping, respectively, of New and Old Bay Mud:

CURVE NO. 1: modulus for clay (Seed \& Sun, 1989), upper range.

CURVE NO. 2: damping for clay (Idriss, 1990).

CURVE NO. 1

$=======$

STRAIN $G / G_{\max }$

.100E-03

$.300 \mathrm{E}-03$

$.100 \mathrm{E}-02$

$.300 \mathrm{E}-02$

$.100 \mathrm{E}-01$

$.300 \mathrm{E}-01$

$.100 E+00$

$.300 E+00$

$.100 E+01$

$.300 E+01$

$.100 E+02$
1.000

1.00

1.000

.981

.941

.847

.656

.438

.238

.170

.130
CURVE NO. 2

$=======$

STRAIN DAMPING

$\begin{array}{ll}.100 E-03 & .24 \\ .300 E-03 & .42 \\ .100 E-02 & .80 \\ .300 E-02 & 1.40 \\ .100 E-01 & 2.80 \\ .300 E-01 & 5.10 \\ .100 E+00 & 9.80 \\ .300 E+00 & 15.50 \\ .100 E+01 & 21.00 \\ .300 E+01 & 25.00 \\ .100 E+02 & 28.00\end{array}$

Curves NO 3 and 4 were used for modulus and damping, respectively, of Alluvium.

CURVE NO. 3: modulus for sand (Seed \& Idriss, 1970) - upper Range.

CURVE NO. 4: damping for sand (Idriss 1990) - (approximately Lower Range from Seed and Idriss, 1970, and identical to damping curve used for Bay Mud).

\begin{tabular}{|c|c|c|c|}
\hline \multicolumn{2}{|c|}{$\begin{array}{l}\text { CURVE NO. } 3 \\
=========\end{array}$} & \multicolumn{2}{|c|}{ CURVE NO. 4} \\
\hline STRAIN & $G / G_{\max }$ & STRAIN & DAMPING \\
\hline & -..-.-- & ------.- & ------- \\
\hline $.100 \mathrm{E}-03$ & 1.000 & $.100 \mathrm{E}-03$ & .24 \\
\hline $.300 \mathrm{E}-03$ & 1.000 & $.300 \mathrm{E}-03$ & .42 \\
\hline $.100 \mathrm{E}-02$ & .990 & $.100 \mathrm{E}-02$ & .80 \\
\hline $.300 \mathrm{E}-02$ & .960 & $.300 \mathrm{E}-02$ & 1.40 \\
\hline $.100 \mathrm{E}-01$ & .850 & $.100 \mathrm{E}-01$ & 2.80 \\
\hline $.300 \mathrm{E}-01$ & .640 & $.300 \mathrm{E}-01$ & 5.10 \\
\hline $.100 E+00$ & .370 & $.100 E+00$ & 9.80 \\
\hline $.300 E+00$ & .180 & $.300 E+00$ & 15.50 \\
\hline $.100 E+01$ & .080 & $.100 E+01$ & 21.00 \\
\hline $.300 E+01$ & .050 & $.300 E+01$ & 25.00 \\
\hline $.100 E+02$ & .035 & $.100 E+02$ & 28.00 \\
\hline
\end{tabular}


Curves NO 17 and 18 were used for modulus and damping, respectively, of fill.

CURVE NO. 17: sand, average confining pressure < $100 \mathrm{kPa}$ (Sun, 1988).

CURVE NO. 18: damping of sand, (Seed \& Idriss, 1970).

CURVE NO.17

$========$

STRAIN
CURVE NO.18

$=============$

STRAIN

DAMPING

$.100 \mathrm{E}-03 \quad 1.00$

$.100 \mathrm{E}-02 \quad 1.60$

$.300 \mathrm{E}-02 \quad 3.12$

$.100 \mathrm{E}-01 \quad 5.80$

$.300 \mathrm{E}-01 \quad 9.50$

$.100 E+00 \quad 15.40$

$.300 E+00 \quad 20.90$

$.100 E+01 \quad 25.00$

$.100 E+02 \quad 25.50$

\subsection{Soil Profiles Studied}

The soil profiles used in this study are outlined in Table 1. Profiles No. 14 and 15 were obtained from preliminary field data from the sites of the Oakland Outer Harbor Wharf and Apeel 2, a United States Geological Service (USGS) array in Redwood City, CA, where a ground motion time history is available. These latter profiles, as interpreted in this study for input into the SHAKE program, are shown in figures 3.1 and 3.2. 
TABLE 9: SOIL PROFILES

No.

Layer Thickness, $m$

Fill New Bay Mud Alluvium Old Bay Mud Water Table

$\begin{array}{llllll}1 & 3 & 3 & 3 & 3 & 3 \\ 2 & 3 & 6 & 3 & 3 & 3\end{array}$

$3 \quad 3 \quad 15$

$\begin{array}{lll}3 & 3 & 3\end{array}$

$\begin{array}{lll}4 & 3 & 30\end{array}$

$3 \quad 3 \quad 3$

530

$\begin{array}{lll}3 & 3 & 3\end{array}$

630

12

3

73

0

24

3

83

3

24

3

93

30

24

3

$\begin{array}{lll}10 & 3 & 30\end{array}$

3

3

1133

30

3

123

3

3

30

3

133

6

6

150

3

14 OAKLANDWHARF (figure 2)

15 APEEL 2 (figure 3)

S31

$9\left(V_{s}=60 \mathrm{~m} / \mathrm{s}\right)$

532

$9\left(V_{s}=120 \mathrm{~m} / \mathrm{s}\right)$

S41

$21\left(V_{s}=60 \mathrm{~m} / \mathrm{s}\right)$

542

$21\left(V_{s}=120 \mathrm{~m} / \mathrm{s}\right)$

543

$46\left(V_{s}=60 \mathrm{~m} / \mathrm{s}\right)$

544

$46\left(V_{s}=120 \mathrm{~m} / \mathrm{s}\right)$ 
OAKLAND OUTER HARBOR WHARF, Preliminary Soil Data

\begin{tabular}{|c|c|c|c|c|c|}
\hline Layer & Soil Type & $\begin{array}{l}\text { Depth } \\
\text { ft }\end{array}$ & $\begin{array}{l}\text { Thickns. } \\
\text { ft }\end{array}$ & $\begin{array}{l}\text { Unit Wt. } \\
\text { kcf }\end{array}$ & $\begin{array}{l}v_{s} \\
f t / s\end{array}$ \\
\hline 1 & Sand & 0 & 6 & 0.103 & 440 \\
\hline 2 & Fine Sand & 6 & 6 & 0.105 & 440 \\
\hline 3 & Fine Sand & 12 & 6 & 0.105 & 440 \\
\hline 4 & Gray Clay & 18 & 4 & 0.110 & 440 \\
\hline 5 & Fine Sand & 22 & 5 & 0.110 & 440 \\
\hline 6 & " & 27 & 10 & 0.110 & 920 \\
\hline 7 & $" \quad$ & 37 & 10 & 0.110 & 920 \\
\hline 8 &. & 47 & 10 & 0.120 & 1,280 \\
\hline 9 & Fine Sand & 57 & 9 & 0.120 & 1,280 \\
\hline 10 & Gray Clay & 66 & 6 & 0.111 & 770 \\
\hline 11 & Stiff Clay & 72 & 4 & 0.120 & 770 \\
\hline 12 & Gray Clay & 76 & 6 & 0.113 & 770 \\
\hline 13 & Sand & 82 & 5 & 0.120 & 770 \\
\hline 14 & Clay & 87 & 6 & 0.120 & 770 \\
\hline 15 &. & 93 & 10 & 0.120 & 770 \\
\hline 16 & " & 103 & 10 & 0.120 & 770 \\
\hline 17 & " & 113 & 10 & 0.120 & 770 \\
\hline 18 & $"$ & 123 & 10 & 0.130 & 1,070 \\
\hline 19 & Clay & 133 & 10 & 0.130 & 1,070 \\
\hline 20 & Sand & 143 & 6 & 0.120 & 1,070 \\
\hline 21 & Silty Clay & 149 & 7 & 0.130 & 1.070 \\
\hline 22 & Silty Clay & 156 & 7 & 0.130 & 1,070 \\
\hline 23 & Gray Sand & 163 & 3 & 0.125 & 1,070 \\
\hline 24 & Clay & 166 & 20 & 0.130 & 1,070 \\
\hline 25 & Clay & 186 & 21 & 0.130 & 1,070 \\
\hline 26 & Sand & 207 & 3 & 0.120 & 1,070 \\
\hline 27 & Clay & 210 & 6 & 0.130 & 780 \\
\hline 28 & " & 216 & 10 & 0.130 & 780 \\
\hline 29 & Clay & 226 & 10 & 0.130 & 780 \\
\hline 30 & Sand & 236 & 2 & 0.125 & 780 \\
\hline 31 & Clay & 238 & 12 & 0.130 & 2,060 \\
\hline 32 & Sand & 250 & 4 & 0.125 & 2,060 \\
\hline 33 & Clay & 254 & 6 & 0.130 & 2,060 \\
\hline 34 & " & 260 & 10 & 0.130 & 780 \\
\hline 35 & " & 270 & 10 & 0.130 & 780 \\
\hline 36 & " & 280 & 10 & 0.130 & 780 \\
\hline 37 & . & 290 & 12 & 0.130 & 1,400 \\
\hline 38 & Sand & 302 & 22 & 0.125 & 1,400 \\
\hline 39 & Stiff Clay & 324 & 6 & 0.130 & 1,400 \\
\hline 40 & Stiff Clay & 330 & 10 & 0.130 & 1,400 \\
\hline 41 & Sandy Loam & 340 & 10 & 0.125 & 1,400 \\
\hline 42 & Sandy Loam & 350 & 11 & 0.130 & 1,400 \\
\hline 43 & Clay & 361 & 11 & 0.130 & 1,400 \\
\hline 44 & Sand & 372 & 12 & 0.125 & 1,400 \\
\hline 45 & Clay & 384 & 10 & 0.130 & 1,400 \\
\hline 46 & Clay & 394 & 10 & 0.130 & 1,400 \\
\hline 47 & Sand & 404 & 20 & 0.130 & 1,400 \\
\hline 48 & Sand & 424 & 20 & 0.130 & 1,400 \\
\hline 49 & Sand & 444 & 50 & 0.130 & 2,380 \\
\hline 50 & Bedrock & 494 & & & \\
\hline
\end{tabular}

$V_{s}=$ measured shear wave velocity; Unit Weight assumed;

$1 \mathrm{ft}=0.3048 \mathrm{~m} ; 1 \mathrm{kcf}=16.03 \mathrm{Mg} / \mathrm{m}^{3}$

Figure 3.1: Soil Profile near California Department of Mines and Geology (CDMG) Strong Motion Station No. 58472 at Oakland Outer Harbor Wharf. 


\begin{tabular}{|c|c|c|c|c|c|}
\hline Layer & Soil Type & $\begin{array}{l}\text { Depth } \\
\mathrm{ft}\end{array}$ & $\begin{array}{l}\text { Thickns. } \\
\mathrm{ft}\end{array}$ & $\begin{array}{l}\text { Unit Wt. } \\
\text { kcf }\end{array}$ & $\begin{array}{l}V_{s} \\
\mathrm{ft} / \mathrm{s}\end{array}$ \\
\hline 1 & Sdy.Cl.Fill & 3.61 & 3.61 & .103 & 574.4 \\
\hline 2 & Silty Clay & & 2.95 & .110 & 180.4 \\
\hline 3 & (Lt. Gray, & & 3.28 & .111 & 180.4 \\
\hline 4 & soft) & & 3.28 & .111 & 180.4 \\
\hline 5 & $"$ & & 3.28 & .112 & 180.4 \\
\hline 6 & " & & 3.28 & .113 & 180.4 \\
\hline 7 & " & & 3.28 & .114 & 180.4 \\
\hline 8 & " & & 3.28 & .114 & 180.4 \\
\hline 9 & $"$ & 31.2 & 4.92 & .115 & 180.4 \\
\hline 10 & Clay,(Yellowis & & 4.92 & .13 & 639.76 \\
\hline 11 & Brown, Hard) & & 6.56 & .13 & 639.76 \\
\hline 12 & " & & 6.56 & .13 & 639.76 \\
\hline 13 & " & & 6.56 & .13 & 639.76 \\
\hline 14 & $n$ & & 6.56 & .13 & 639.76 \\
\hline 15 & $"$ & 65.9 & 3.61 & .13 & 639.76 \\
\hline 16 & Silty Clay, & & 6.23 & .13 & 574.15 \\
\hline 17 & (Gray w. Olive & & 6.23 & .13 & 574.15 \\
\hline 18 & Mottles, Stiff) & & 6.23 & .13 & 574.15 \\
\hline 19 & " & & 6.23 & .13 & 574.15 \\
\hline 20 & $"$ & 100.7 & 9.84 & .13 & 574.15 \\
\hline 21 & Dense Deposit & ts ino c & data) & & \\
\hline
\end{tabular}

Figure 3.2: Soil Profile near Strong Motion Station USGS Apeel 2, Redwood City, CA. 


\section{RESULT OF RESPONSE CALCULATIONS}

\subsection{Presentation of results}

Since the calculations produce a great number of data points, the most practical way to study the results is from graphical presentations. What we are comparing is the rock outcrop motion used to calculate the bedrock motion at the base of the deposit and the calculated ground motion at the surface of the deposit. Since ground motions are measured in the field as acceleration time histories, they are presented in this form in the report. However, acceleration time histories, even when plotted, are difficult to compare. One parameter that can be compared is the maximum acceleration in the record. However, such a comparison is insufficient, because this quantity alone does not characterize the entire acceleration time history.

One effective way of comparing ground motions is by comparing their effect on structures with different fundamental periods. This is done by means of response spectra, which show the maximum response of hypothetical single degree of freedom resonators with different natural frequencies and damping ratios. In this report response spectra were calculated for a $5 \%$ of critical damping ratio. The spectra are presented in two plots. One plot compares acceleration response spectra, plotted as a function of period on a semi-logarithmic scale which magnifies the high frequency (low period) range. A second plot compares relative displacements, pseudo relative velocities, and pseudo accelerations as a function of period in a single plot using four logarithmic scales. This plot conveys more information on the spectra. The plot uses virtual (pseudo) values for relative velocities and accelerations, using the following relationships, which are for sinusoidal forcing functions, and produce quantities which, on the average, tend to be smaller than those actually calculated for the time histories:

$$
\begin{gathered}
P R V=U(2 \pi f) \\
P A A=U(2 \pi f)^{2}
\end{gathered}
$$

Where: $\quad P R V=$ pseudo spectral relative velocity

$P A A=$ pseudo spectral absolute acceleration

$U=$ calculated spectral relative displacement amplitude

$f=$ frequency, $\mathrm{Hz}$ (reciprocal of period in plot)

In accordance with conventions for building design, periods rather than frequencies are shown in the plots. In some instances Fourier spectra are shown in order to provide more information about the frequency content of acceleration time histories. 


\subsubsection{Oakland Outer Harbor Wharf Motion.}

Some comparison of a predicted with an observed acceleration time history can be obtained for the Loma Prieta strong motion record at the Oakland Outer Harbor Wharf. Calculated ground surface motions were obtained by using the soil profile in figure 2, and the rock outcrop motion in the East-West direction recorded at the Yorba Buena strong motion station.

In this instance, a comparison of the recorded Oakland Outer Harbor Wharf acceleration time history with the calculated time history of the ground surface motion indicated that there was a tendency to underestimate the amplitude of the ground motion. Since some of the variables used to calculate the ground surface motion are estimated, a range of values for these estimated variables was used in order to ascertain their effect on the calculated ground surface motion. The estimated variables include the baserock stiffness (for which no data were available), the rock outcrop motion used as input for the calculations (the Yorba Buena and the Rincon Hill records were used), and the effective strain used in the equivalent linear model (a quantity which is specified).

Figure 4.1 shows three acceleration time histories: the Yorba Buena rock outcrop motion, and time histories at the soil-rock interface, calculated for base rock stiffnesses associated with a mass density of the base rock of $2.56 \mathrm{Mg} / \mathrm{m}^{3}$ and shear wave propagation velocities in the base rock of $762 \mathrm{~m} / \mathrm{s}$ and $1,220 \mathrm{~m} / \mathrm{s}$, respectively. The time histories at the soil/rock interface for these two latter cases were calculated assuming that the time history of the incident wave for these cases was identical with the time history of the incident wave which produced the Yorba Buena rock outcrop motion. It can be seen from figure 4.1 that the amplitude of the motion at the soil/rock interface increases with the stiffness of the base rock. (For the case of $V_{s}($ rock $)=762 \mathrm{~m} / \mathrm{s}$ the maximum acceleration at the soil/rock interface was $56 \%$ of that of the outcrop motion, and for the case of $V_{s}($ rock $)=1220 \mathrm{~m} / \mathrm{s}$ it was $65 \%$ of that of the outcrop motion). An upper bound for the motion at the soil/rock interface, which would occur for an infinitely stiff base rock, would be a motion at the soil/rock interface which is identical with the Yorba Buena rock outcrop motion. It is assumed in this latter analysis that the bedrock motion at Yorba Buena was identical with that at the base of the deposit, except for the effect of confinement. This was not necessarily the case, and it is not unreasonable to assume that some of the energy of the bedrock motion was lost as it propagated to the exposed bedrock surface, which is located at a much higher elevation. Figure 4.2 shows three time histories: the time history recorded at the Oakland Outer Harbor Wharf strong motion station in a $305^{\circ}$ direction; a calculated ground motion using the Yorba Buena rock outcrop motion in an East-West direction at the soil/rock interface (using the unconfined rock motion at the base of the deposit is equivalent to the assumption that the rock is infinitely stiff); and a calculated ground motion using a confined rock motion calculated from the Yorba Buena rock outcrop motion and assuming that the shear wave propagation velocity in the base rock is $1,200 \mathrm{~m} / \mathrm{s}$.

Figures 4.3 and 4.4 compare response spectra calculated for $5 \%$ damping. The calculated response spectra are for the recorded ground motion, and for calculated ground motions using 
the Yorba Buena rock outcrop motion at the soil/rock interface, and confined baserock motions calculated for base rock shear wave propagation velocities of 1200 and $762 \mathrm{~m} / \mathrm{s}$.

Figure 4.3 compares acceleration response spectra, and figure 4.4 compares response spectra for relative displacement, pseudo relative velocity, and pseudo acceleration. It is interesting to note, that in terms of frequency response the spectra are quite similar, however they differ in amplitude. It is evident that the set of assumptions used in the calculations tended to underestimate the amplitude of the spectral response for periods less than $2 \mathrm{~s}$.

For the sake of comparison, calculations were also performed using the Rincon Hill outcrop motion record, which is not as close to the Oakland Outer Harbor Wharf site as the Yorba Buena outcrop motion. This is shown in figures 4.5 and 4.6 for an assumed shear wave propagation velocity in the base rock of $762 \mathrm{~m} / \mathrm{s}$. It can be seen from the figure, that the results obtained from the Yorba Buena and the Rincon Hill outcrop motions are similar, and that those calculated from the Yorba Buena motion more closely resemble the frequency response obtained from the recorded ground motion.

Another variable that was investigated is the effective strain used to calculate the ground motion, which is specified as a percentage of the calculated maximum strain for each layer. The effective strain is used to select dynamic soil properties which in turn are used to calculate the ground motion. Three effective strain levels were checked: $55 \%$ of maximum, which was used in most of the calculations in this study; $61 \%$ of maximum which corresponds to an effective strain level of $[(M-1) / 10] \gamma_{\max }$, where $M=$ Richter Magnitude of Earthquake and $\gamma_{\max }$ is the maximum shear strain calculated for the time history in the center of each layer, a strain level suggested in another part of the NIST study (refer to introduction), and $35.5 \%$ of maximum, which corresponds to the ratio of the RMS value of earthquake accelerations, calculated between the time limits of 0.15 and 0.85 in the Husid plot, to the maximum acceleration. [The Husid plot is a plot of equation 6 below and is indicative of the fraction of the earthquake energy released as a function of time (ldriss, 1978, Husid, 1968)].

$$
\frac{\int_{0}^{t} A^{2}(t) d t}{\int_{0}^{t} A^{2}(t) d t}
$$

where: $\quad A=$ Acceleration at time $t$

$t f=$ time at end of record

The effect of the level of the assumed effective strain is shown in figures 4.7 and 4.8 . It is evident that, within the range examined, the level of effective strain did not significantly affect the results of the calculations. For assumed effective strain levels of $35.5 \%, 55 \%$, and $61 \%$, maximum calculated strains were $0.17 \%, 0.23 \%$, and $0.25 \%$, respectively, in the center of 
the most strained layer, calculated dominant periods were 1.69s, $1.75 \mathrm{~s}$, and $1.77 \mathrm{~s}$, respectively, and maximum accelerations at the surface of the deposit were $0.218 G, 0.204 G$, and $0.198 \mathrm{G}$, respectively. It can be seen from figure 1 , that for the strain levels in question a change in strain of 0.08 percent will not substantially affect the dynamic soil properties.

Similarly, use of dynamic soil properties recommended by Sun, 1988, and Vucetic and Dobry, 1991, had little effect on the amplitude of the calculated ground motion.

In summary, calculations using equivalent linear response analysis and incorporating the dynamic soil properties shown in figure 2.1, preliminary soil deposit data from the site of the Oakland Outer Harbor Wharf, and base rock motions equivalent to the Yorba Buena and Rincon Hill rock outcrop motions recorded in the Loma Prieta Earthquake, produced ground motions at the surface of the deposit which tended to be smaller in amplitude but reasonably similar in frequency content when compared with the strong motion time history recorded during the Loma Prieta earthquake. An increase in the assumed base rock stiffness, for which no data were available, tended to reduce, but not eliminate, the difference. However, the difference is eliminated when the base rock is assumed to be rigid. This latter assumption cannot be justified.

It is suggested that the amplitude of the incident shear waves at the base of the deposit may have been greater than that recorded at the Yorba Buena and Rincon Hill strong motion stations. Another possible reason for the difference between calculated and observed ground motion amplitudes could be that the damping ratios used in the analysis, which are based on laboratory test data, rather than in situ measurements, significantly overestimate the actual damping by the deeper soil deposits. Oversimplifications, inherent in the SHAKE model, may also have contributed to the difference. 

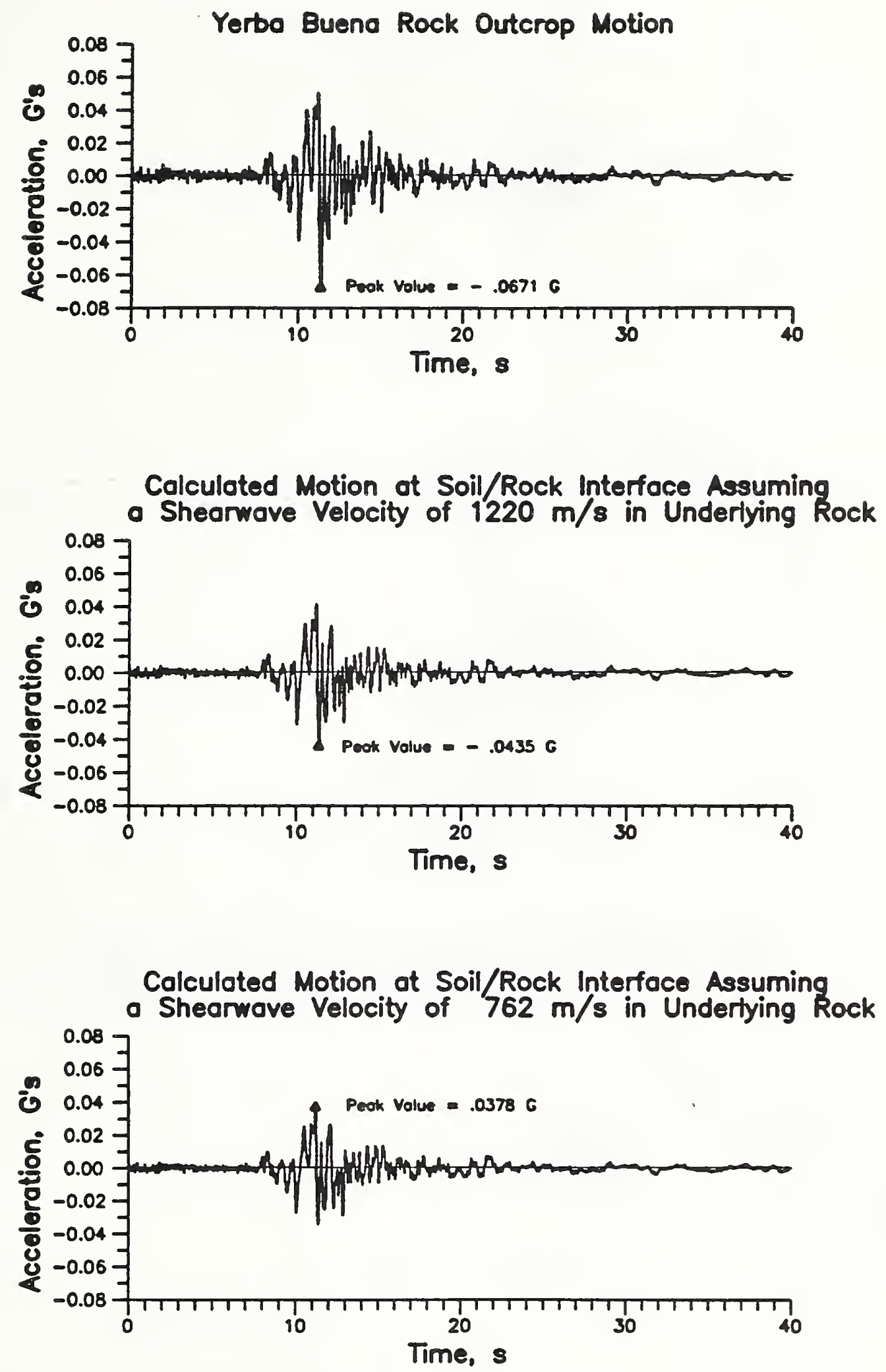

Figure 4.1 Effect of Base Rock Stiffness on the Base Rock Motion amplitude at the Oakland Outer Harbor Wharf Strong Motion Site, Calculated for the Yorba Buena Rock Outcrop motion. 


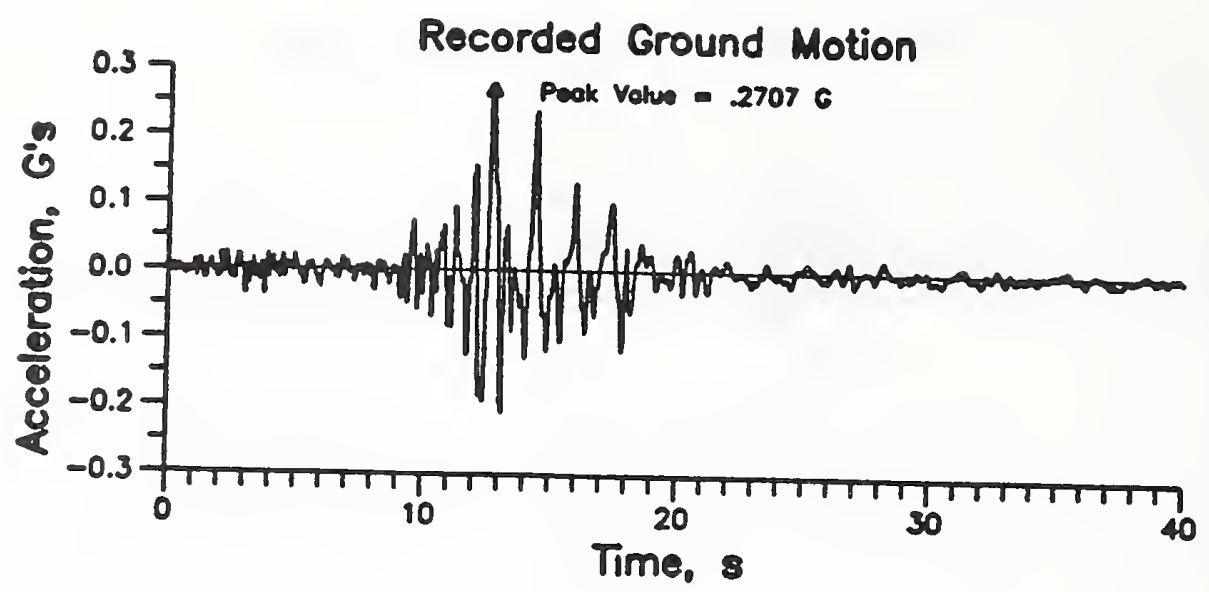

Calculated Ground Motion Using the Yerba

Buena Record as Soil/Rock interface Motion

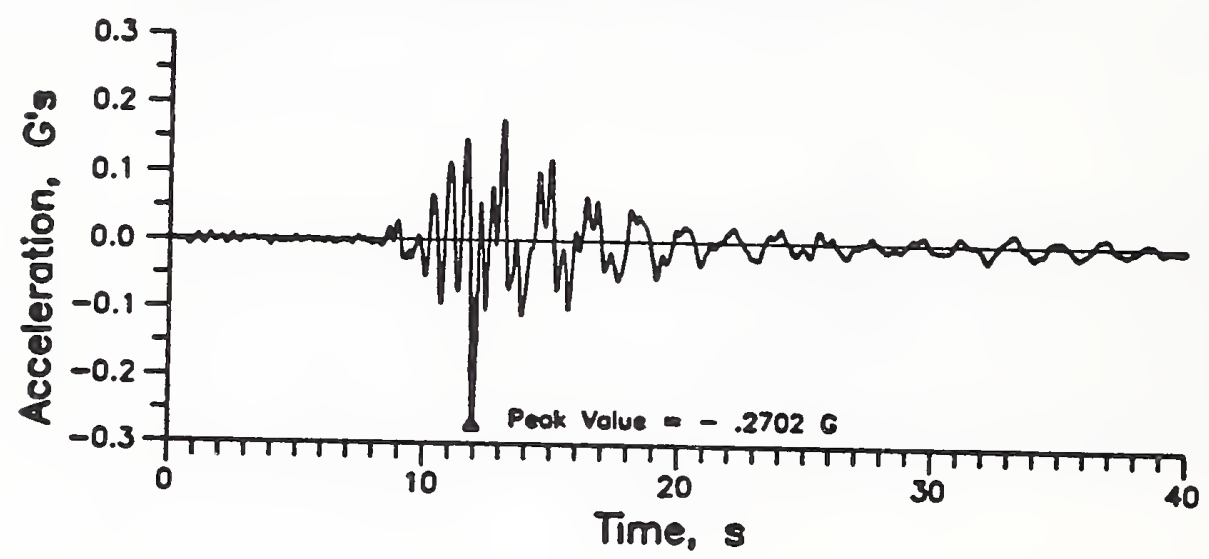

Calculated Ground Surface Motion Using the Yerbo Buena Record as an Outcrop Motion and Assuming Bedrock Shearwave Propogation Velocity of $1220 \mathrm{~m} / \mathrm{s}$

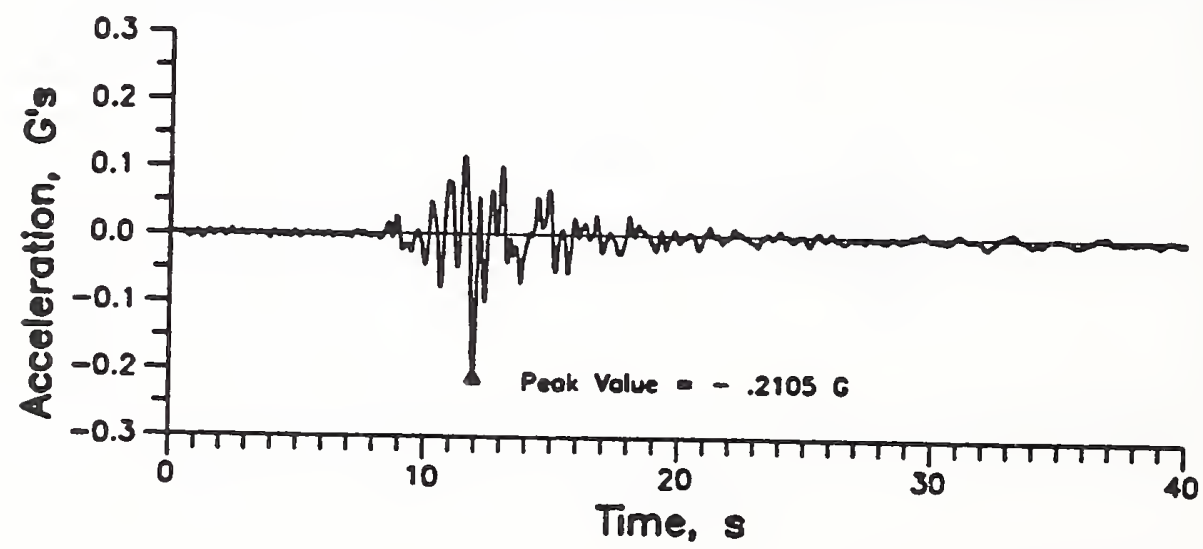

Figure 4.2: Recorded and Calculated Acceleration Time History at the Oakland Outer Harbor Wharf Strong Motion Station. 


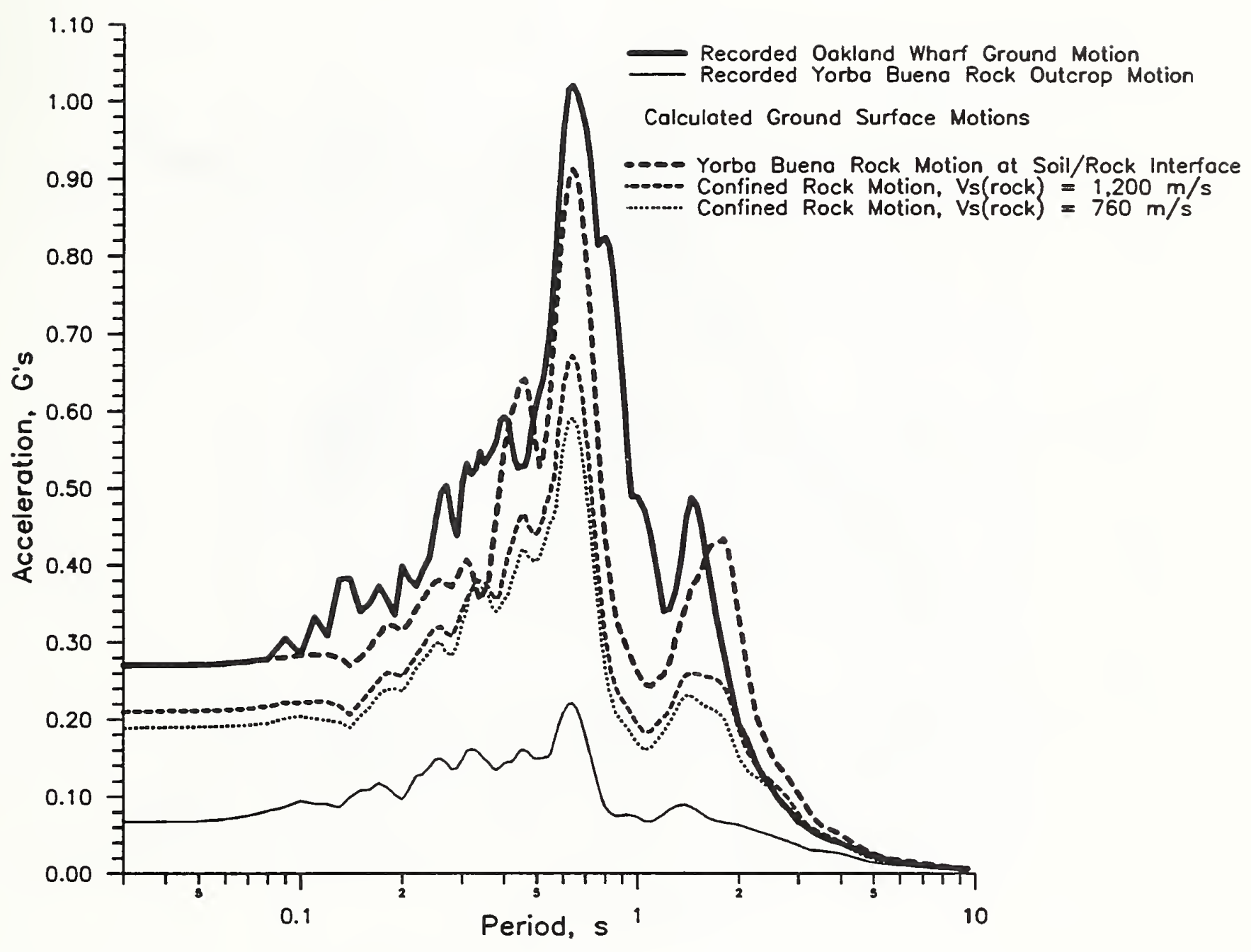

Figure 4.3: Comparison of Acceleration Response Spectra for 5\% Damping for the Recorded Ground Motion and for Calculated Ground Motions at the Oakland Outer Harbor Wharf Strong Motion Station. 


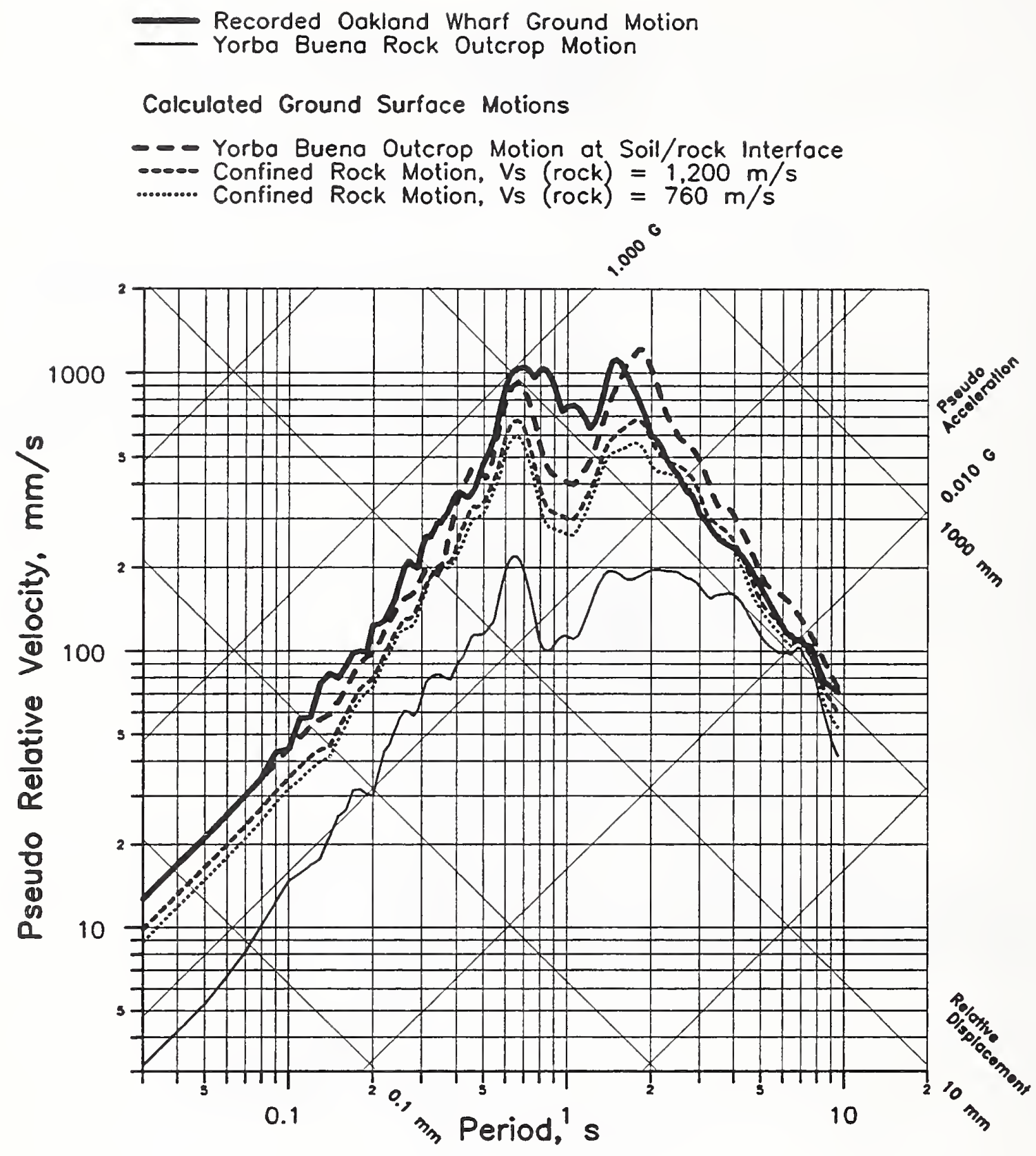

Figure 4.4: Comparison of Displacement, Pseudo Relative Velocity, and Pseudo Acceleration Response Spectra for 5\% Damping for the Recorded Ground Motion and for Calculated Ground Motions at the Oakland Outer Harbor Wharf Strong Motion Station. 
Oakland Whorf Ground Motion

Rincon Hill Bedrock Motion

Yorba Buena Bedrock Motion

Colculated Ground Surfoce Motions

- Case 14, Yorbo Bueno Outcrop Motion

-.... Cose 14, Rincon Hill Outcrop Motion

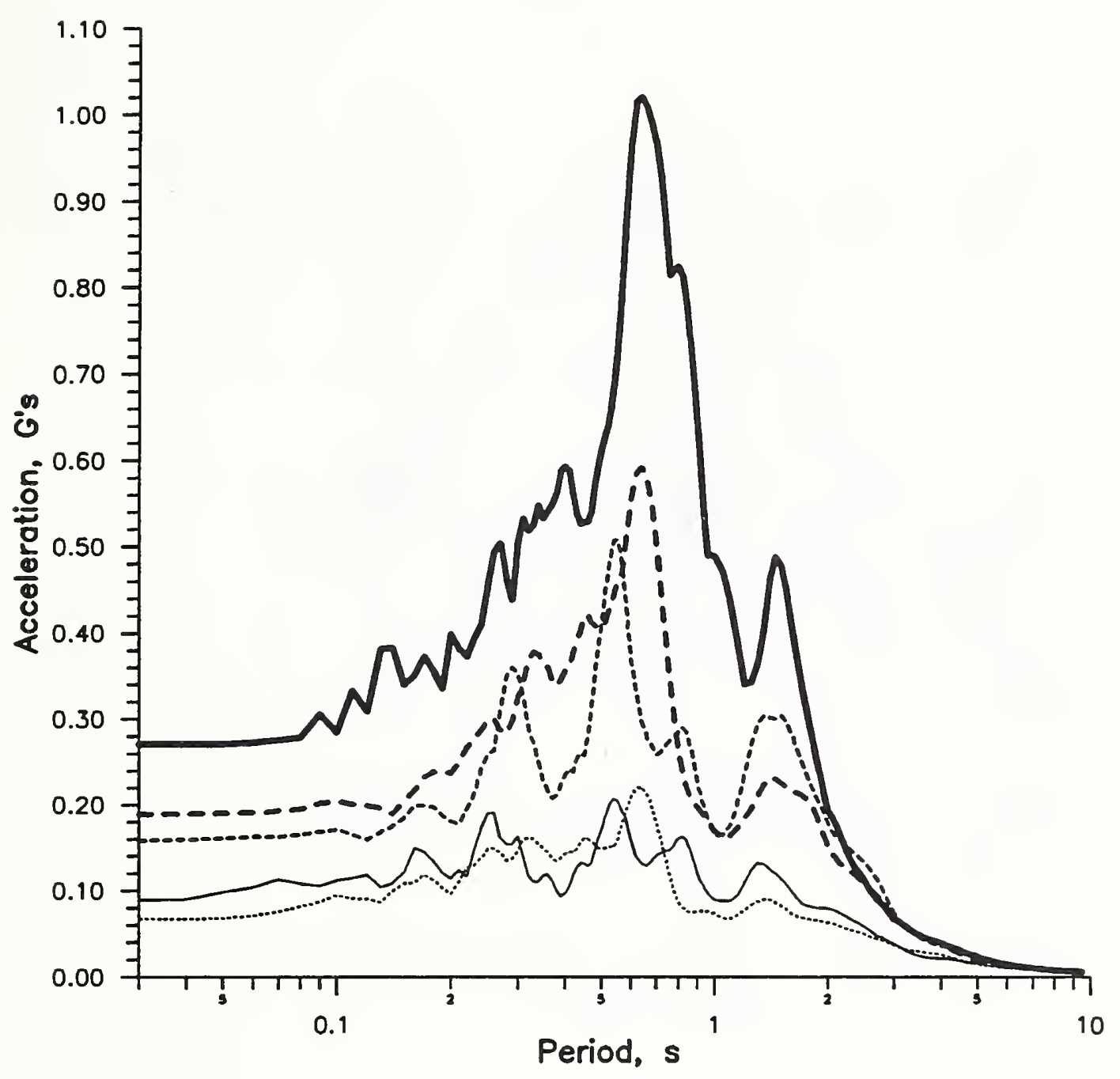

Figure 4.5: Comparison of Acceleration Response Spectra for $5 \%$ Damping for the Recorded Oakland Outer Harbor Wharf Ground Motion and for Ground Motions Calculated Using the Yorba Buena and the Rincon Hill Rock Outcrop Motions. 


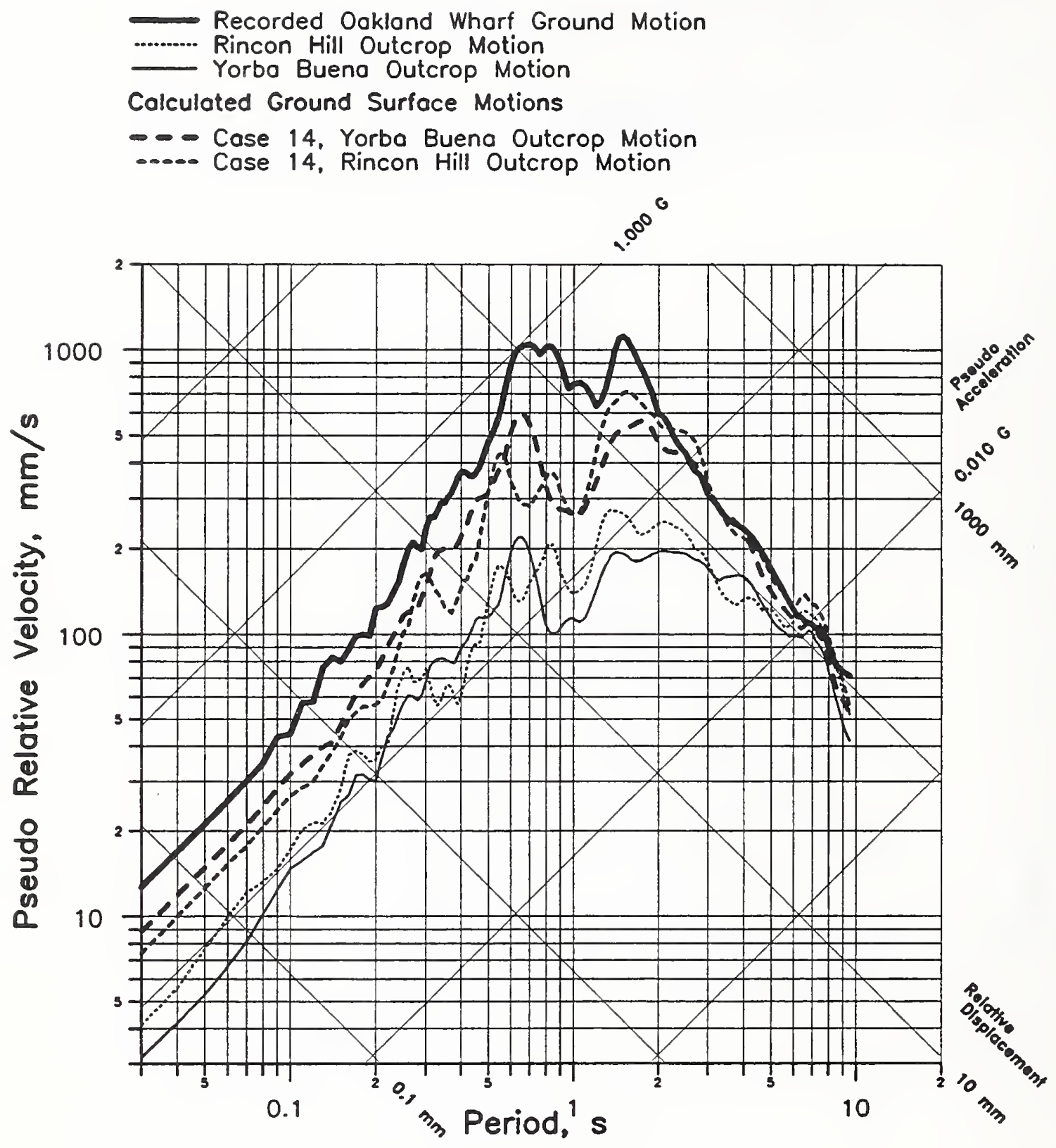

Figure 4.6: Comparison of Response Spectra for 5\% Damping for the Recorded Oakland Outer Harbor Wharf Ground Motion and for Ground Motions Calculated Using the Yorba Buena and the Rincon Hill Rock Outcrop Motions. 
Recorded Oaklond Wharf Ground Motion

Calculated Ground Surface Motions

- - - Colculoted Motion, Effective Stroin 35.5\% of Maximum

Colculoted Motion, Effective Stroin 55\% of Maximum

Colculated Motion, Effective Strain 619 of Maximum

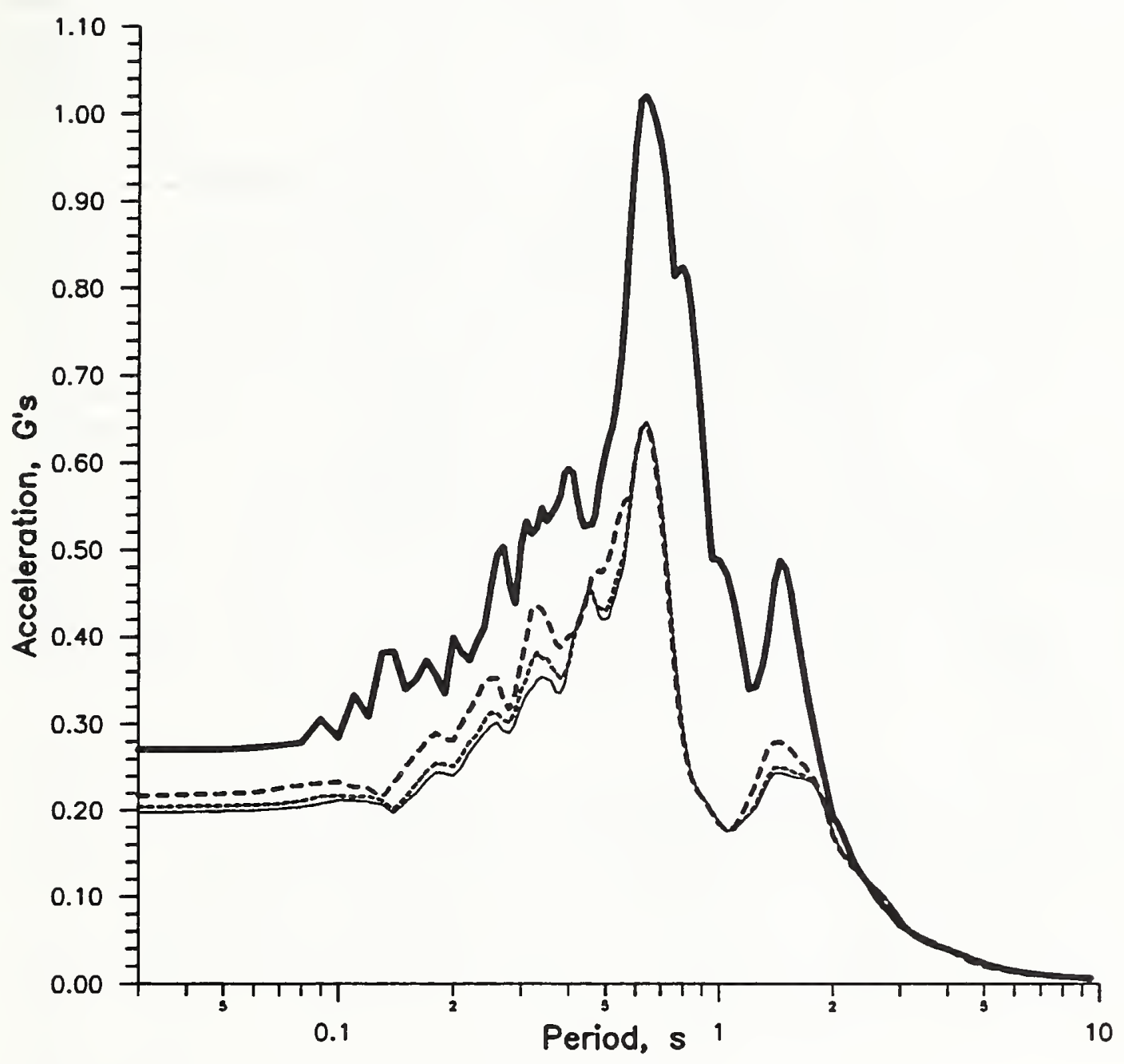

Figure 4.7: Effect of Assumed Effective Strain Level on the Calculated Ground Motion Acceleration Response Spectra. 
Recorded Ookland Wharf Ground Motion

Calculated Ground Surface Motions

- - Calculated Motion, Effective Strain 35.5\% of Maximum

....... Calculated Motion, Effective Strain 55\% of Maximum

- Calculated Motion, Effective Strain $61 \%$ of Maximum

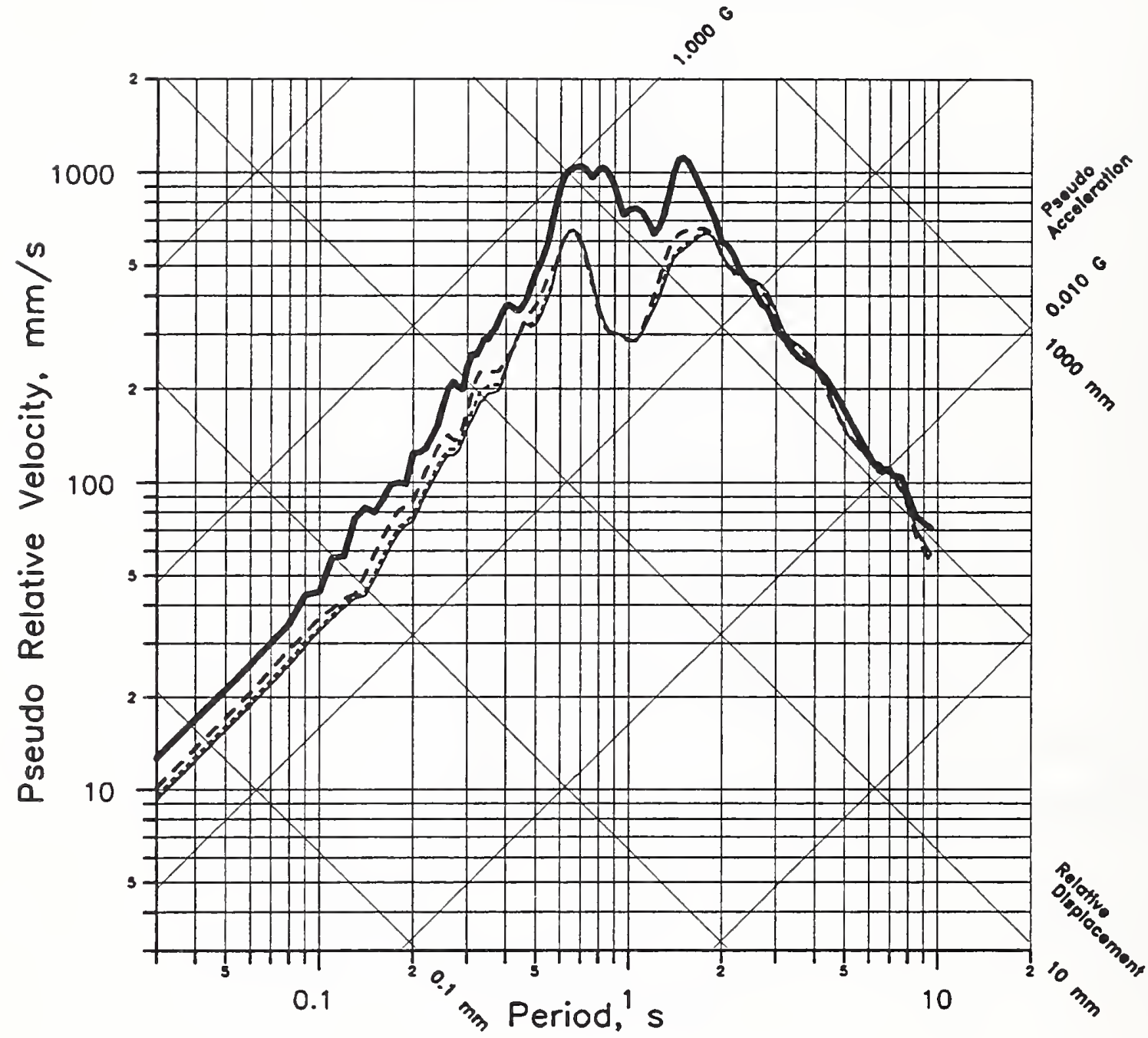

Figure 4.8: Effect of Assumed Effective Strain Level on Response Spectra for the Calculated Ground Motion. 


\subsubsection{Profiles Studied}

The profiles are shown in Table 1. Profile 1 has $3 \mathrm{~m}(10 \mathrm{ft})$ of fill, $3 \mathrm{~m}$ of New Bay Mud, $3 \mathrm{~m}$ of alluvium, and $3 \mathrm{~m}$ of Old Bay Mud over a halfspace of bedrock. The sequence of these layers is in the same order as it is encountered in many locations in the San Francisco Bay area. In profiles 2, 3, and 4, the depth of the New Bay mud is increased to 6, 15, and $30 \mathrm{~m}$, respectively. The intent of these hypothetical profiles is to study the effect of increasing the depth of the New Bay Mud. In all the cases studied the groundwater level is at the bottom of the fill, and the dynamic shear modulus of the bedrock at small strains is assumed to be 2,320 MPa.

\subsubsection{Effect of New Bay Mud depth}

Response Spectra for a $5 \%$ critical damping ratio for ground motions, calculated for cases 1 , 3 , and 4 when subjected to a base rock excitation represented by the Rincon Hill outcrop motion in the East-West direction, are shown in figures 4.9 and 4.10. The amplification at very low periods shown in figure 4.9 is a function of the maximum acceleration in the time history of the calculated ground motions (at very low periods the spectral acceleration response equals the maximum acceleration). It can be seen from figure 4.9, that the maximum acceleration of the time history was amplified by all the soil profiles. The maximum acceleration of the Rincon Hill record is $0.09 \mathrm{G}$. This compares with $A_{\text {max }}$ values of $0.17 \mathrm{G}$, $0.19 \mathrm{G}$, and $0.21 \mathrm{G}$ for cases 1,3 , and 4 , respectively, which represent amplifications with respect to the rock outcrop motions of 1.9,2.1, and 2.3, respectively. This compares with average amplification ratios of 2.6 observed for Bay Mud sites in the Loma Prieta Earthquake (EERI, 1989). The ratios between the maximum acceleration of the base rock motions and that of the rock outcrop motion is $0.89,0.86$, and 0.83 , respectively, for cases 1,3 , and 4 .

As can be seen from figures 4.9 and 4.10, the trend of the effect of the depth of the New Bay Mud is to amplify the response in the vicinity of the characteristic period of the deposit. Thus profiles 3 and 4 result in a high response for periods ranging from 0.5 to 2 seconds. This is the range of periods which will affect most low to medium rise buildings. Case 2 is an interesting exception to the otherwise consistent trend of the calculated results. Figure 4.11 shows the data from figure 4.9, with the acceleration response spectrum for Case 2 superimposed and highlighted. The maximum calculated ground acceleration for Case 2 is only $0.13 \mathrm{G}$, which represents an amplification of $A_{\max }$ of 1.4 with respect to the Rincon Hill outcrop motion. Note that the characteristic period for Profile 2 is $0.39 \mathrm{~s}$. This coincides with a low spectral response for the Rincon Hill motion.

The cyclic strains induced in the various soil layers by the Rincon Hill rock outcrop motion are relatively small. Maximum shear strains range from $0.07 \%$ in Profile 2 to $0.14 \%$ in Profile 4 . It is suggested that the SHAKE program could be used up to maximum cyclic strains of the order of $1 \%$, provided the soils are not susceptible to liquefaction. Thus another strong motion record was selected to investigate the response in the vicinity of the suggested upper limit of cyclic strain. The earthquake motion selected was the rock outcrop motion in the NorthSouth direction recorded for the Loma Prieta earthquake by the strong motion station in Santa 
Cruz. This latter strong motion record, which is for an outcropping bedrock site, has a maximum acceleration of $0.4413 \mathrm{G}$ and a frequency content which differs from that of the Rincon Hill earthquake. The difference in frequency content is illustrated in figures 4.12 and 4.13. Figure 4.12 compares Fourier spectra, and figure 4.13 normalized response spectra. It is thought that, at least in part, the difference in the frequency content of these ground motions is attributable to their distance from the source of the ground motion. Figure 4.13 distorts the relative scale of the response spectra. In figure 4.14 the same spectra are plotted to scale.

Figures 4.15 and 4.16 show a comparison between acceleration response spectra for the recorded Santa Cruz motion and those calculated at the ground surface for profiles 1,3 , and 4. It can be seen that while the response in the low period (high frequency) range is substantially amplified by profile 1 , there is no amplification for periods smaller than $0.2 \mathrm{~s}$ by profiles 3 and 4 . The difference between the responses to the low amplitude Rincon Hill motion and the high amplitude Santa Cruz motion is best illustrated by the calculated amplification spectra for these motions. This is shown in figure 4.17. The amplification factor plotted in the figure is the ratio between the amplitudes of the ground surface motion and that of the base rock motion, which is a function of frequency. In this case the maximum acceleration of the base rock motion was approximately $85 \%$ of that of the rock outcrop motion. Note that for the Santa Cruz earthquake the amplification factor dropped below unity for frequencies in excess of $5 \mathrm{~Hz}$, while for the Rincon Hill it dropped below unity for frequencies in excess of $10 \mathrm{~Hz}$. In this instance Profile 2 followed the trend of the other profiles. This is illustrated in figure 4.18 , where the acceleration response spectrum for Case 2 is superimposed on figure 4.15 and highlighted.

It is also of interest to compare the response spectra for case 4, calculated by the Rincon Hill and Santa Cruz motions. This is done in figures 4.19 and 4.20. Note that for periods in excess of $1.3 \mathrm{~s}$ the amplitudes of the response spectra for these two bedrock motions are about equal. The implication of this observation would be that in deep soft soils the response of taller buildings would not be very sensitive to the distance of the source of the ground motion. However this phenomenon is at least in part attributable to the difference in the frequency contents between the two bedrock motions. While this difference appears to be logical, it has not been demonstrated at this time that it represents a trend which is typical for most earthquake data.

\subsubsection{Effect of Layer Thickness used in Analysis}

As previously noted, the revised SHAKE program developed in this project enables us to use 50 soil layers (including the halfspace). This enables us to accommodate deep and complex soil profiles, such as that associated with the Oakland Outer Harbor Wharf, which was previously discussed. It was thought that a larger number of layers would also be useful in studying the high frequency range of the spectrum. It was reasoned that layer thickness should not exceed $1 / 4$ of the wavelength associated with the highest frequency considered in the analysis. In this study, all frequencies above $25 \mathrm{~Hz}$ were filtered out. Thus, theoretically, layer depths should correspond to the wavelengths associated with this frequency. In practice, however, for the time histories used in this analysis, very small acceleration amplitudes were associated with frequencies above $15 \mathrm{~Hz}$. Thus it would be difficult to determine the effect of layer thickness on the basis of calculated time histories or 
response spectra (on the high frequency end of the response spectra the acceleration response amplitude simply equals the maximum acceleration in the record and is not sensitive to the high frequency components of the input motion). A more direct way to determine the effect of layer thickness is therefore via the amplification spectra.

Figures 4.21 through 4.23 illustrate the effect of varying the layer thickness. Figure 4.21 represents a shallow soil profile with relatively few layers. In this instance the effect of increasing the number of layers was substantial. It should be noted however, that the effect on the amplification spectrum, which is confined to frequencies over $7 \mathrm{~Hz}$, did not show up in the calculated response spectra. In figures 4.22 and 4.23 , which represent deep soil profiles, the effect of changing the number of layers is insignificant. It was therefore concluded that for deeper soil profiles it was not necessary to keep the layer thickness below $1 / 4$ wave length.

\subsubsection{Effect of Alluvium (Cases 5 to 7 )}

Alluvial profiles are explored in cases 5 to 7 . Response spectra for cases 5 to 7 are shown in figures 4.24 and 4.25 for the Rincon Hill rock outcrop motion in the East West direction, and in figures 4.26 and 4.27 for the Santa Cruz rock outcrop motion in the North-South direction. The spike in the response spectrum for profile 6 in figure 4.24 is attributable to the characteristic period of profile 6 of $0.27 \mathrm{~s}$ which coincides with a peak in the response spectrum for the Rincon Hill outcrop motion. Amplification of the calculated ground surface motions for Profiles 5 to 7 with respect to the maximum acceleration of the Rincon Hill outcrop motion range from 1.45 to 1.8. This compares with an average amplification factor of 1.8 for alluvial sites in the San Francisco Bay area observed in the Loma Prieta earthquake (EERI, 1989).

Note that for the Santa Cruz outcrop motion the response spectra for profiles 6 and 7 are virtually identical between the periods of 0.5 and $1.2 \mathrm{~s}$, which are of interest with respect to building response. There was substantial amplification of the Santa Cruz outcrop motion for periods below 1.2s. For both, the Santa Cruz and the Rincon Hill motion there was no amplification for periods exceeding 1.2s. Amplification spectra for case 7 for the Rincon Hill and Santa Cruz motions are compared in figure 4.28.

Response spectra for cases 4 and 7 are compared in figures 4.29 through 4.32 . Note that for the Rincon Hill outcrop motion the low period range of the spectrum is about equally amplified by profiles 4 and 7 , and that the Santa Cruz motion is substantially amplified in the low period range by profile 7 .

\subsubsection{Composite Profiles}

\subsubsection{New Bay Mud Over Alluvium}

The effect of alluvial deposits underlying New Bay mud was explored by profiles 8 and 9 . The results are illustrated in figures 4.33 through 4.38 . In figures 4.33 and 4.34 cases 7,9 , and 4 are compared for the Rincon Hill outcrop motion. Note that there is no significant difference between cases 9 and 4 . Thus the addition of a $24 \mathrm{~m}$ thick layer of alluvium at the base of the $30 \mathrm{~m}$ layer of New Bay mud did not significantly alter the calculated effect of the ground 
surface motion on structures. A similar conclusion can be drawn from figures 4.34 and 4.35, which compare the response of profiles 7, 9, and 4 for the Santa Cruz outcrop motion. Amplification spectra for cases 9 and 4 are compared in figures 4.37 and 4.38 for the Rincon Hill and Santa Cruz outcrop motions, respectively.

\subsubsection{Old Bay Mud, Alluvium and New Bay Mud}

The combination of Old Bay mud (or comparably stiffer soils), alluvium, and New Bay mud, which is common in the Bay area, is explored in profile 13, which has $150 \mathrm{~m}$ of Old Bay mud, $6 \mathrm{~m}$ of alluvium, $6 \mathrm{~m}$ of New Bay mud, and $3 \mathrm{~m}$ of fill. This profile is thought to be somewhat similar to that of the site of the $1-880$ collapse in Oakland. In figures 4.39 and 4.40 response spectra for calculated ground motions for Case 13, using a maximum base rock shear wave velocity of $1,220 \mathrm{~m} / \mathrm{s}$, are compared with response spectra for the recorded ground motions in the East West direction at Emeryville and Oakland Outer Harbor Wharf. The Emeryville ground motion, which has a response peak at the 1.0-s period, could have been influenced by an adjacent building. If this was the case, it would not be a true free field motion. This is illustrated by the regularity of the calculated velocity and displacement time histories which are shown in figure 4.41. The correlation between these calculated ground motions and the recorded ground motion at Oakland Outer Harbor Wharf is similar to that with the ground motion which was calculated from actual subsurface data. In figure 4.42, the calculated ground motion at Oakland Outer Harbor Wharf is compared with the ground motions calculated for case 13. Note that for periods greater than $0.6 \mathrm{~s}$ there is no significant difference between the three calculated ground motions. Thus the hypothetical soil profiles used in this study seem to produce results which are similar to those obtained from actual soil data. However, in both instances the amplitude of the ground motion was underestimated.

\subsubsection{Comparison of New Bay Mud, Alluvium, and Old Bay Mud}

In profiles 4, 11, and 12, the thickness of New Bay mud, alluvium, and Old Bay mud is increased to $30 \mathrm{~m}$, while the thickness of the other layers in profile 1 is kept at $3 \mathrm{~m}$. Cases 4, 11, and 12, calculated for the Rincon Hill and Santa Cruz outcrop motions are compared in figures 4.43 to 4.46 . Predictably, the results for the alluvium and Old Bay mud are quite similar. 


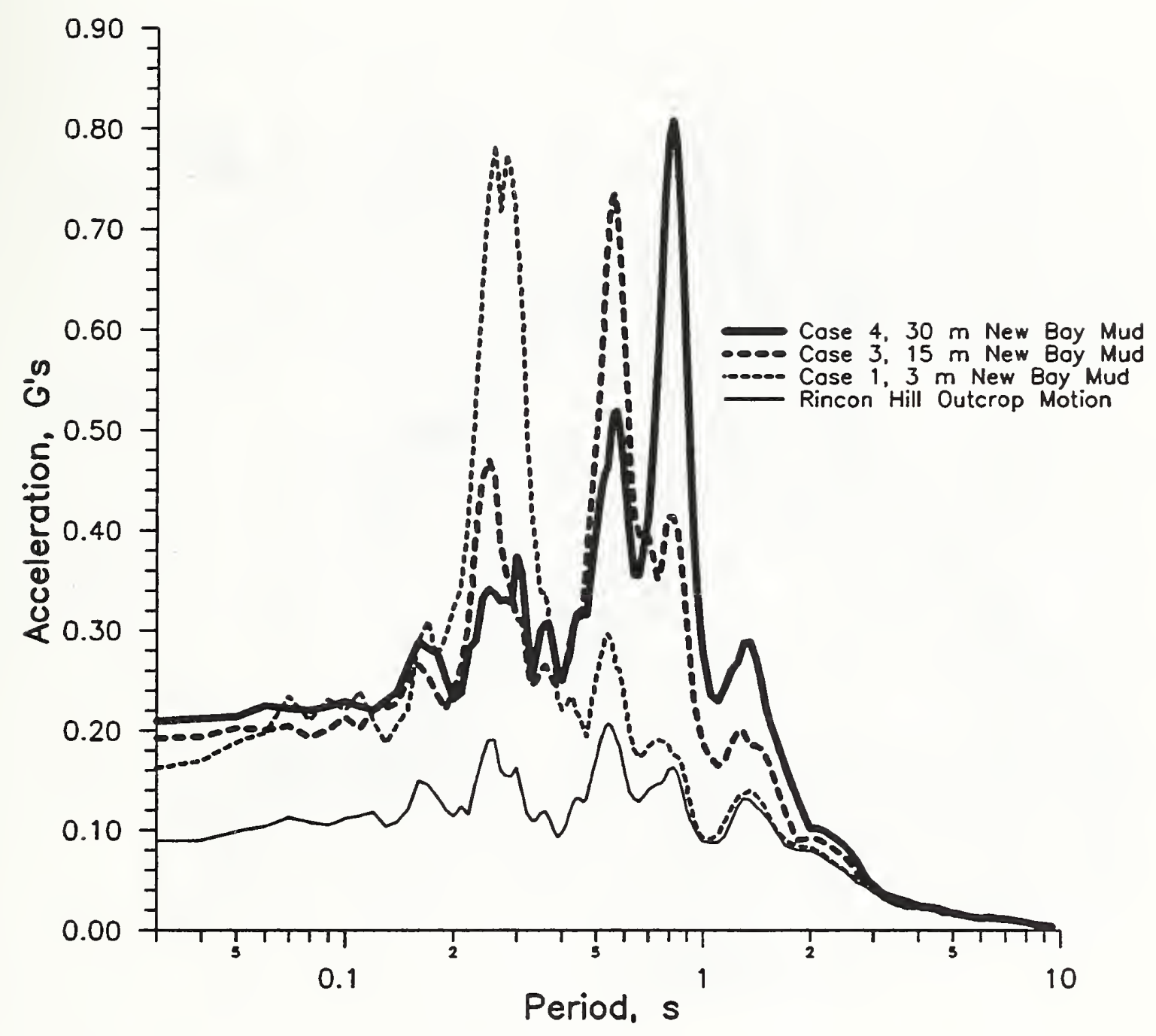

Figure 4.9: Comparison of Acceleration Response Spectra for Cases 1, 3, and 4 - Rincon Hill Outcrop Motion. 


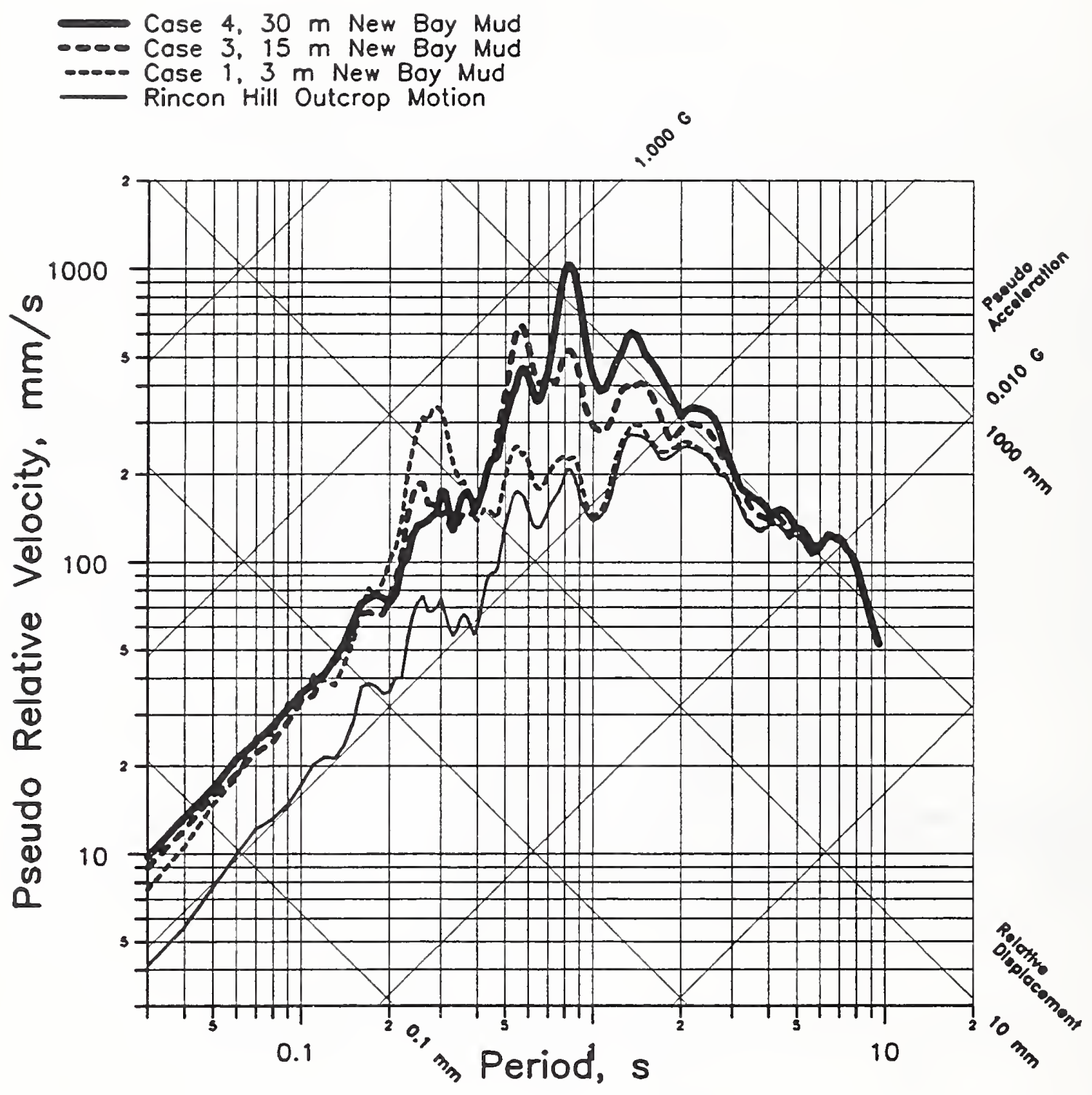

Figure 4.10: Comparison of Response Spectra for Cases 1, 3, and 4 - Rincon Hill Outcrop Motion. 


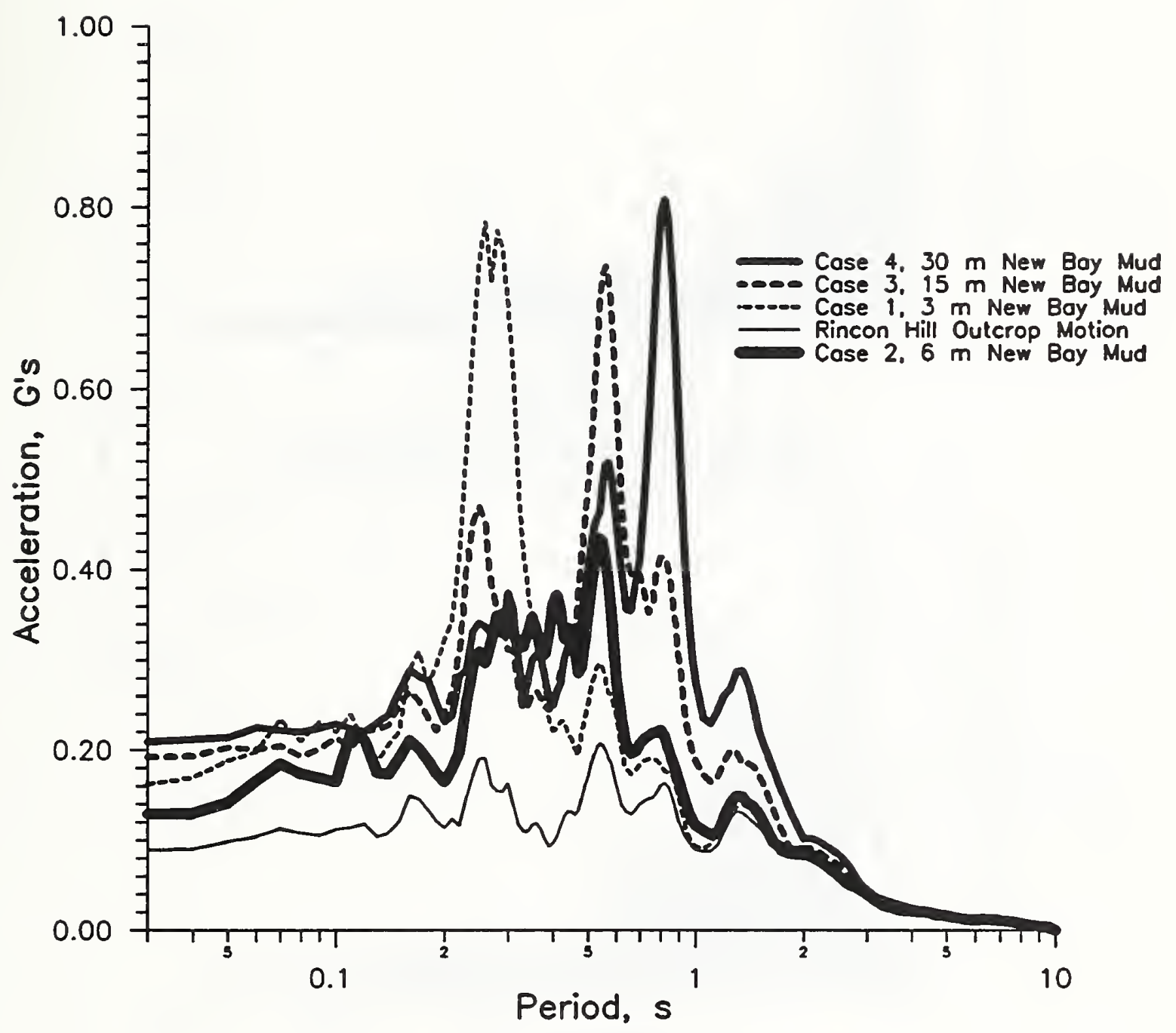

Figure 4.11: Comparison of Acceleration Response Spectrum for Case 2 with those for Cases 1, 3, and 4 - Rincon Hill Outcrop Motion. 

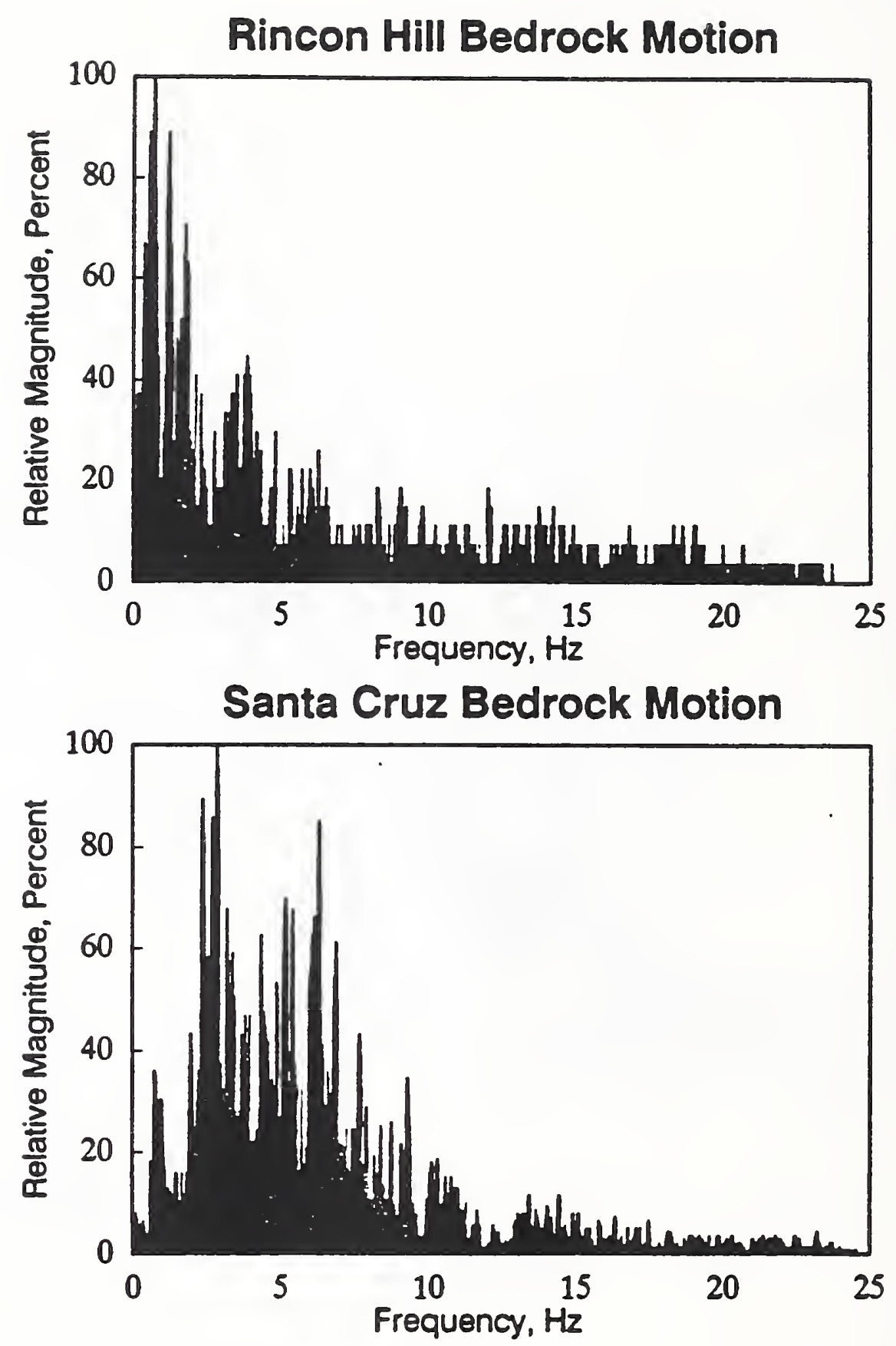

Figure 4.12: Fourier Spectra for the Rincon Hill and Santa Cruz Rock Outcrop Motions. 


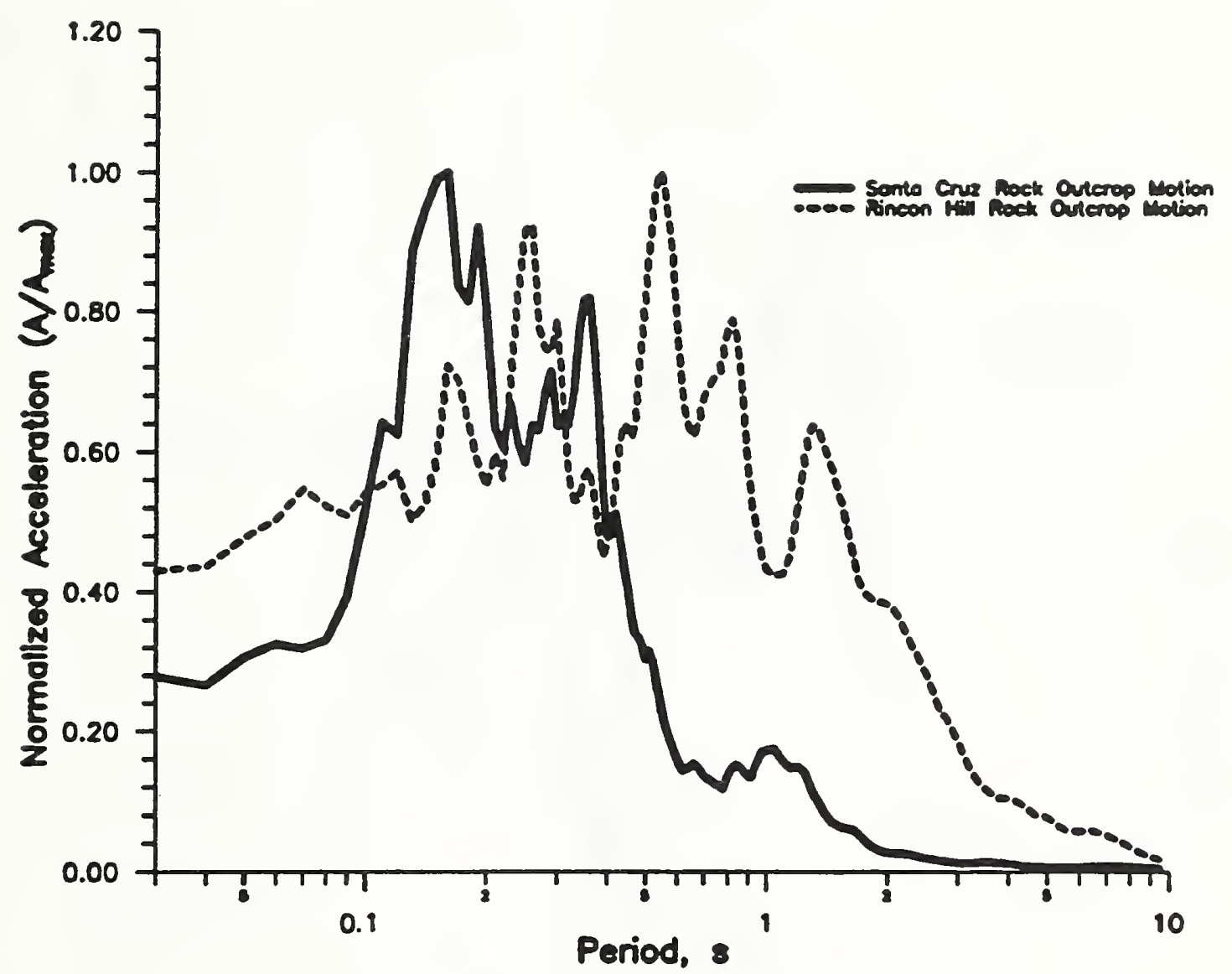

Figure 4.13: Comparison of Normalized Acceleration Response Spectra for the Rincon Hill and Santa Cruz Rock Outcrop Motions. 


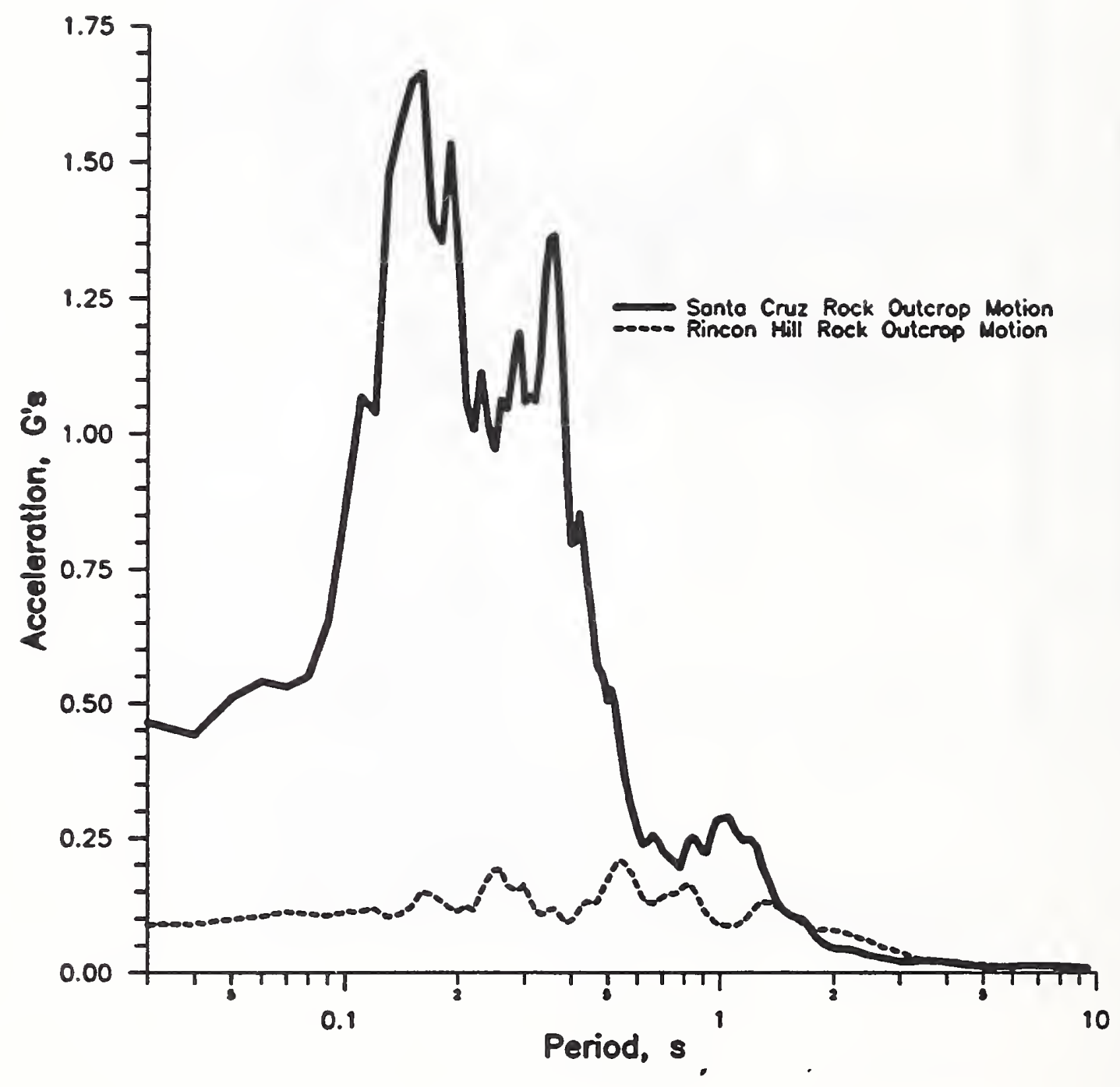

Figure 4.14: Comparison of Acceleration Response Spectra for the Rincon Hill and Santa Cruz Rock Outcrop Motions. 


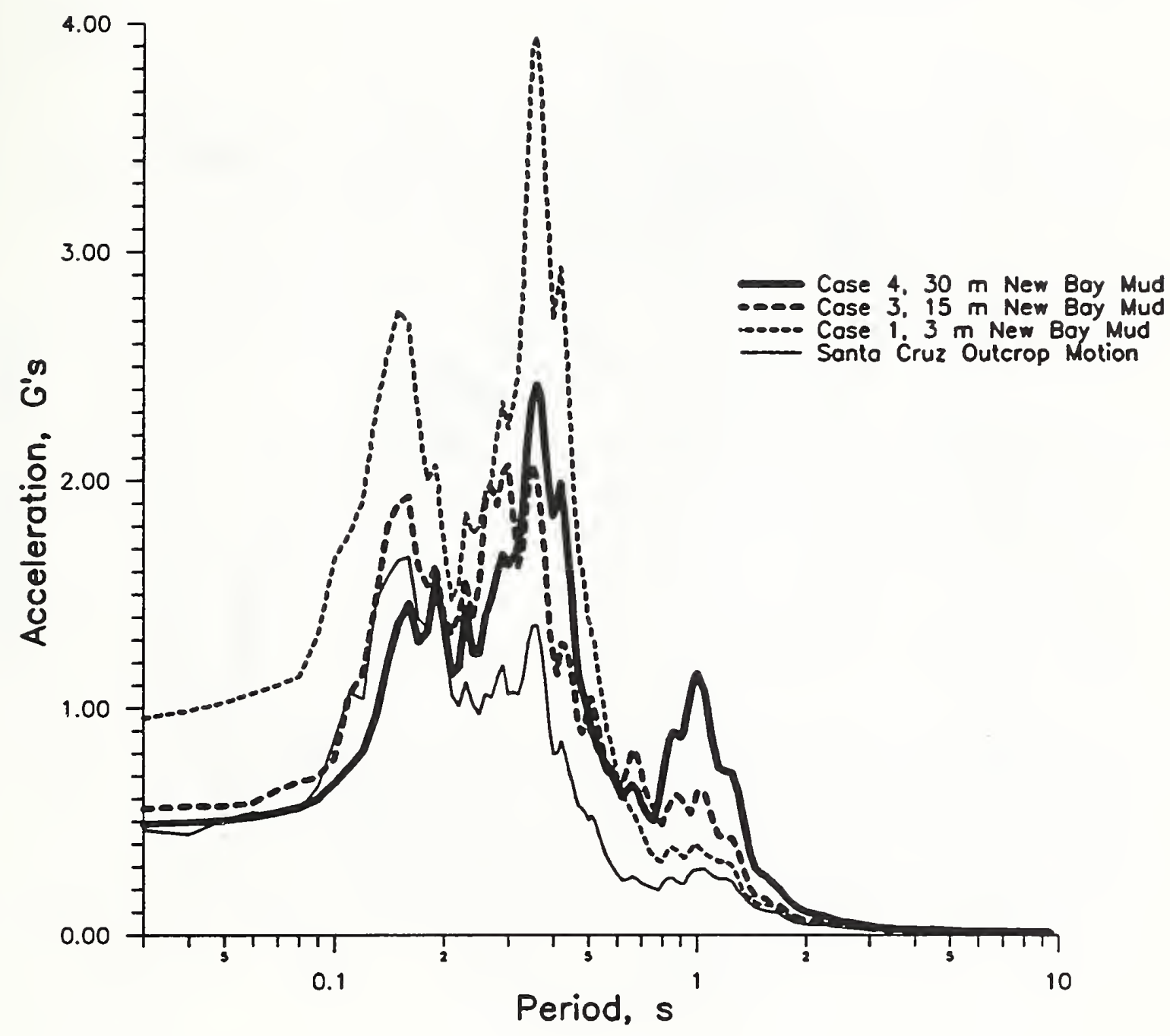

Figure 4.15: Comparison of Acceleration Response Spectra for Cases 1, 3, and 4 - Santa Cruz Rock Outcrop Motion. 


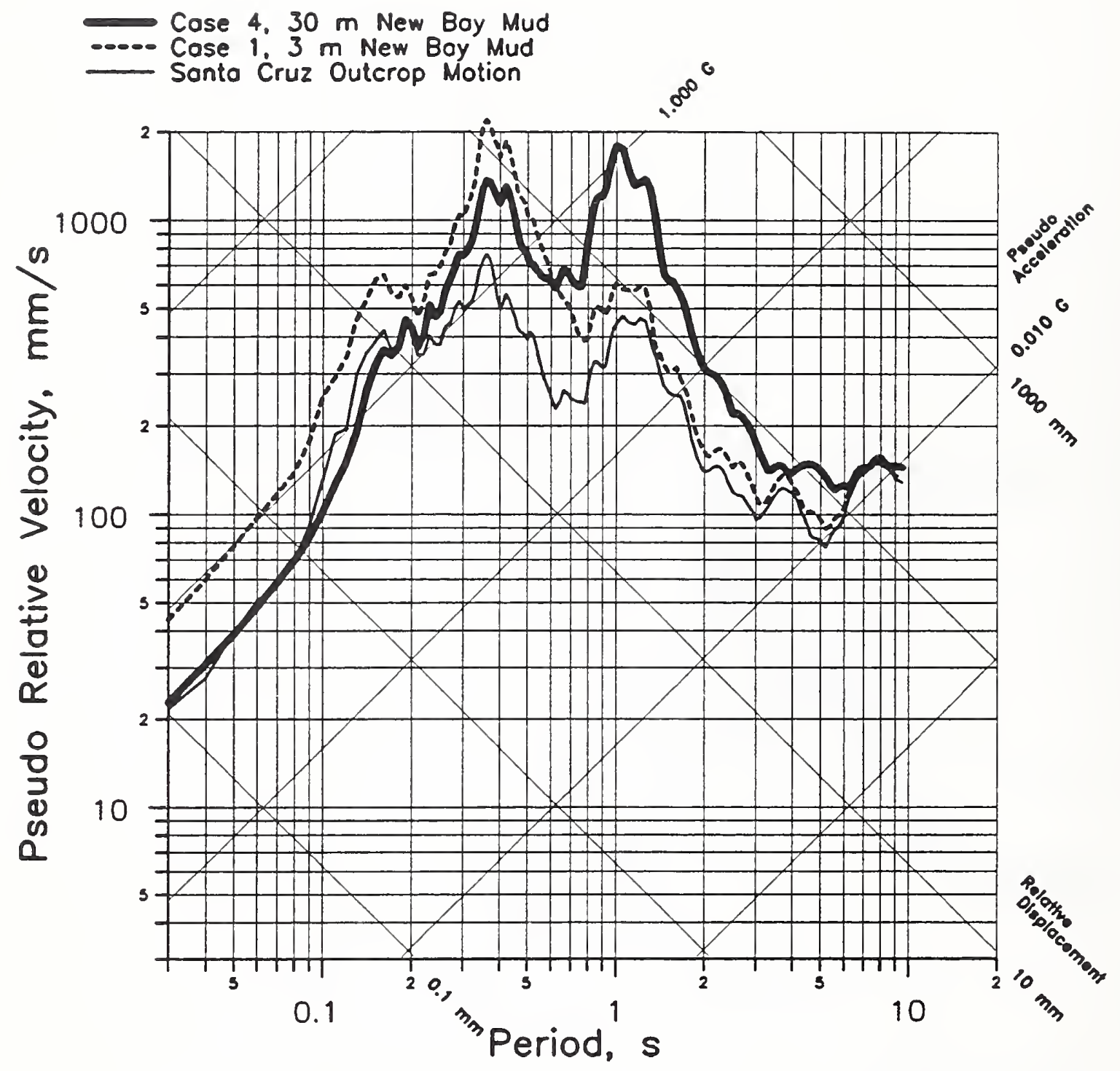

Figure 4.16: Comparison of Response Spectra for Cases 1 and 4 - Santa Cruz Rock Outcrop Motion. 


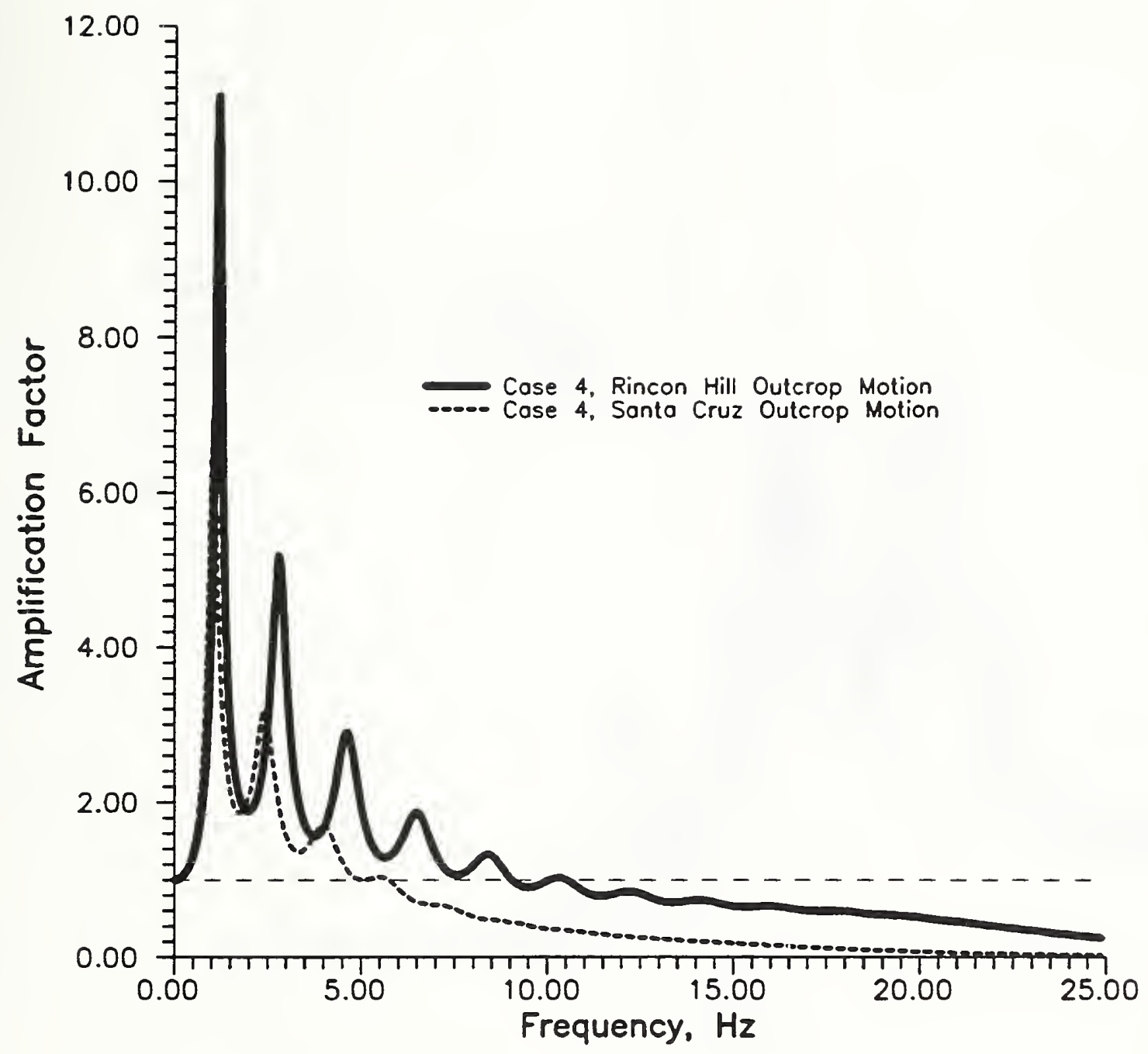

Figure 4.17: Amplification Spectra for Case 4. 


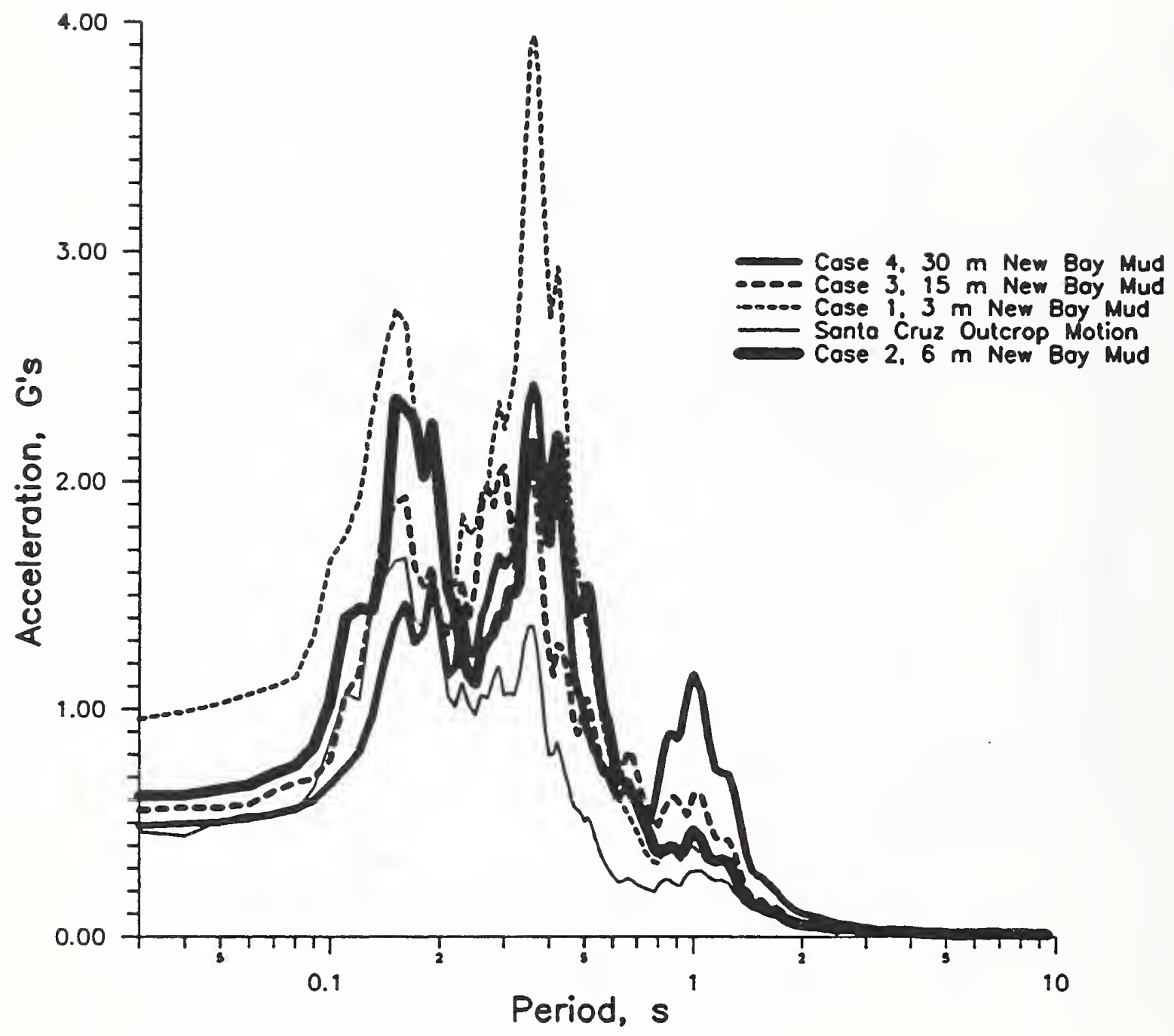

Figure 4.18: Comparison of Acceleration Response Spectra for Cases 1, 2, 3, and 4 - Santa Cruz Rock Outcrop Motion. 


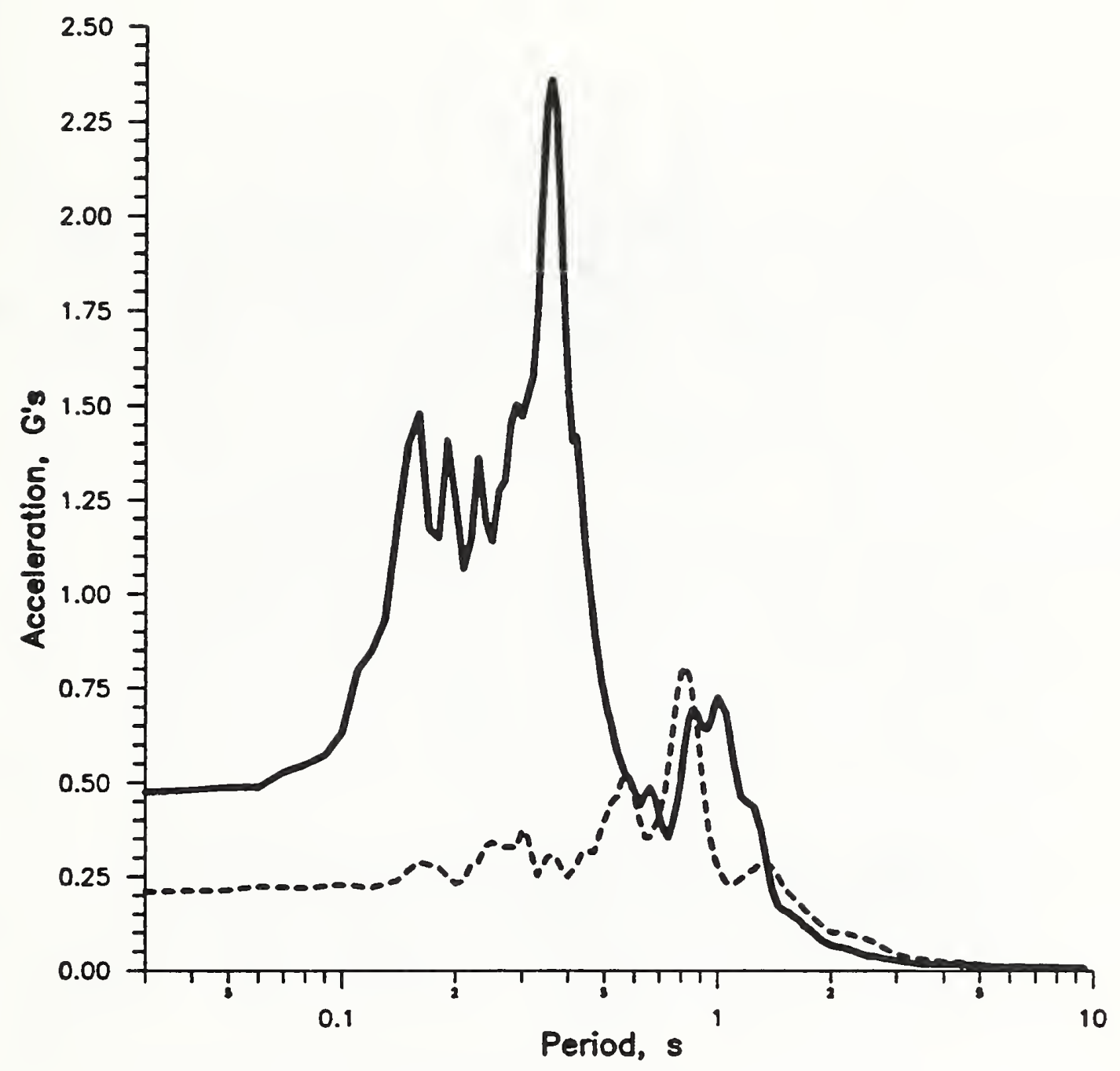

Case 4. Sonto Cruz Outcrop Motion

-c Cose 4. Rincon Hill Outerop Motion

Figure 4.19: Comparison of Acceleration Response Spectra for Profile 4, Rincon Hill and Santa Cruz Outcrop Motions. 


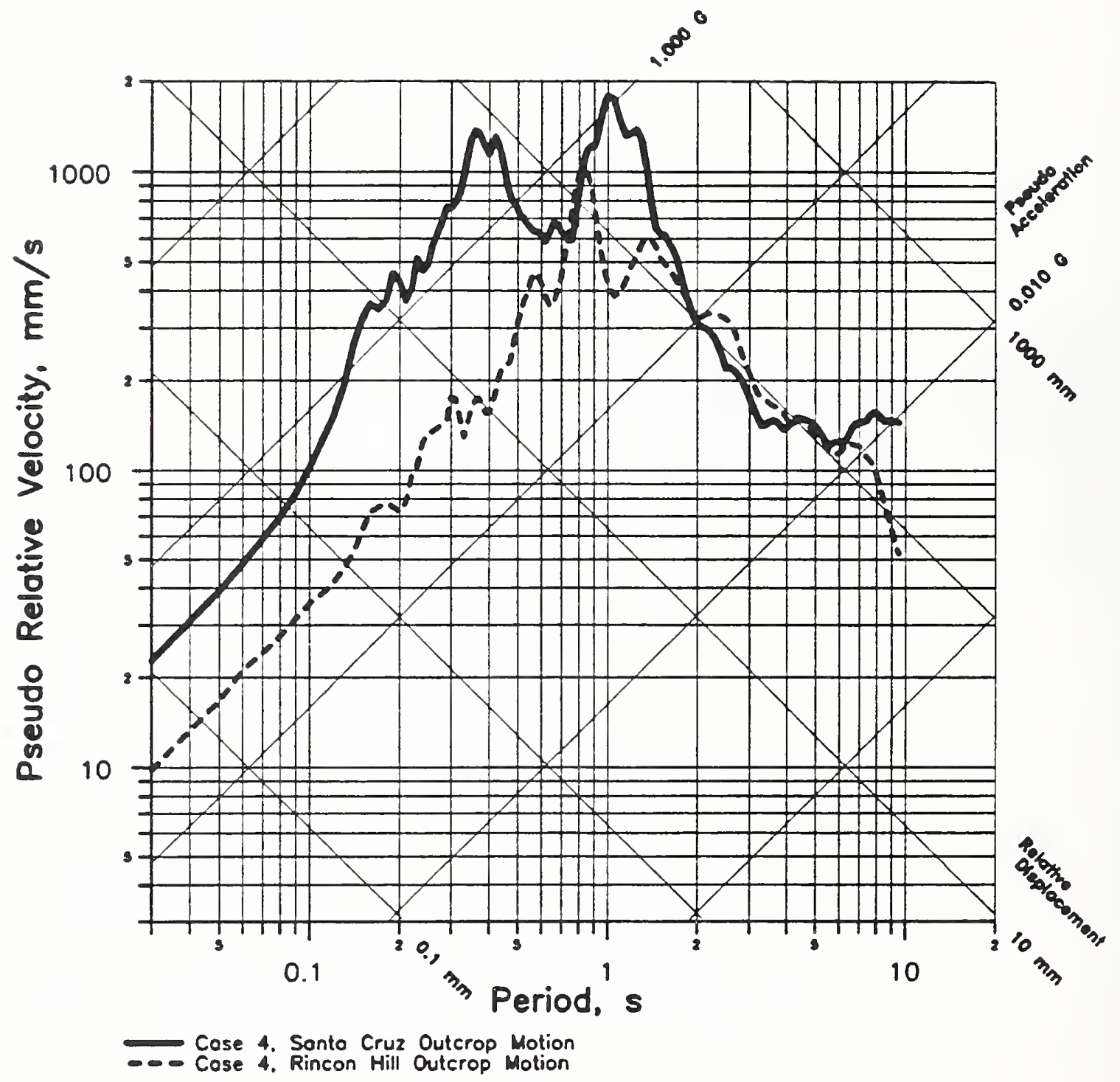

Figure 4.20: Comparison of Response Spectra for Profile 4, Rincon Hill and Santa Cruz Outcrop Motions. 


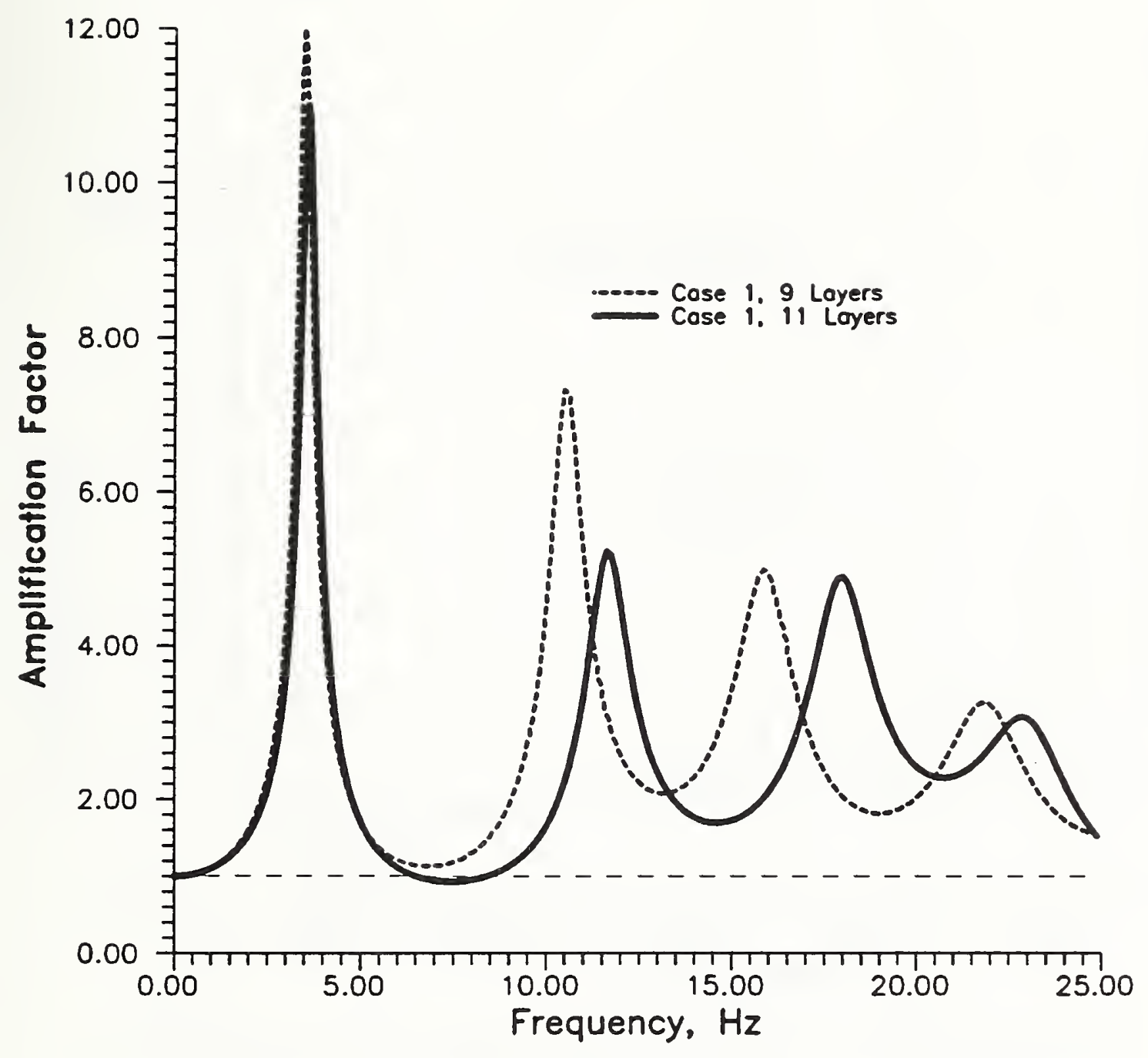

Figure 4.21: Amplification Spectra for Case 1, Calculated for 9 and 11 Layers. 


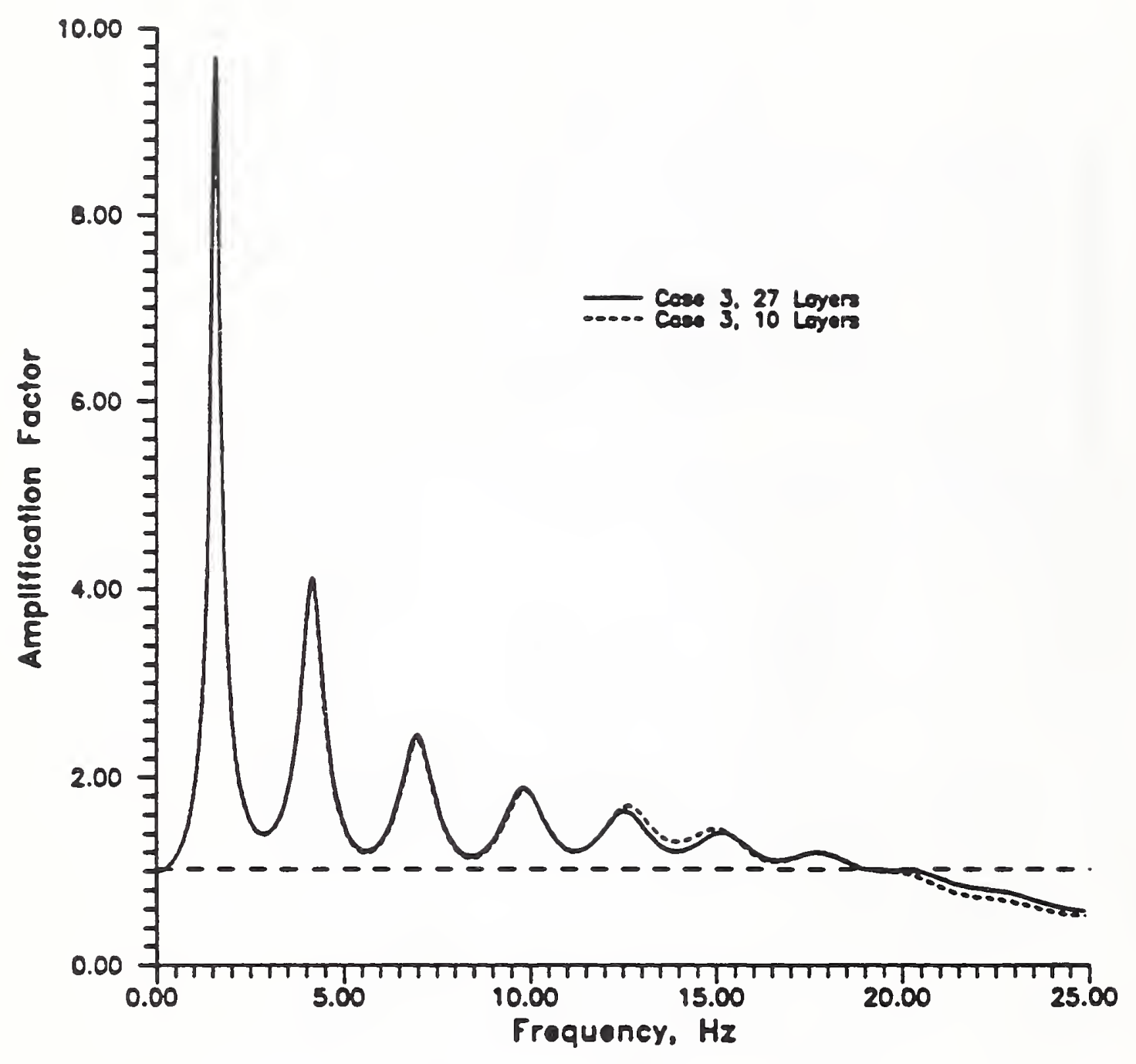

Figure 4.22: Amplification Spectra for Case 3, Calculated for 10 and 27 Layers. 


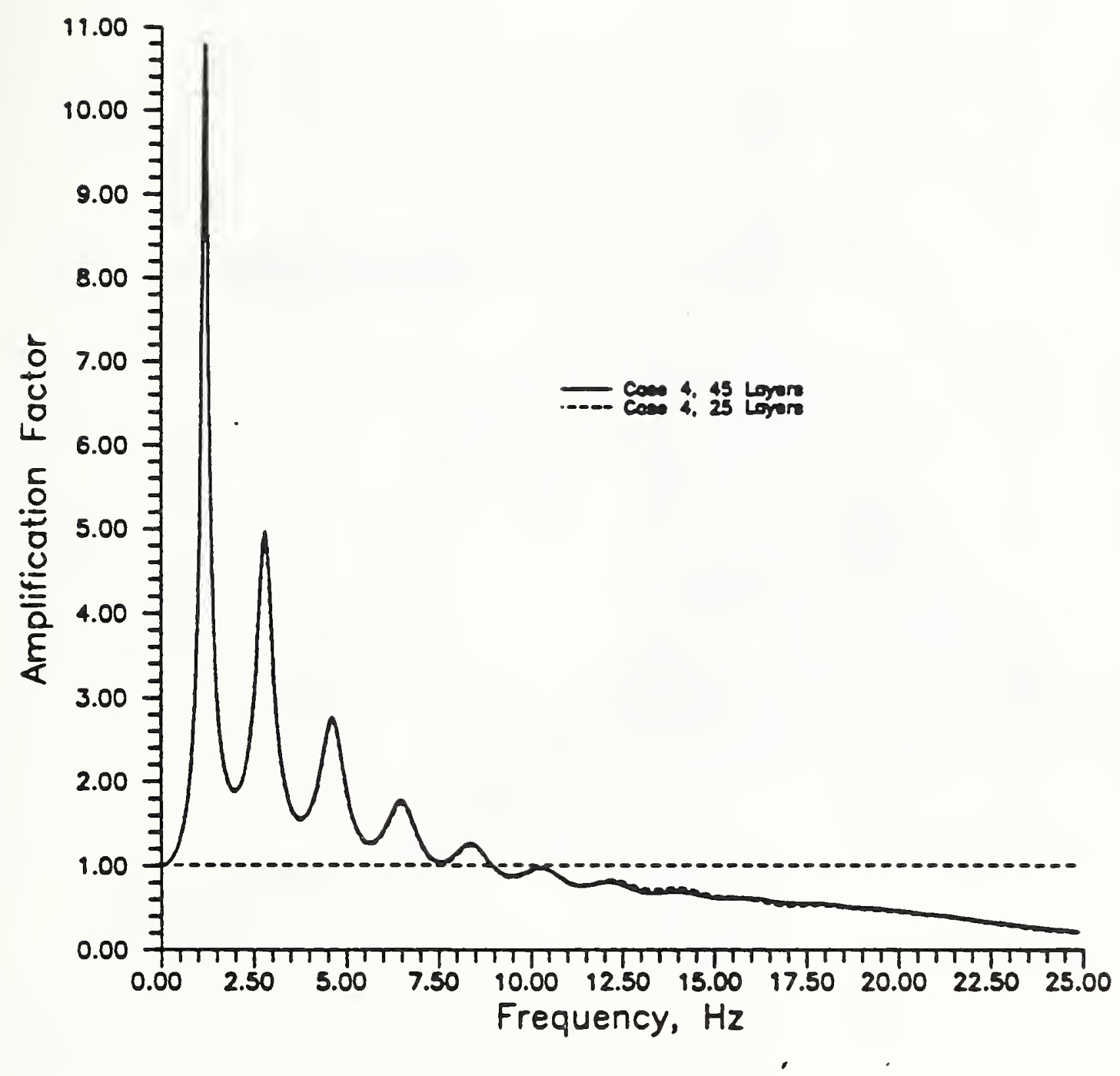

Figure 4.23: Amplification Spectra for Case 4, Calculated for 25 and 45 Layers. 


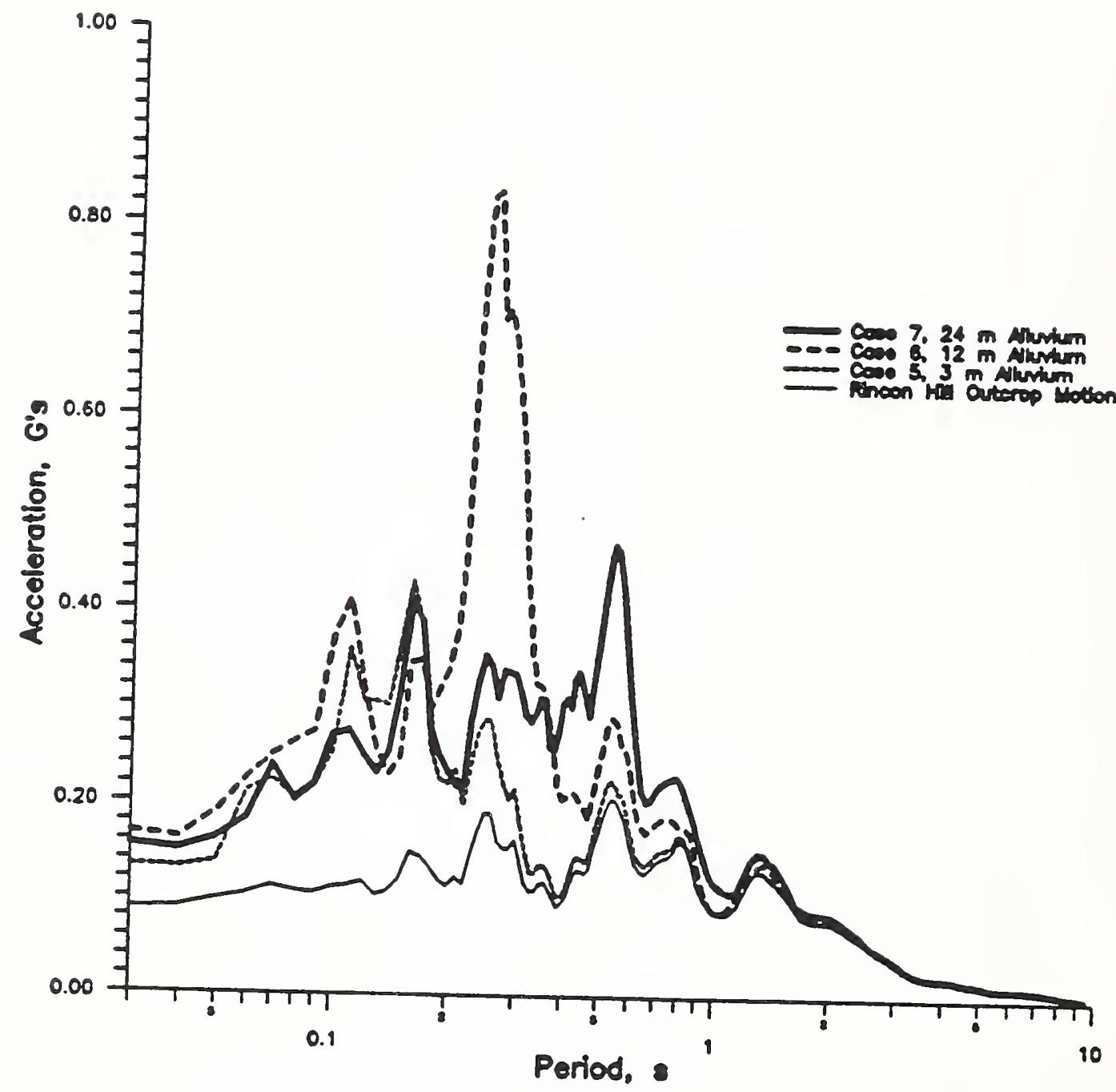

Figure 4.24: Comparison of Acceleration Response Spectra for Profiles 5 to 7, Calculated for the Rincon Hill Outcrop Motion. 


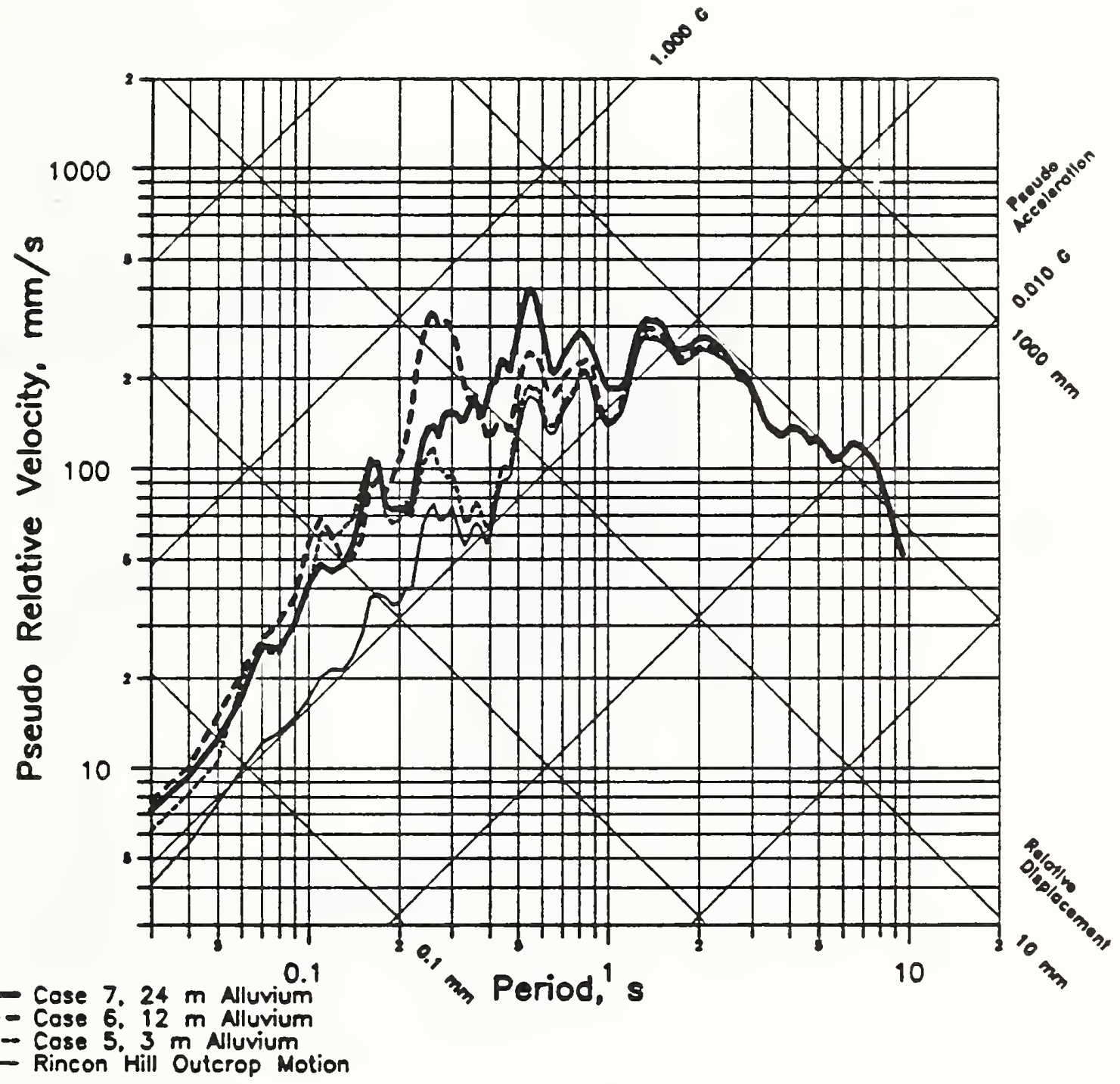

Figure 4.25: Comparison of Response Spectra for Profiles 5 to 7. Calculated for the Rincon Hill Outcrop Motion. 


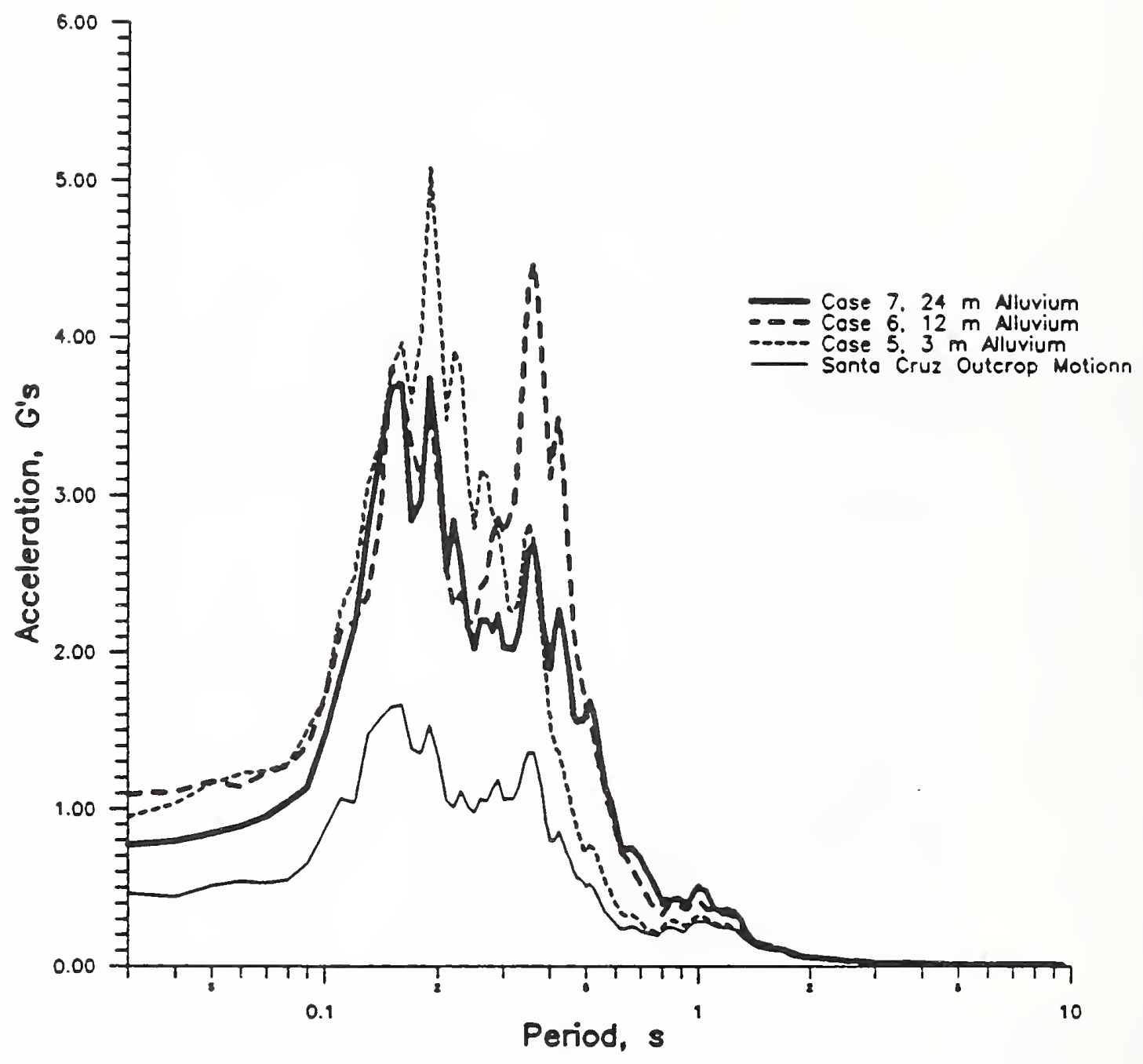

Figure 4.26: Comparison of Acceleration Response Spectra for Profiles 5 to 7, Calculated for the Santa Cruz Outcrop Motion. 


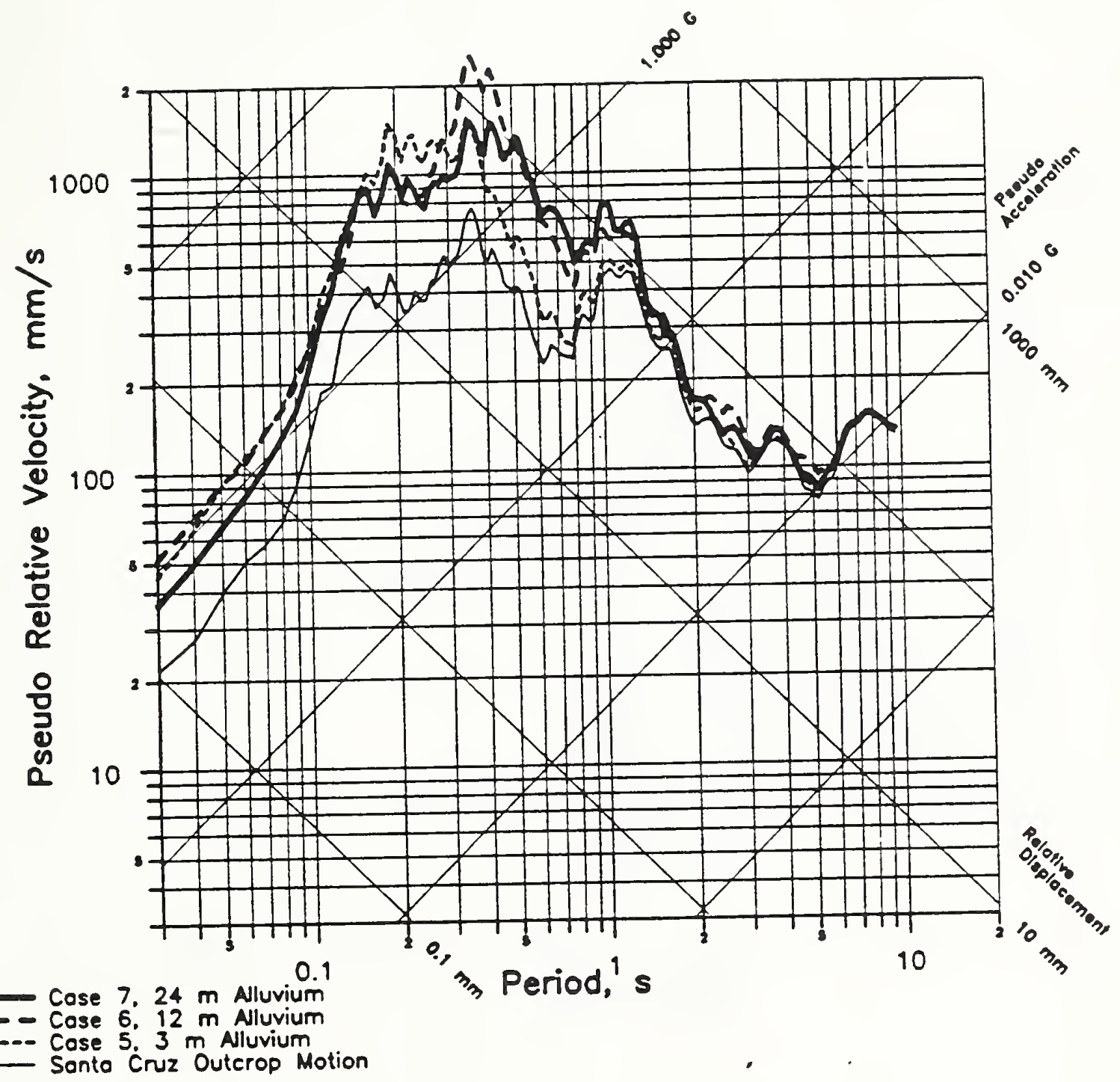

Figure 4.27: Comparison of Response Spectra for Profiles 5 to 7, Calculated for the Santa Cruz Outcrop Motion. 


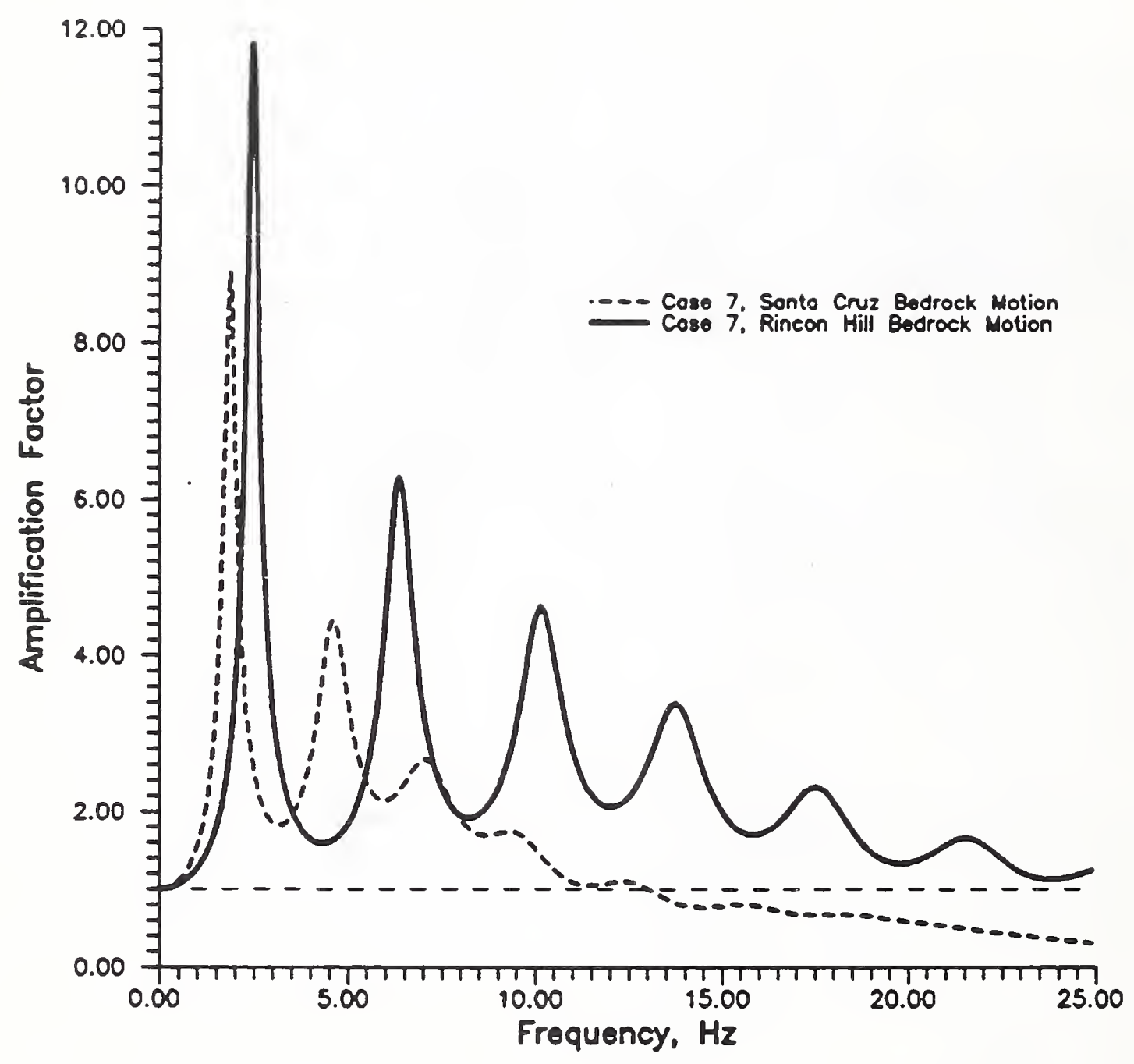

Figure 4.28: Comparison of Amplification Spectra for Case 7, Calculated for the Rincon Hill and Santa Cruz outcrop motions. 


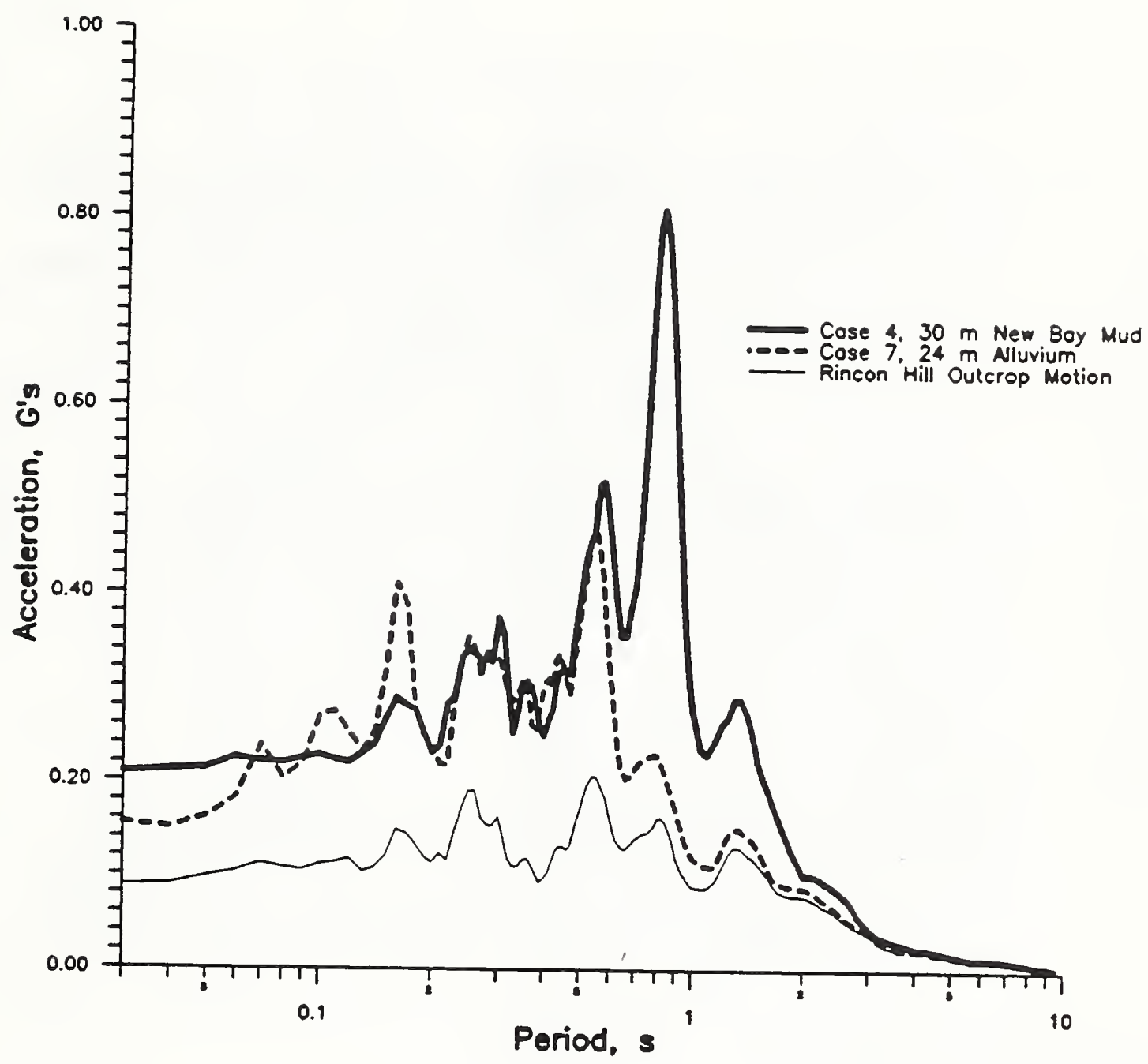

Figure 4.29: Comparison of Acceleration Response Spectra for Profiles 4 and 7, Calculated for the Rincon Hill Outcrop Motion. 


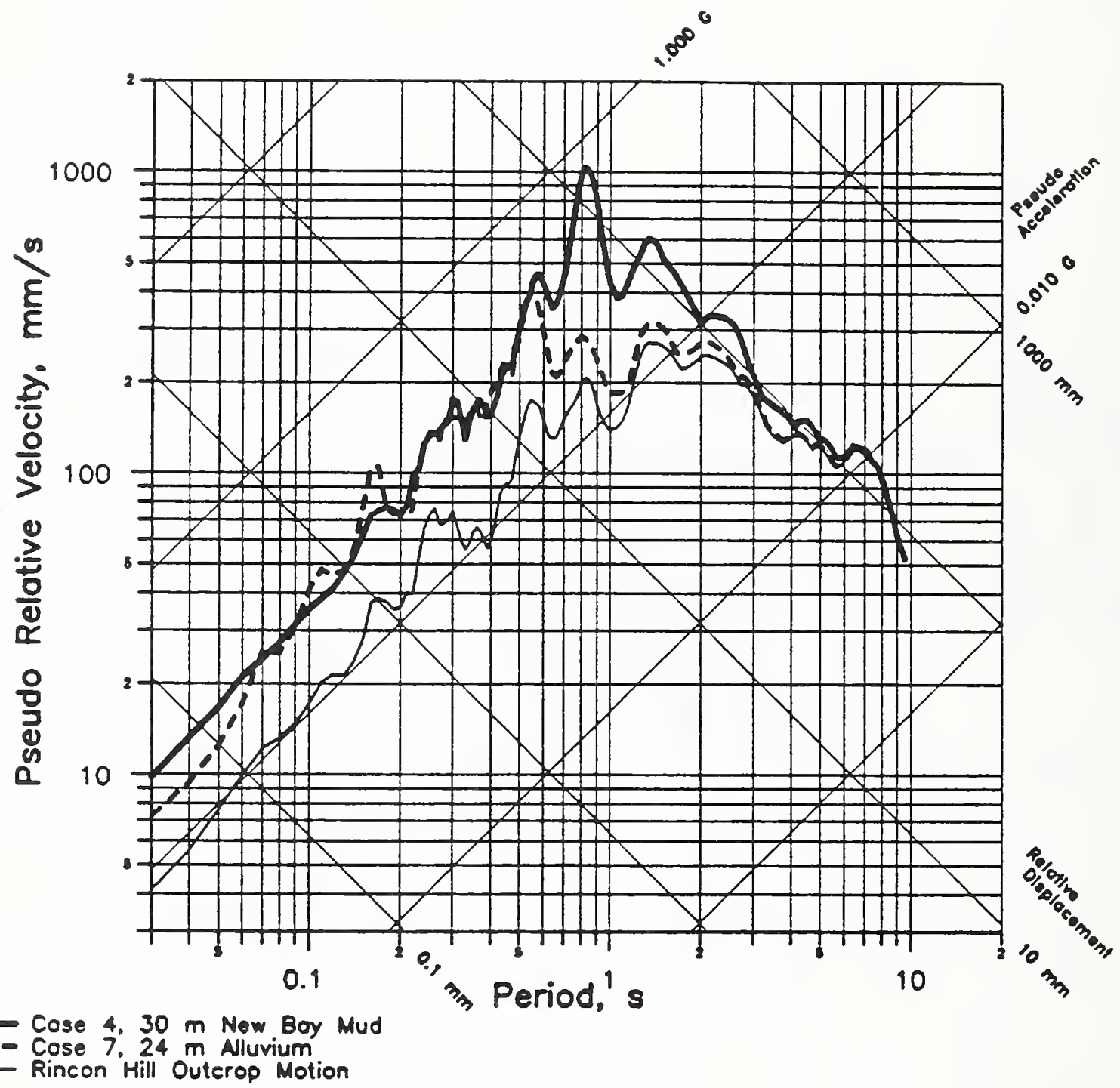

Figure 4.30: Comparison of Response Spectra for Profiles 4 and 7, Calculated for the Rincon Hill Outcrop Motion. 


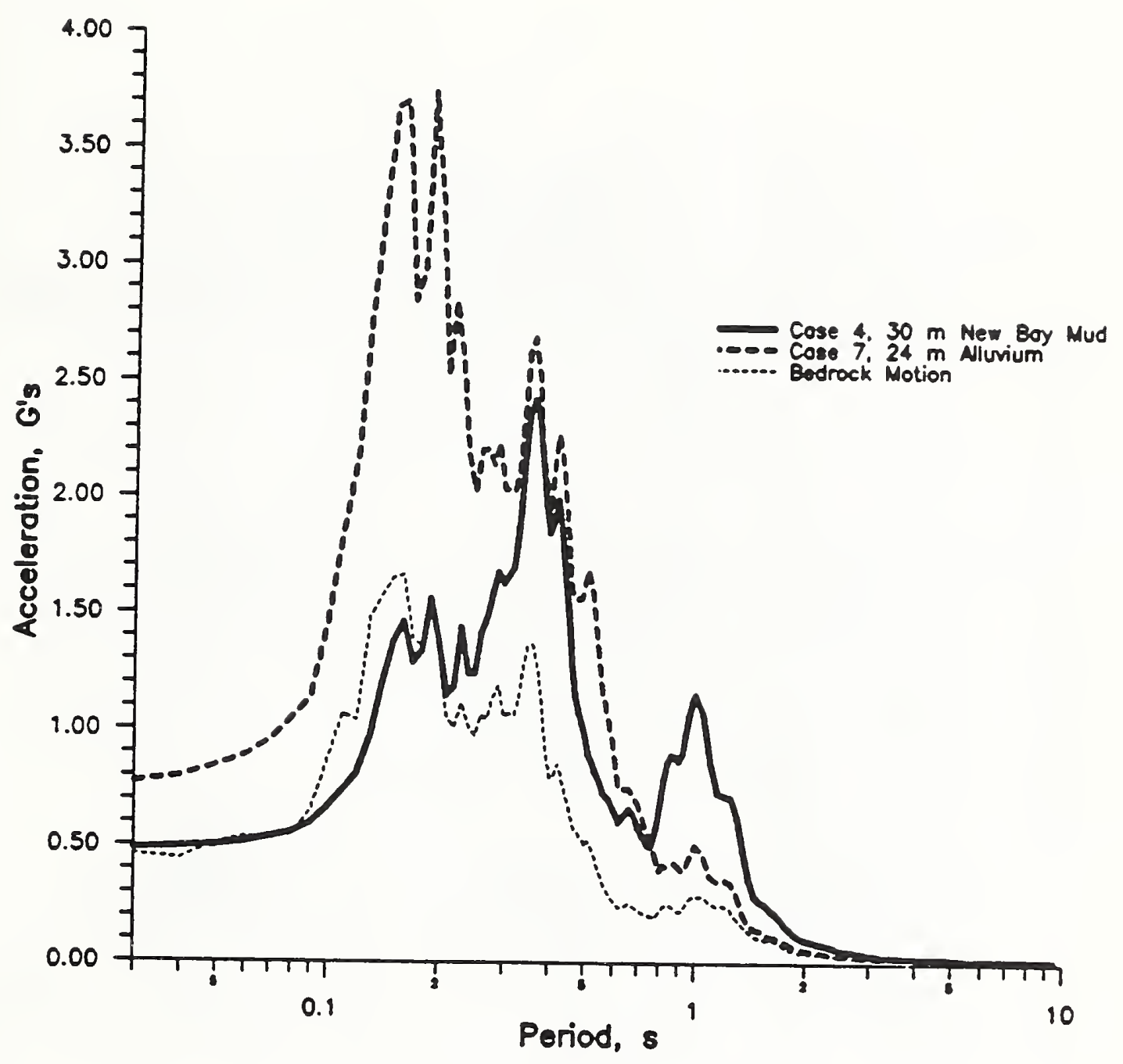

Figure 4.31: Comparison of Acceleration Response Spectra for Profiles 4 and 7, Calculated for the Santa Cruz Outcrop Motion. 


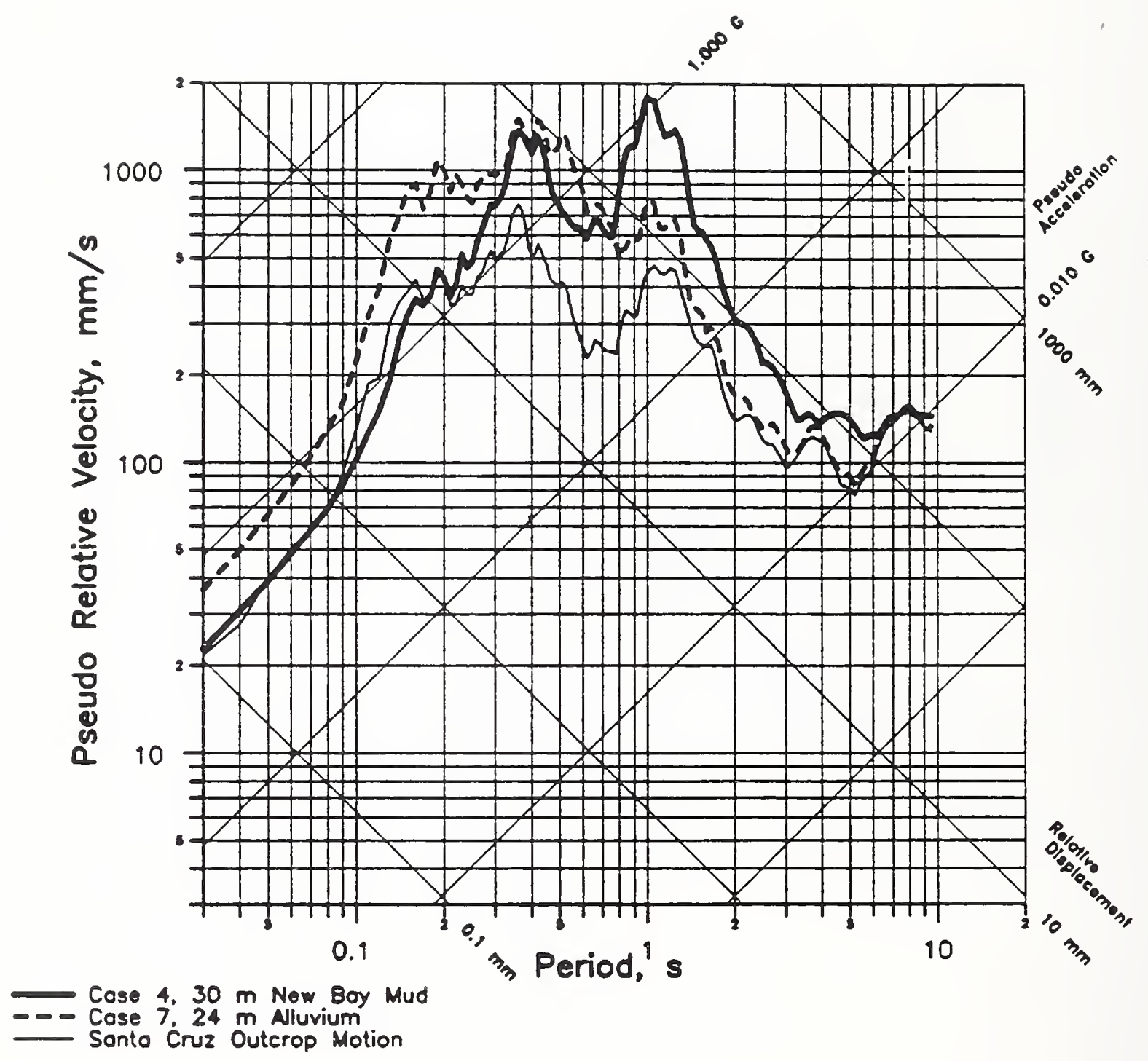

Figure 4.32: Comparison of Response Spectra for Profiles 4 and 7, Calculated for the Santa Cruz Outcrop Motion. 


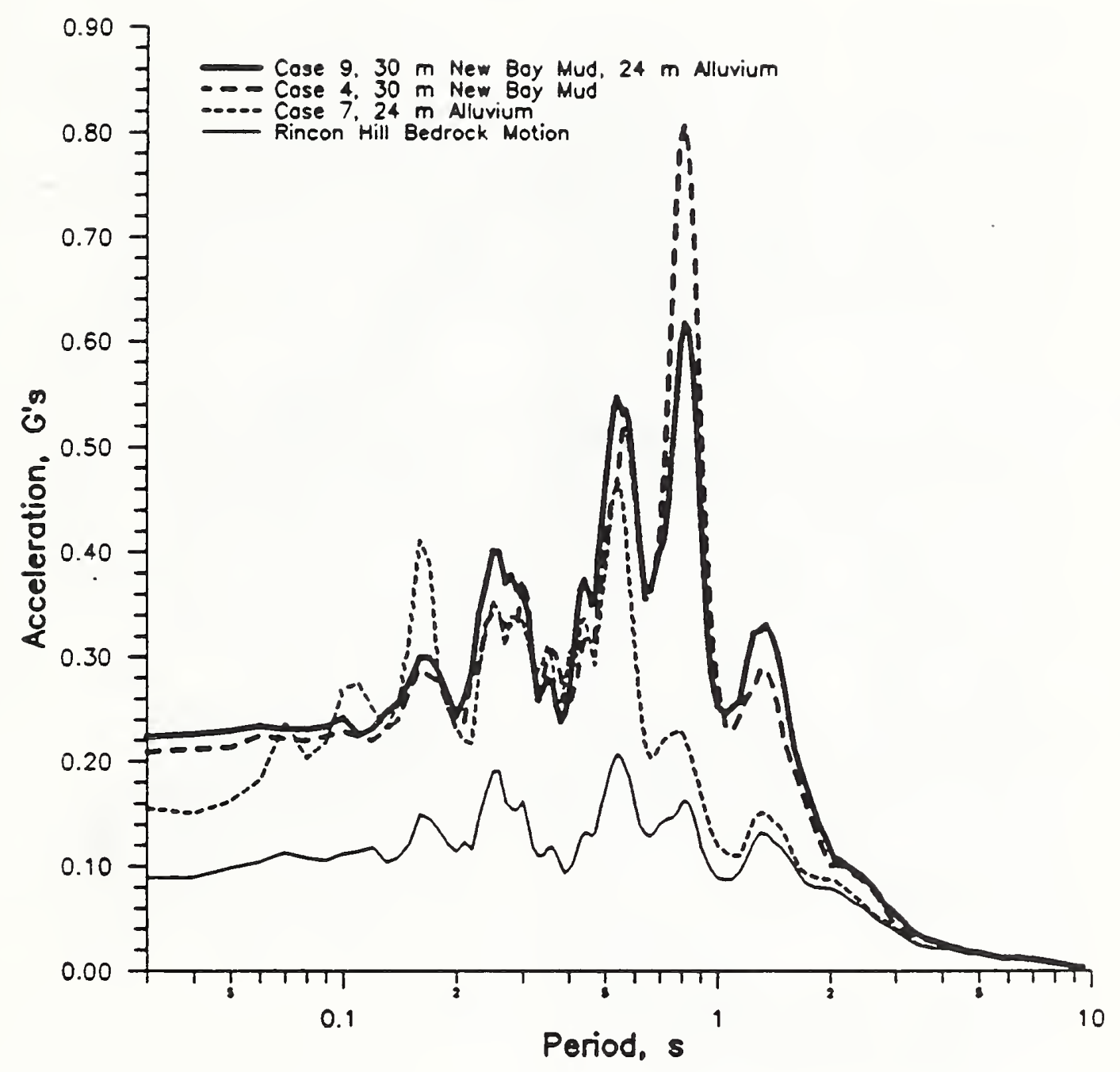

Figure 4.33: Comparison of Acceleration Response Spectra for Profiles 4, 7, and 9, Calculated for the Rincon Hill Outcrop Motion. 


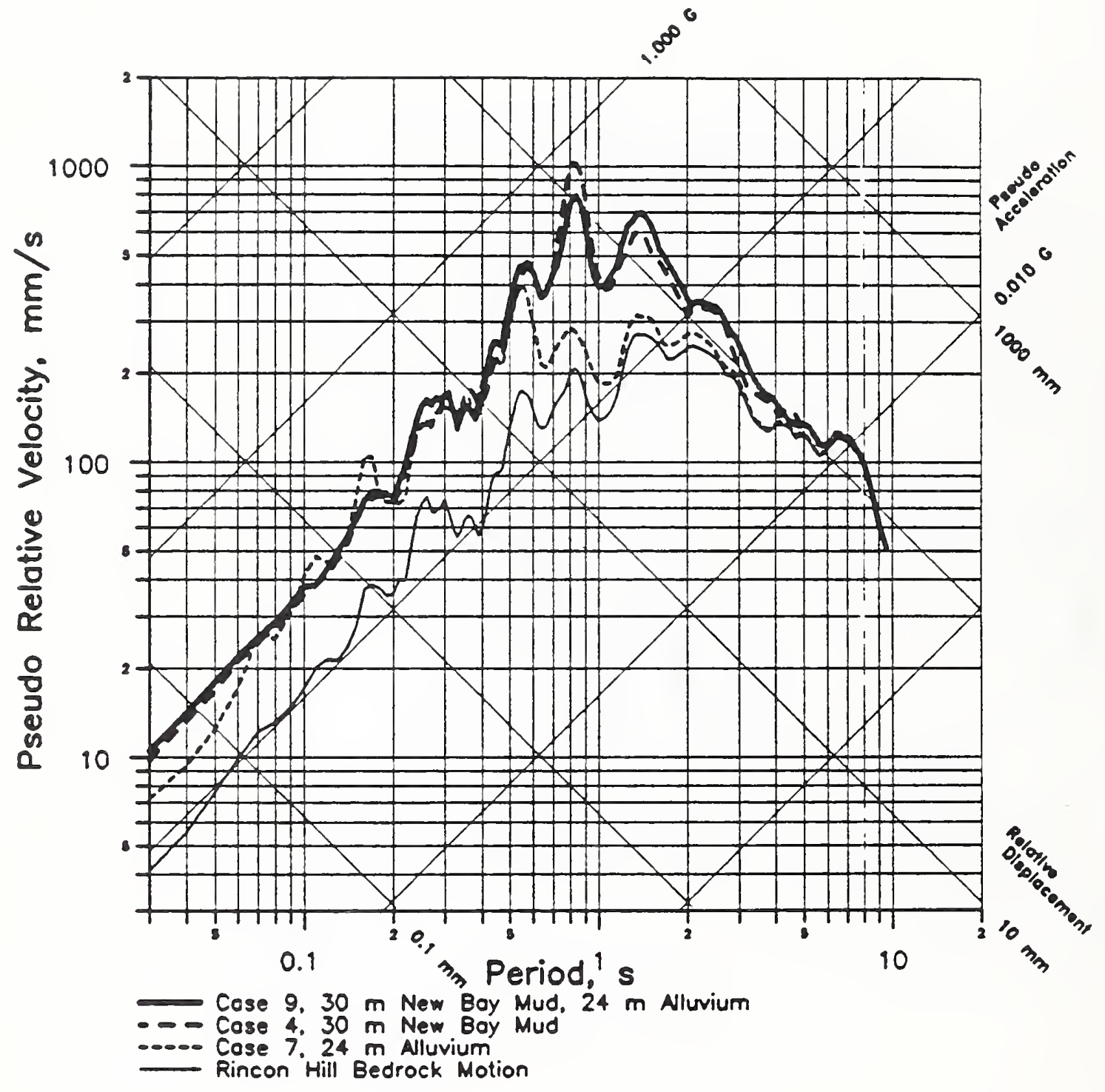

Figure 4.34: Comparison of Response Spectra for Profiles 4, 7, and 9, Calculated for the Rincon Hill Outcrop Motion. 


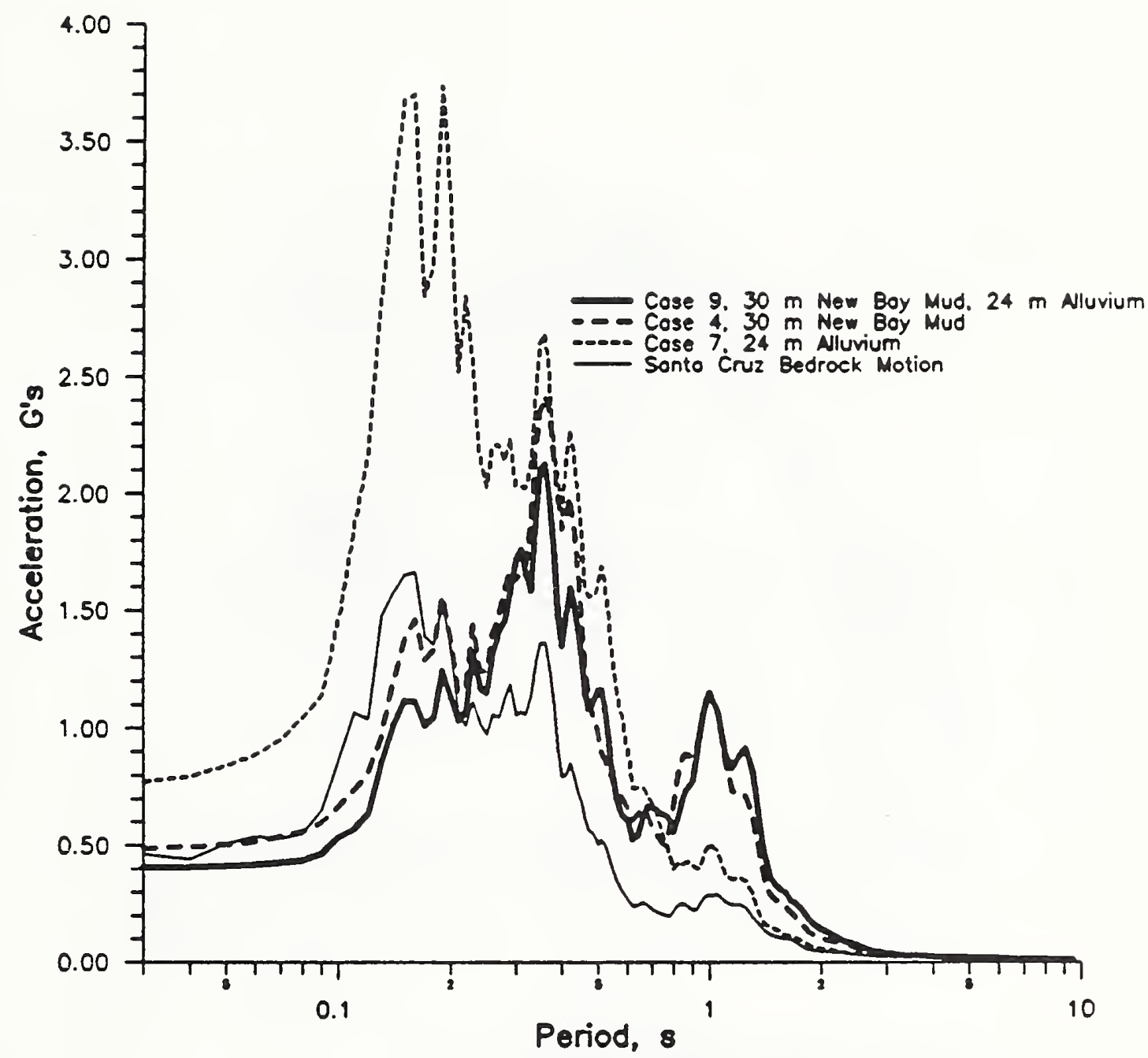

Figure 4.35: Comparison of Acceleration Response Spectra for Profiles 4, 7, and 9, Calculated for the Santa Cruz Outcrop Motion. 


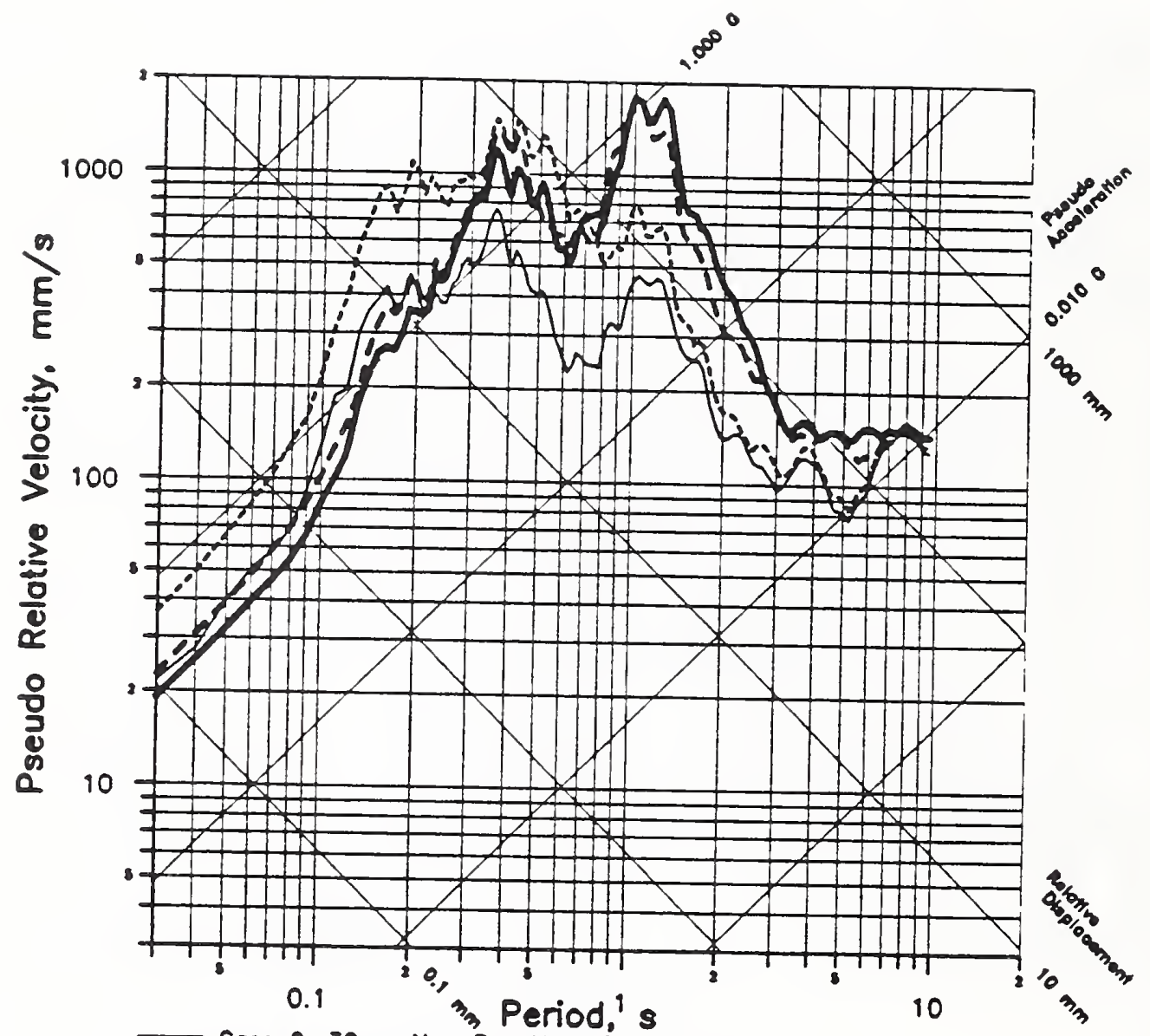

$\longrightarrow$ Cose 9. $30 \mathrm{~m}$ New Boy Mud, $24 \mathrm{~m}$ Nluvium

con $30 \mathrm{~m}$ New Boy Mud

Cose 7., $24 \mathrm{~m}$ Aluvium

Sonto Cruz Bedrock Motion

Figure 4.36: Comparison of Response Spectra for Profiles 4, 9, and 7, Calculated for the Santa Cruz Outcrop Motion. 


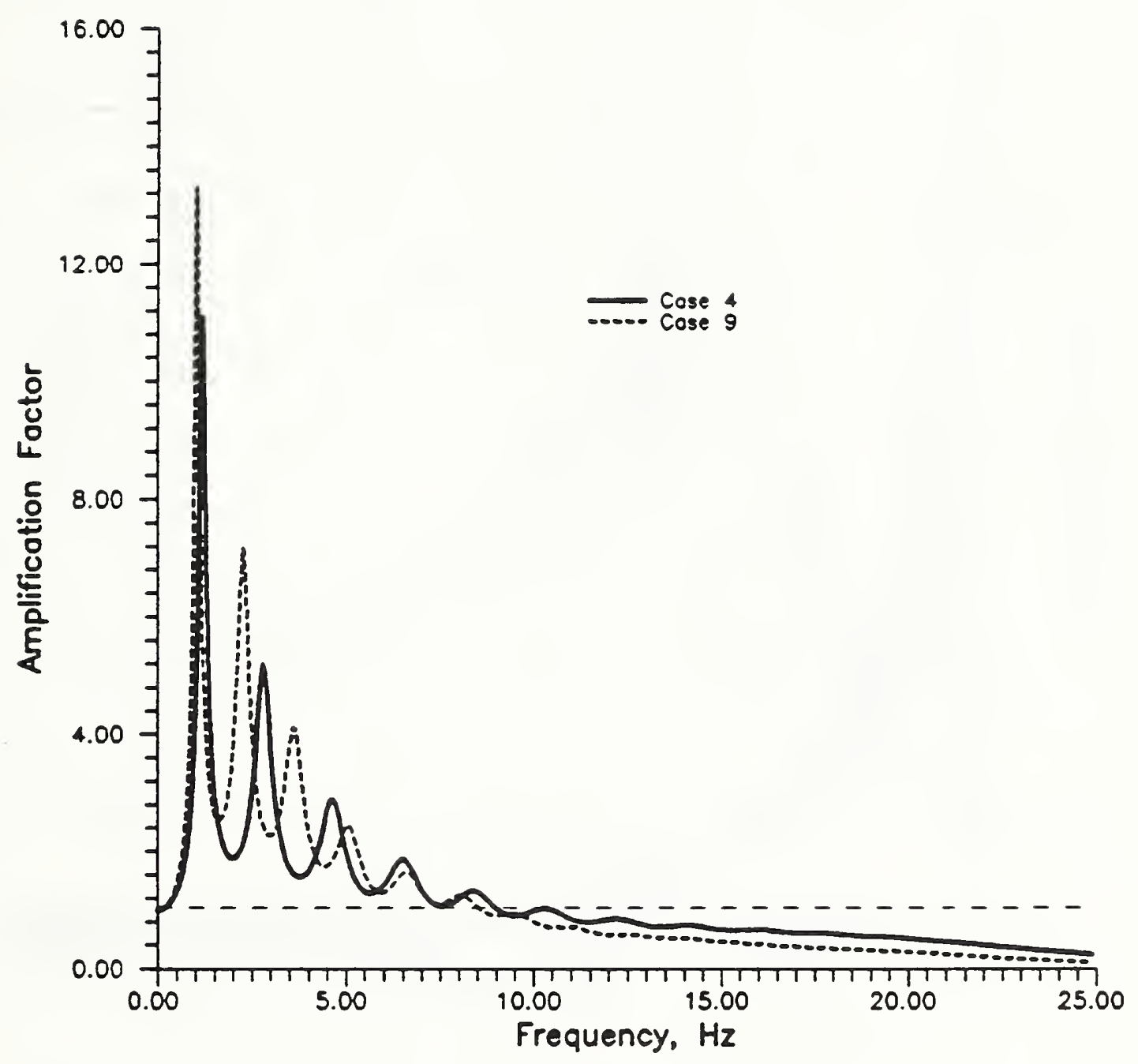

Figure 4.37: Comparison of Amplification Spectra for Cases 4 and 9, Rincon Hill Outcrop Motion. 


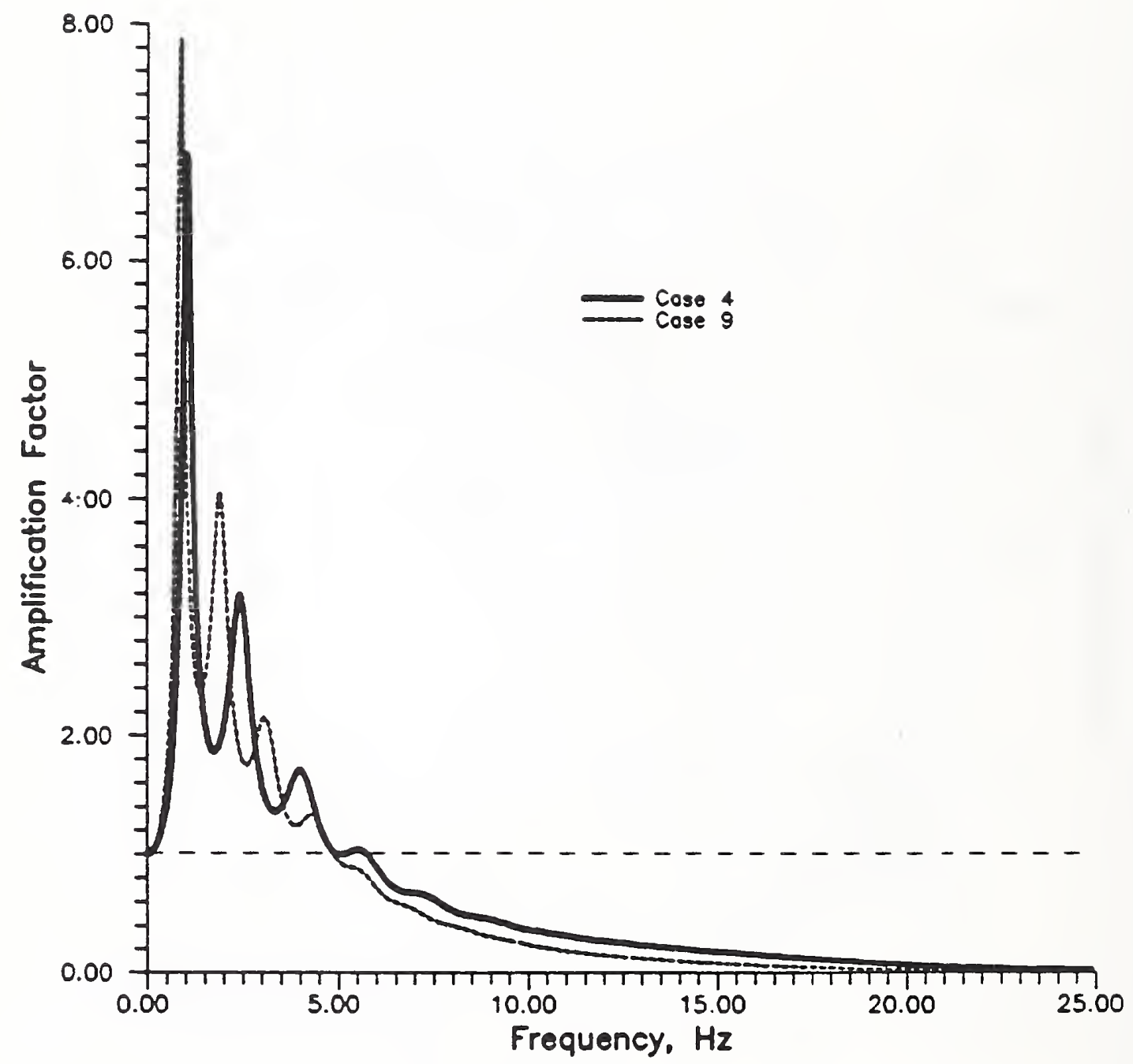

Figure 4.38: Comparison of Amplification Spectra for Cases 4 and 9, Santa Cruz outcrop motion. 


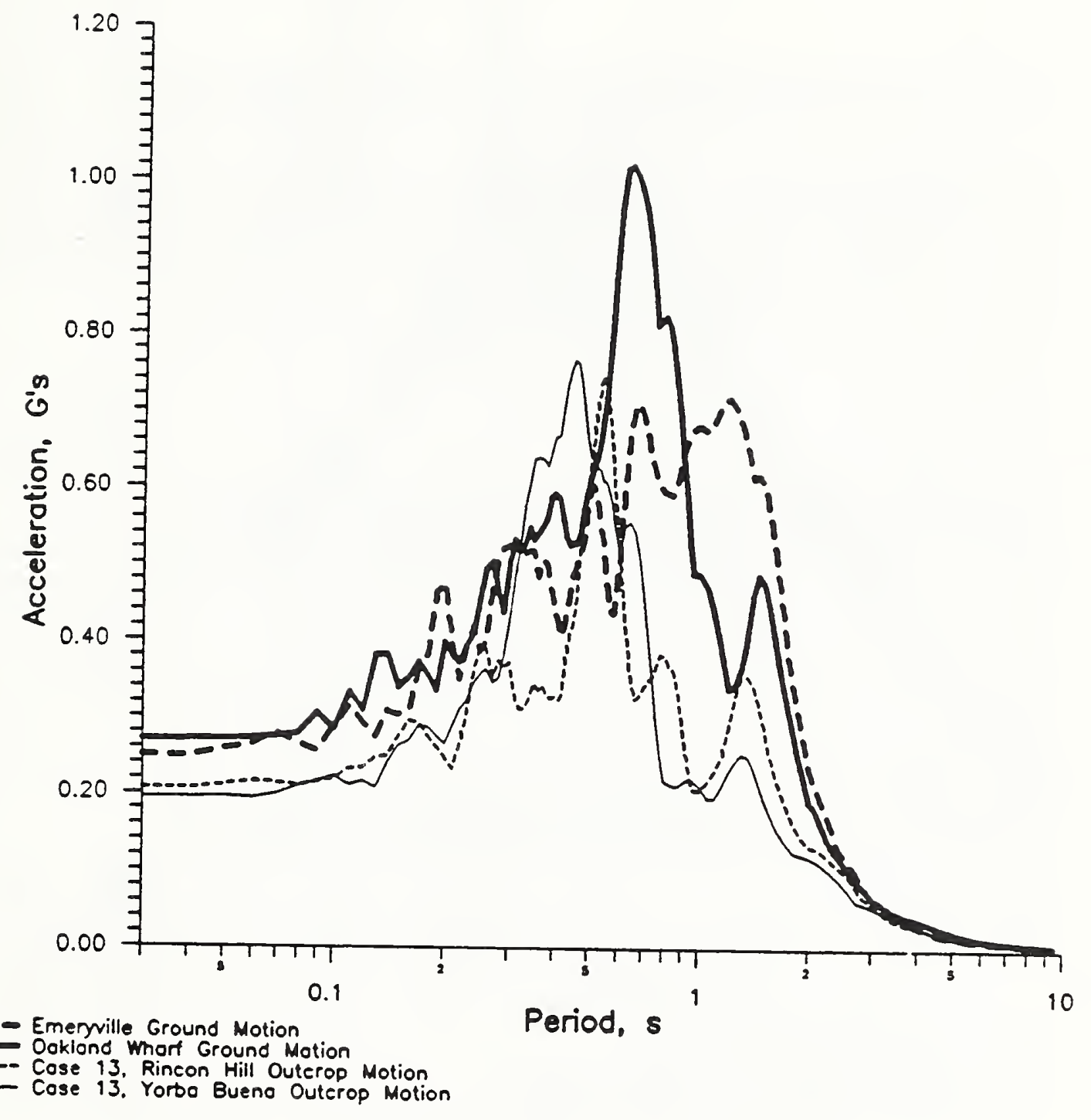

Figure 4.39: Comparison of Acceleration Response Spectra for Case 13 with the Recorded Ground Motions at Oakland Outer Harbor Wharf and Emeryville. 


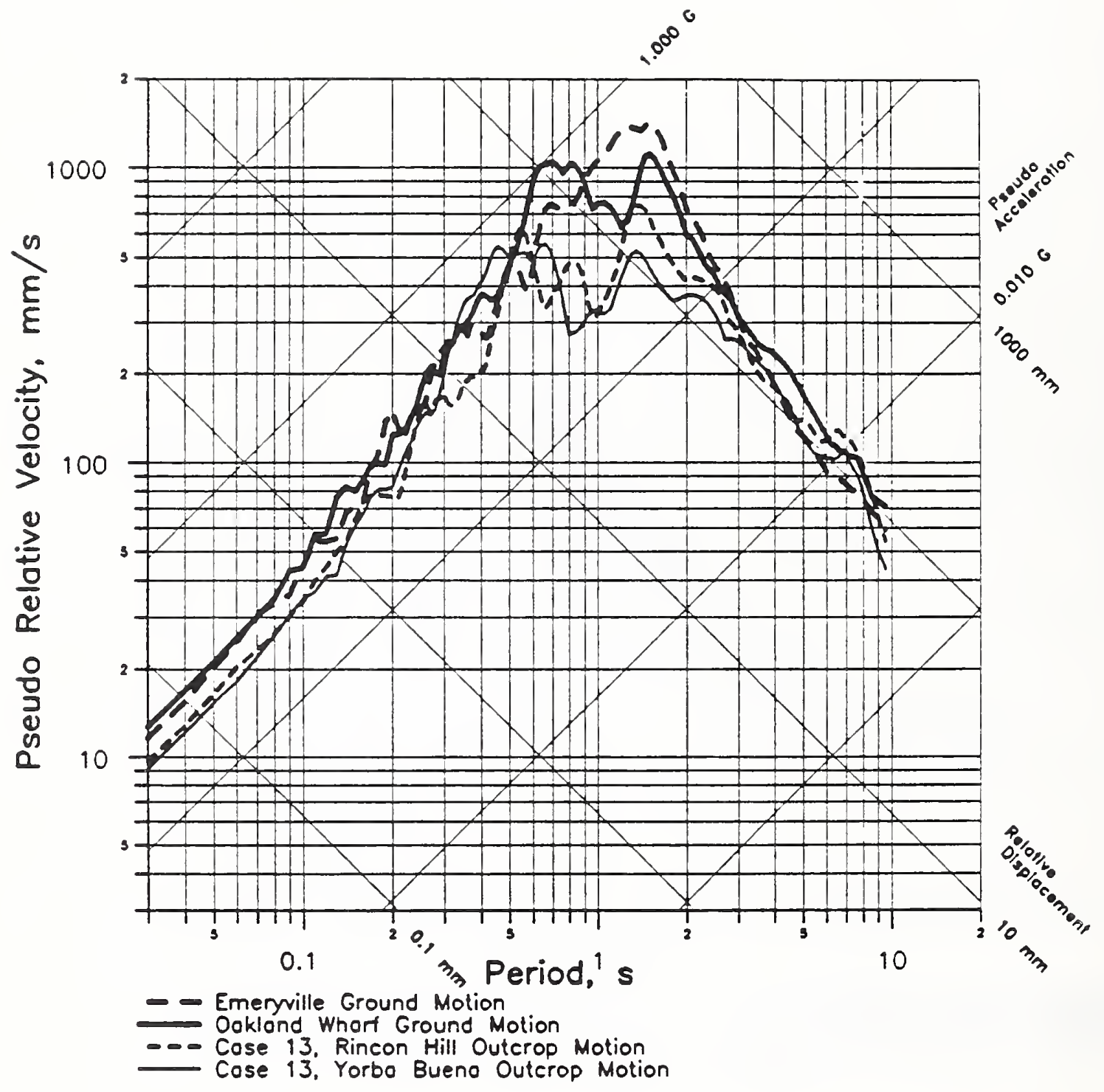

Figure 4.40: Comparison of Response Spectra for Case 13 with the Recorded Ground Motions at Oakland Outer Harbor Wharf and Emeryville. 

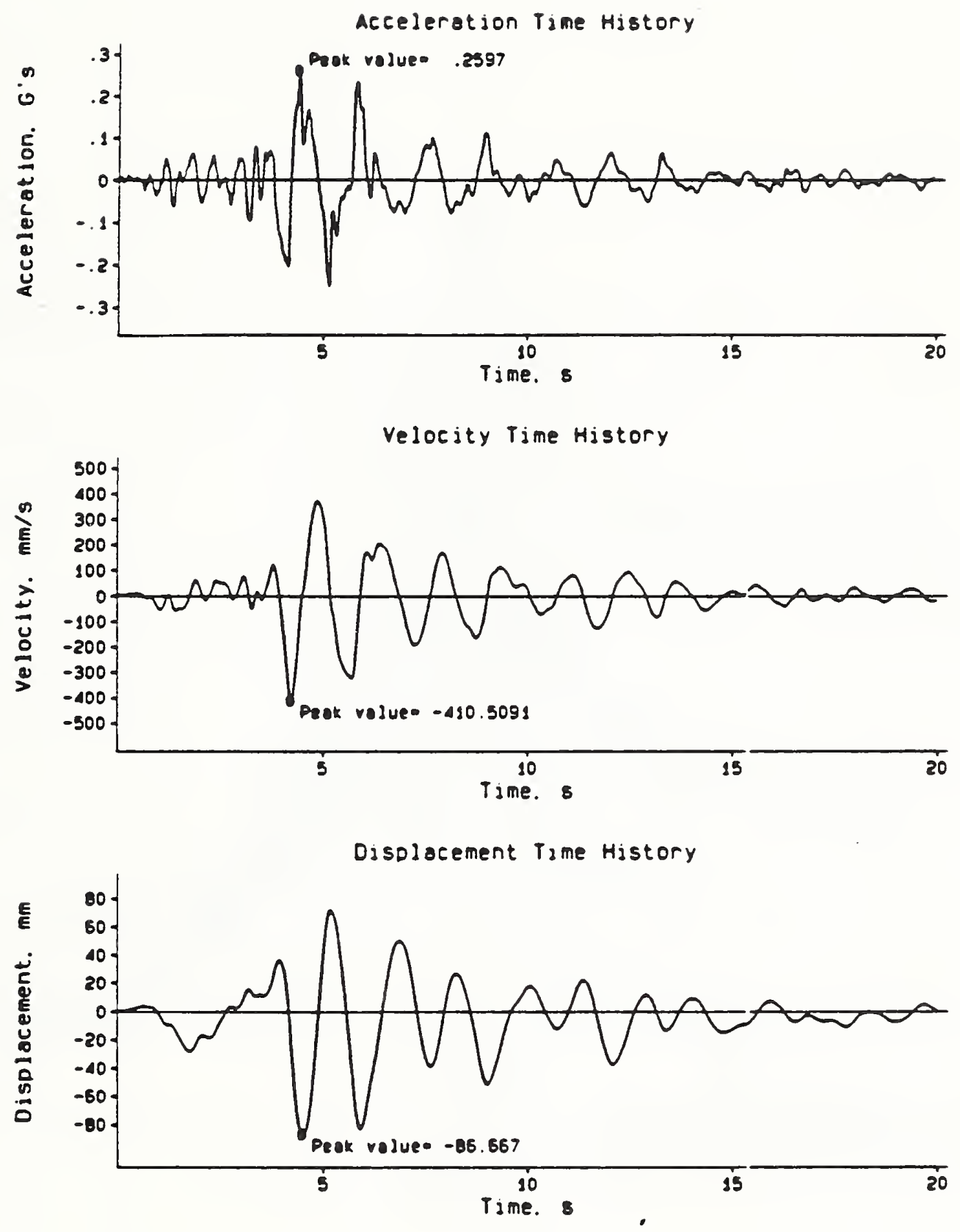

Figure 4.41: Acceleration, Velocity, and Displacement Time Histories for the Recorded Emeryville Ground Motion. 


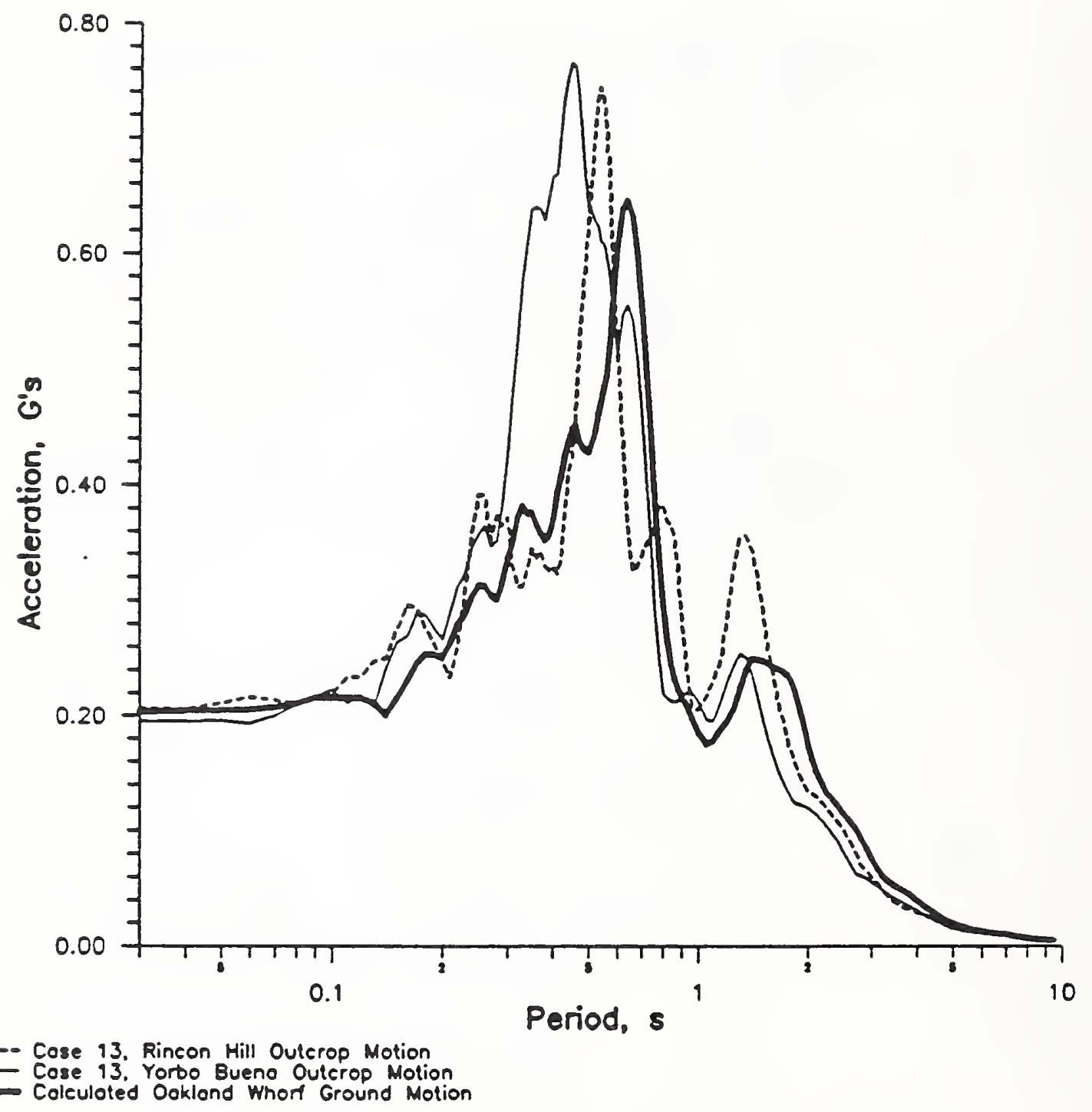

Figure 4.42: Comparison of Calculated Ground Motions for Case 13 and Oakland Outer Harbor Wharf. 


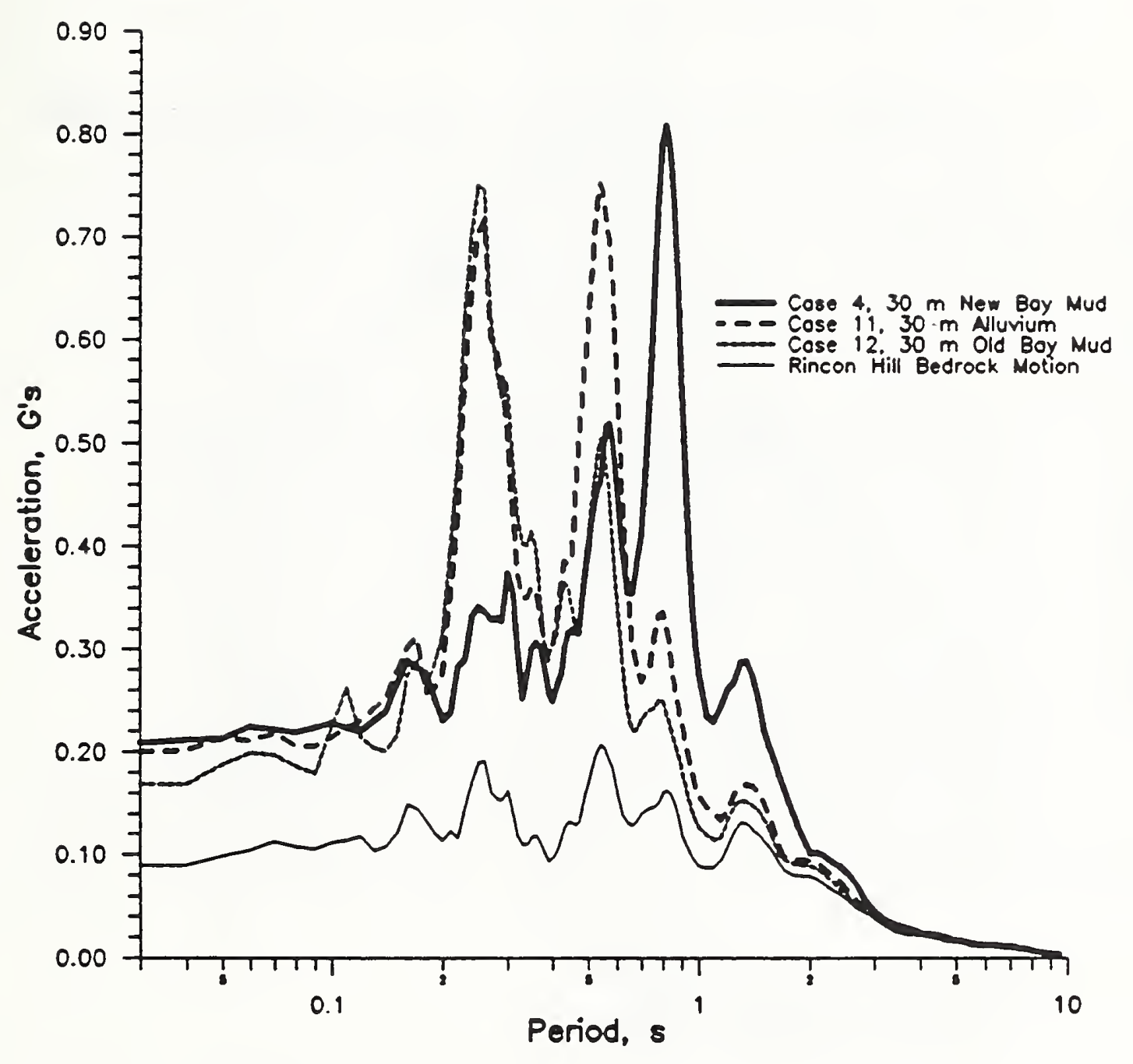

Figure 4.43: Comparison of Acceleration Response Spectra for Profiles 4, 11, and 12, Calculated for the Rincon Hill Outcrop Motion. 


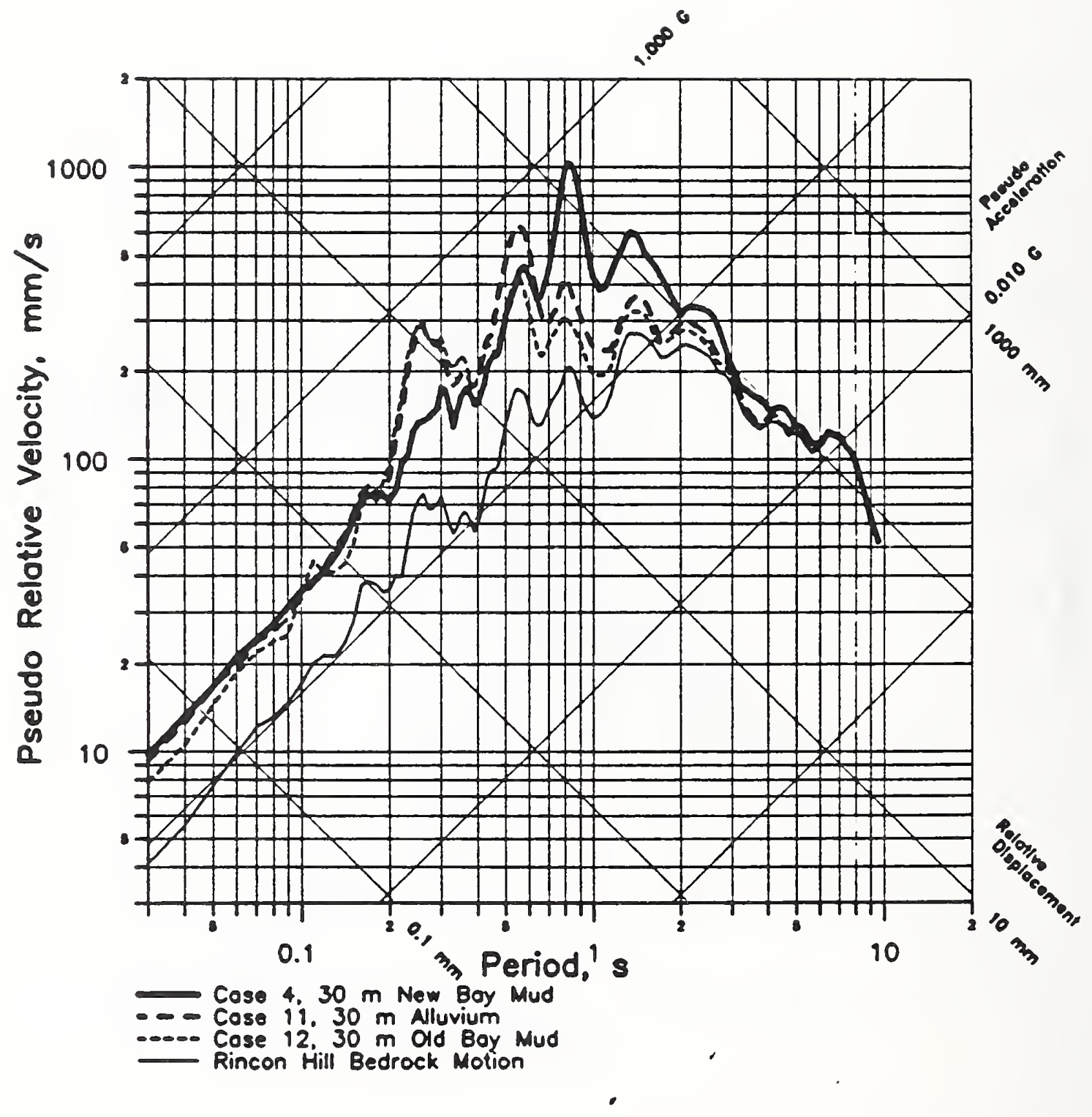

Figure 4.44: Comparison of Response Spectra for Profiles 4, 11, and 12, Calculated for the Rincon Hill Outcrop Motion. 


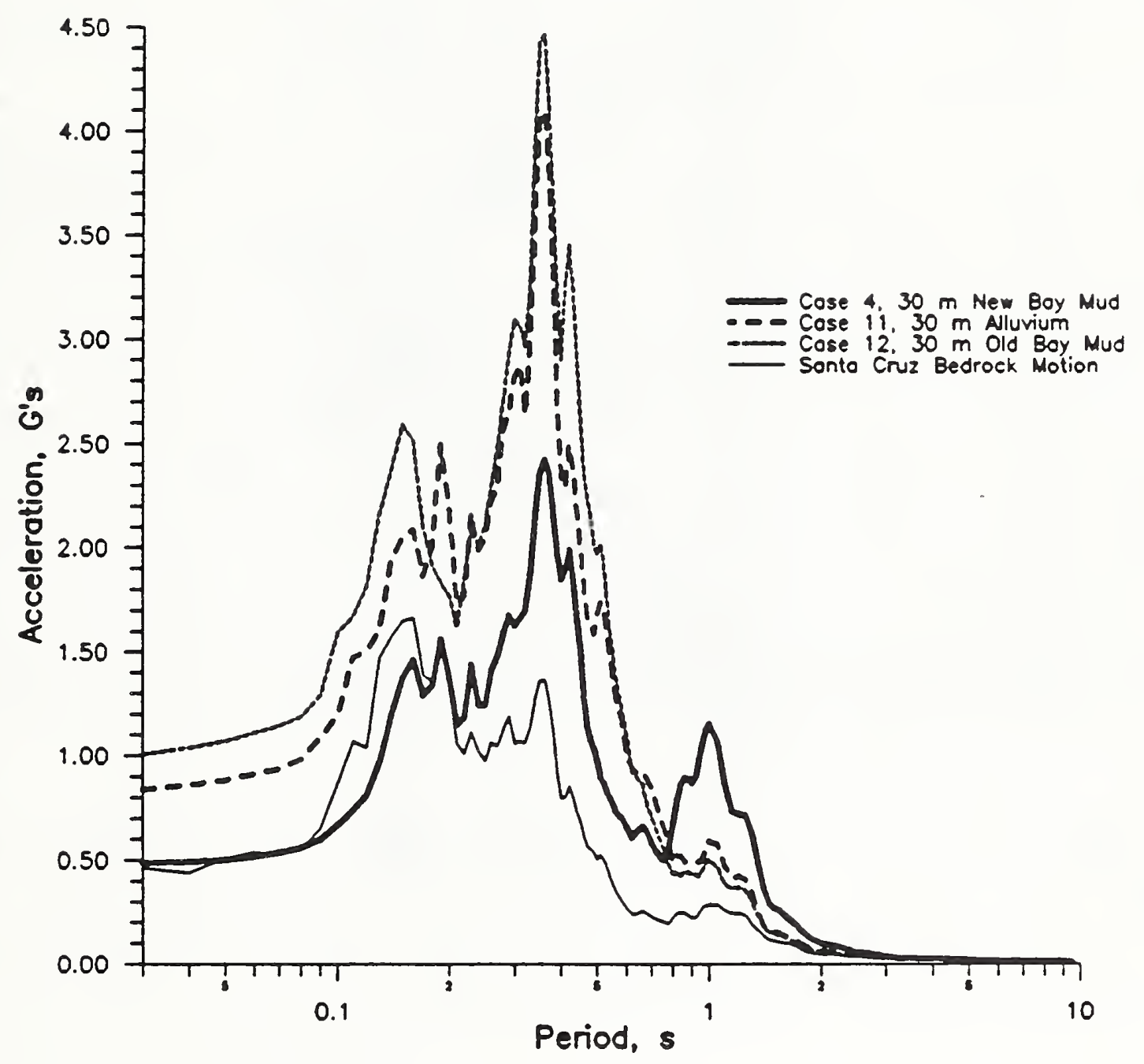

Figure 4.45: Comparison of Acceleration Response Spectra for Profiles 4, 11, and 12, Calculated for the Santa Cruz Outcrop Motion. 


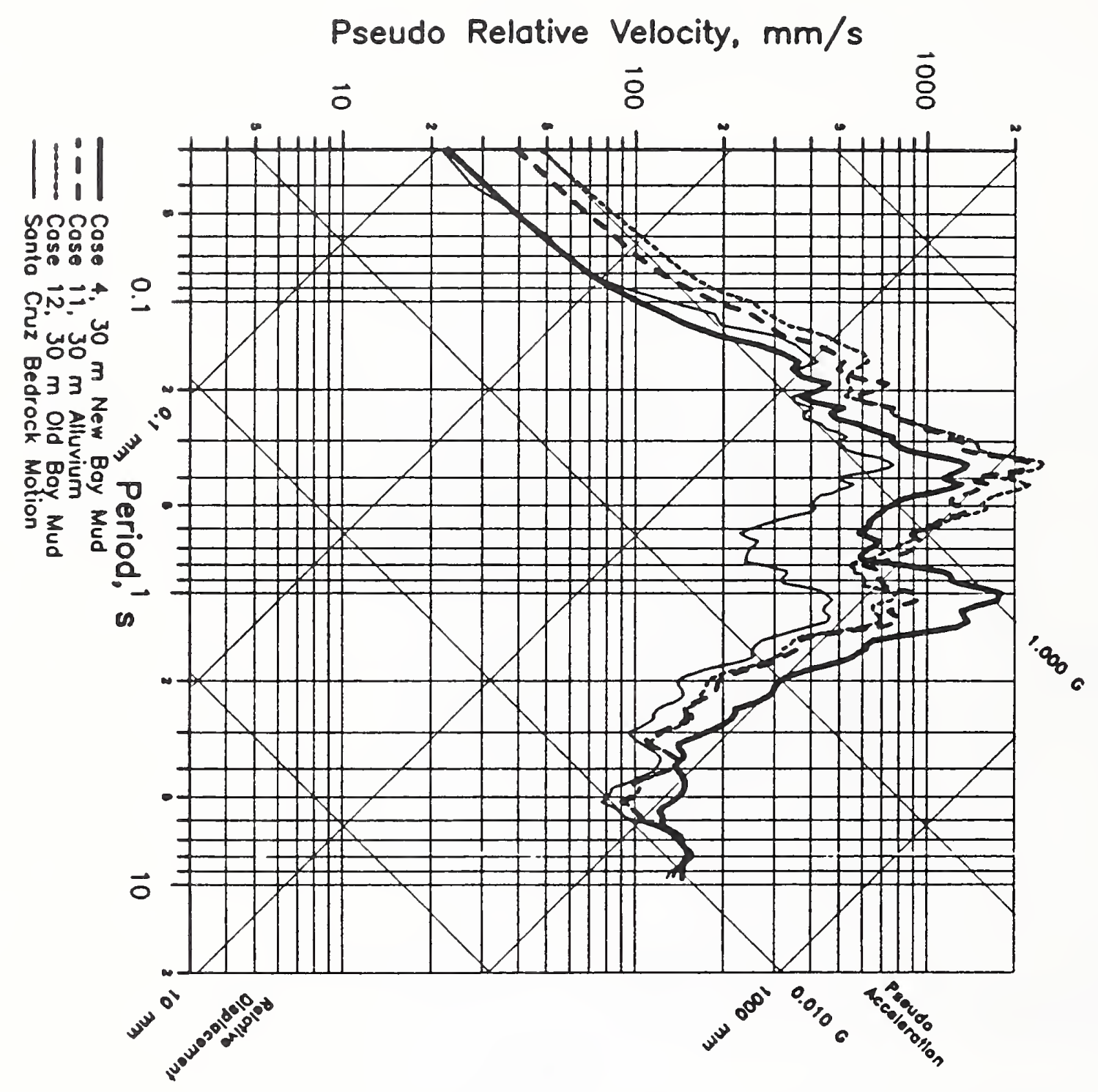

Figure 4.46: Comparison of Response Spectra for Profiles 4, 11, and 12, Calculated for the Santa Cruz Outcrop Motion. 


\section{COMPARISON OF CALCULATED RESPONSE SPECTRA WITH NEHRP DESIGN SPECTRA}

\subsection{Design Spectra Considered}

Elastic design spectra are used to specify the base shear of buildings as a function of their fundamental period. Several different design spectra are presently used. These include among others the SEAOC spectra (SEAOC, 1990), the UBC spectra (ICBO, 1988) and the NEHRP spectra (NEHRP, 1988). These spectra are not identical. However, for the sake of simplicity, this discussion is confined to the NEHRP recommended spectra.

Figures 5.1 and 5.2 show the elastic design spectra recommended in the 1988 edition of the NEHRP recommended provisions. Two mapped parameters are used to specify these spectra for various regions in the U.S.: $A_{a}$, the seismic coefficient representing the effective peak acceleration; and $A_{v}$, the seismic coefficient representing the effective peak velocity-related acceleration. $A_{a}$ is used to define the upper, cut off value of the spectra (the horizontal portion of the spectra in figure 5.1). $A_{v}$ is used to define the curved portion of the spectra in figure 5.1. The rationale for specifying $A_{a}$ and $A_{v}$ independently is that the longer-period components of the earthquake motion, which determine the part of the design spectrum defined by $A_{v}$, will decay more slowly as the earthquake motion propagates from the source. Thus the contours for $A_{v}$ differ from those for $A_{a}$. The spectra are defined so that the peak spectral acceleration for rock outcrop sites corresponds to $2.5 \cdot A_{a}$, and $A_{a}$ represents the expected "effective" peak acceleration (which corresponds to, but does not necessary equal, the expected peak acceleration of the ground motion). According to the commentary (Vol. 2) of NEHRP, 1988, spectral accelerations for velocity were chosen so that $V=0.762 \cdot A_{v}$, where $V=$ effective peak velocity in $\mathrm{m} / \mathrm{s}$ and $A_{v}$ is in G's. $V$ corresponds to, but does not necessarily equal, the expected peak velocity of the ground motion. It is important to note that, since the publication of NEHRP 1988, it has been decided by ballot of the appropriate NEHRP committee that the maximum acceleration for soil profile types $\mathrm{S} 3$ and $S 4$ should be raised from $2.0 \cdot A_{a}$ to $2.5 \cdot A_{a}$.

Spectra are defined for four soil profile types: Profile Type $S 1$ is defined as rock $\left(V_{s}>762\right.$ $\mathrm{m} / \mathrm{s}$ ) and "stiff" soil conditions (stable deposits of sand, gravel, or stiff clay less than $61 \mathrm{~m}$ deep); Profile Type S2 is defined as stable deposits of sand, gravel, or stiff clays deeper than $61 \mathrm{~m}$; Profile Type S3 is defined as $9 \mathrm{~m}$ or more of soft to medium stiff clays with or without intervening layers of cohesionless soils; and Profile Type $S 4$ is defined as more than $21 \mathrm{~m}$ of soft clays or silts $\left(V_{s}<122 \mathrm{~m} / \mathrm{s}\right)$. There are gaps between the defined soil profiles. As a consequence, many potential soil profiles do not fit any of the four profile types and their interpretation is up to the designer.

For the San Francisco Region, $A_{a}=A_{v}=0.4 \mathrm{G}$, and the equations defining the elastic design spectrum for profile types 1 and 2 become (NEHRP, 1988):

$$
C_{s}=\frac{0.48 S}{T^{0.67}} \leq 1
$$


Where:

$$
\begin{aligned}
& C_{s}=\text { spectral acceleration } \\
& S=\text { soil profile coefficient } \\
& T=\text { period }
\end{aligned}
$$

$S=1,1.2,1.5$, and 2 for profile type $S 1, S 2, S 3$, and $S 4$, respectively. For profile types 3 and $4, C_{s} \leq 0.8$, rather than 1 (in the published version of NEHRP' 88 - a provision which has now been dropped).

\subsection{Comparison of the NEHRP design Spectra with Response Spectra for Calculated and Observed Ground Motions}

Response spectra represent the peak response of resonators with different fundamental frequencies and a given damping ratio to an earthquake ground motion, while design spectra are used to specify the design base shear of structures as a function of their dynamic characteristics. Thus there is not necessarily a 1 to 1 correspondence between calculated response spectra and specified design spectra. Nevertheless, one should expect some similarity between the specified design spectra and the response spectra for observed or anticipated ground motions.

For the sake of comparison of design spectra with response spectra for recorded or calculated ground motions in the San Francisco Bay area, response spectra were calculated for profiles S31, S32, S41, S42, S43, and S44 (refer to Table 1, p. 9), using the Rincon Hill and Santa Cruz rock outcrop motions as input. These latter profiles are thought to represent a range of conditions representative of the $\$ 3$ and $\$ 4$ profiles. The Oakland profile shown in figure 2 in this study does not quite qualify for profile type $\mathrm{S} 3$ conditions, but there are $27 \mathrm{ft}(8.2 \mathrm{~m})$ of soft deposits, and it therefore comes close to the definition of a type S3 profile. Another far source time history which is of interest was recorded in a USGS array in the vicinity of Redwood City, CA, named Apeel 2, approximately $47 \mathrm{~km}$ from the source of the Loma Prieta earthquake. Available preliminary information on the subsurface condition in Apeel 2 to a depth of $30 \mathrm{~m}$ (USGS, 1991) is shown in figure 3.2. On the basis of adjacent information from Foster City, CA, it is deduced that the profile shown in figure 3.2 is probably on top of a deep deposit of Old Bay mud. The Apeel 2 profile has a $9 \mathrm{~m}$ layer of very soft New Bay mud and thus meets the definition of a type $\$ 3$ soil profile. The response spectra for the Apeel 2 time history in both, the North South and the East West direction exhibit a very high peak between the $1.0 \mathrm{~s}$ and $1.1 \mathrm{~s}$ periods. Profiles 4 and 9 are considered type $S 4$, and profiles 7 , 11 and 12 type S2. The outcrop motions in Santa Cruz, Rincon Hill, and Yorba Buena are for Type $\mathbf{S 1}$ profiles.

In figure 5.3 the design spectra are compared with the response spectra (which should be roughly equivalent to the design spectra) for recorded and calculated far source ground motions which form a critical envelope. These include the observed Oakland Outer Harbor Wharf and Apeel 2 motions, and the calculated ground motion for profile 4. The spectrum for profile 7 is also shown for comparison. It can be seen from figure 5.3 that the response spectra for the observed and calculated far-source ground motions in the Loma Prieta earthquake do not all fall within the design spectra for the San Francisco region, even if the design spectra for all the soil profile types are extended to the $0.8 \mathrm{G}$ maximum acceleration. 
Of particular concern is the Apeel 2 ground motion, which raises serious questions about the adequacy of the spectrum for profile type $\mathrm{S3}$.

In order to examine whether the recorded Apeel 2 ground motion is atypical for the recorded soil profile, a ground motion was calculated for the soil profile shown in figure 3.2, assuming that the profile shown is underlain by soft rock, and using the Rincon Hill outcrop motion. Since Rincon Hill is approximately $79 \mathrm{~km}$ from the source of the Loma Prieta Earthquake, and the source distance of Apeel 2 is $47 \mathrm{~km}$, the Rincon Hill acceleration was amplified by a factor of 2 , which is an average value obtained from the Joyner-Boore equation (Joyner \& Boore, $1981)$ and from correlations for rock sites recently developed for the Loma Prieta earthquake. Figure 5.4 shows a comparison between the response spectra for the recorded and calculated ground motion, which are quite close. Even though there is considerable uncertainty about the subsurface condition below the soil profile shown in figure 3.2 and about the probable bedrock motion, figure 5.4 indicates that it is not unreasonable to expect this type of ground motion for a type $\mathrm{S} 3$ soil profile.

The response spectra shown in figure 5.3 are for earthquake records with large source distances $(47-80 \mathrm{~km})$. However, earthquakes could originate in the San Andreas and Hayward faults at distances much closer than that for the source of the Loma Prieta event. Thus it is appropriate to compare the design spectra for the San Francisco region with spectra generated by, or likely to be generated by, the Santa Cruz outcrop motion, which has a source distance of approximately $20 \mathrm{~km}$. This is done in figures 5.5 and 5.6 . It can be seen from these latter figures, that for periods less than 1.5s the design spectra appear to be inadequate for a near-source earthquake. They may be adequate for bedrock motions, however soil profile type S1 also includes stiff soil sites to a depth of $61 \mathrm{~m}$.

Of particular concern is the considerable amplification of the near-source rock outcrop motion for periods less than 1.0s, attributable to most of the soil profiles studied, even for relatively stiff or shallow soil profiles. This is not inconsistent with the observation in the Loma Prieta Earthquake, that most of the structural and lifeline damage occurred in areas of deeper soil deposits, while areas where bedrock is at a shallow depth remained relatively undamaged (Lew et al., 1990, 3-8). Note that in figure 5.5 the response spectrum for the Santa Cruz outcrop motion is reasonably within the design spectrum for profile type $\mathrm{S} 1$.

\subsection{Spectral Maps Prepared by USGS}

Recently the United States Geological Survey (USGS) prepared new earthquake risk maps which specify predicted response spectra by two parameters (Algermissen et al., 1991): The spectral acceleration ordinate for a 0.3 s period, which can be considered equivalent to $A_{a}$ as used in NEHRP 1988; and the spectral acceleration ordinate at a 1.0 s period, which serves the same function as coefficient $A_{v}$ in NEHRP 1988, except that $A_{v}$ is not defined for a specified period. The two spectral ordinates define a hypothetical spectrum for a type $S 2$ soil profile. A spectral envelope which according to the authors approximates the actual shape of the response spectrum can be defined as follows: 


$$
C_{s}=\frac{S_{A(1.0)} S}{T^{n}} \leq S_{A(0.3)}
$$

where: $\quad S_{A}=$ seismic coefficients for spectral acceleration

$n=$ exponent defining the shape of the curved part of the spectrum

The soil factor $S$ in this case is taken as 1 for soil profile type 2 and adjusted accordingly for other soil profile types. For the design spectrum the authors recommend using $n=1$ for $T$ $\leq 1 \mathrm{~s}$, and $n=2 / 3$ for $T>1 \mathrm{~s}$. The authors also imply that $n=1$ approximates the actual predicted spectral shape and $n=2 / 3$ is introduced to preserve the conservatism for long period structures which is implicit in NEHRP 1988.

Figures 5.7 and 5.8 compare design spectra for the San Francisco region in accordance with NEHRP 1988 with those recommended by Algermissen et al. In figure 5.8 the curves for type S3 and S4 soil profiles are not plotted, because they fall outside the range of the log-log grid. Coefficients $S_{A}$ were determined by scaling the ordinates of the figure for San Francisco presented by the authors. The map prepared by the authors actually shows higher values for $S_{A(0.3)}$ (up to $2 \mathrm{G}$ ) over part of San Francisco, and higher values of $S_{A(1.0)}$ (up to $2 \mathrm{G}$ ) for the Santa Cruz area. It can be seen that adoption of the USGS spectra as design spectra would increase the lateral forces used in structural design in the region. In figures 5.9 and 5.10, the USGS spectra for San Francisco are compared with the response spectra for recorded and calculated ground motions. In figure 5.10 only near source ground motions are included and the NEHRP spectra are also shown for comparison. For the Santa Cruz rock outcrop motion the spectra seem very conservative (it was noted previously that present design spectra reasonably represent that motion). However, for periods less than $1.5 \mathrm{~s}$ the Algermissen spectra fit the spectra for deeper soil profiles reasonably well. For periods greater than $1.5 \mathrm{~s}$ the spectra further increase the already considerable conservatism inherent in the present NEHRP design spectra. For the San Francisco region, the change of the $n$ exponent from 1 to $2 / 3$ for $T>1$ s seems conservative in the extreme. However, this may not necessarily be the case for other regions in the U.S. 


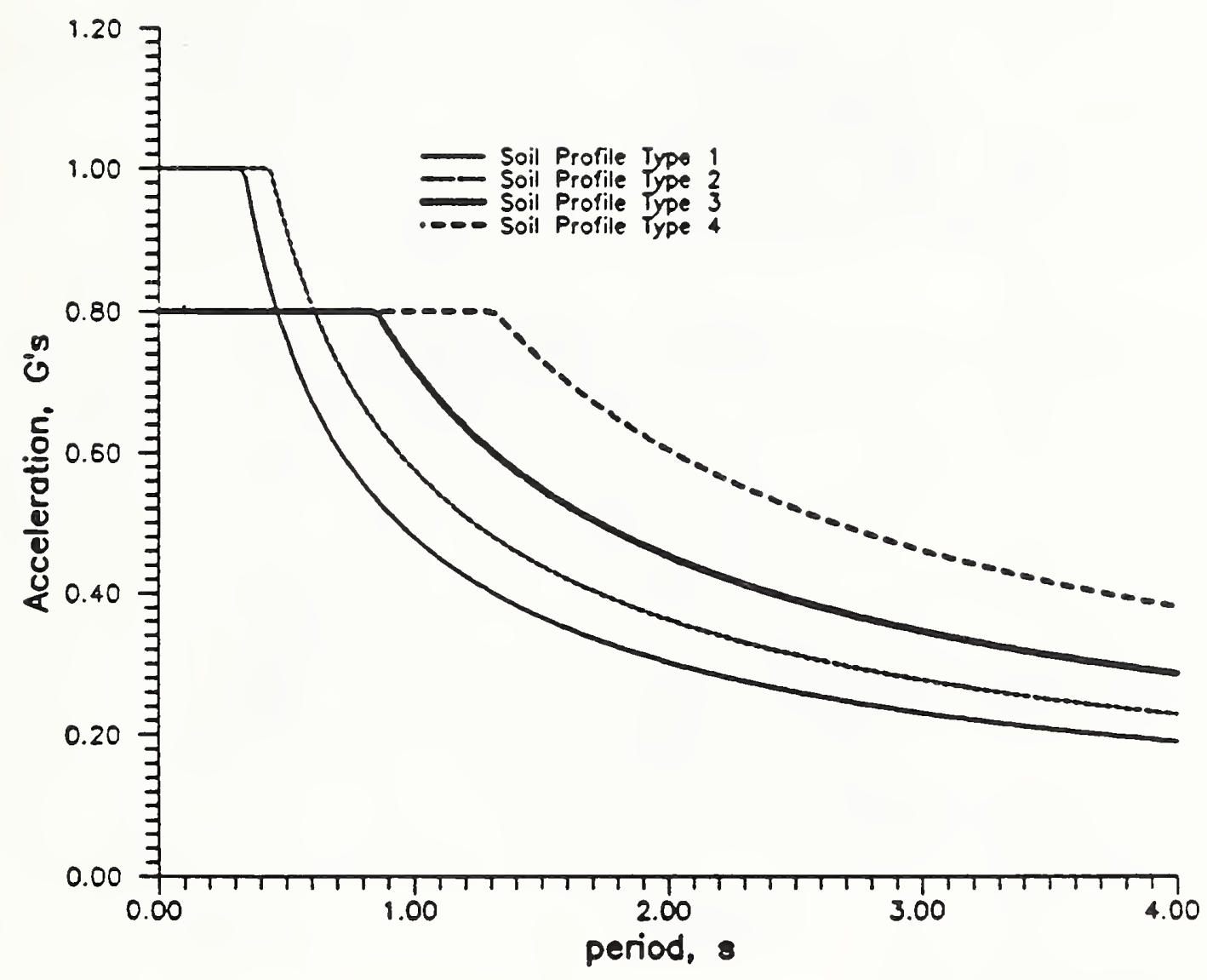

Figure 5.1: Design Spectral Accelerations Specified by NEHRP, 1988, for the San Francisco Bay Region 


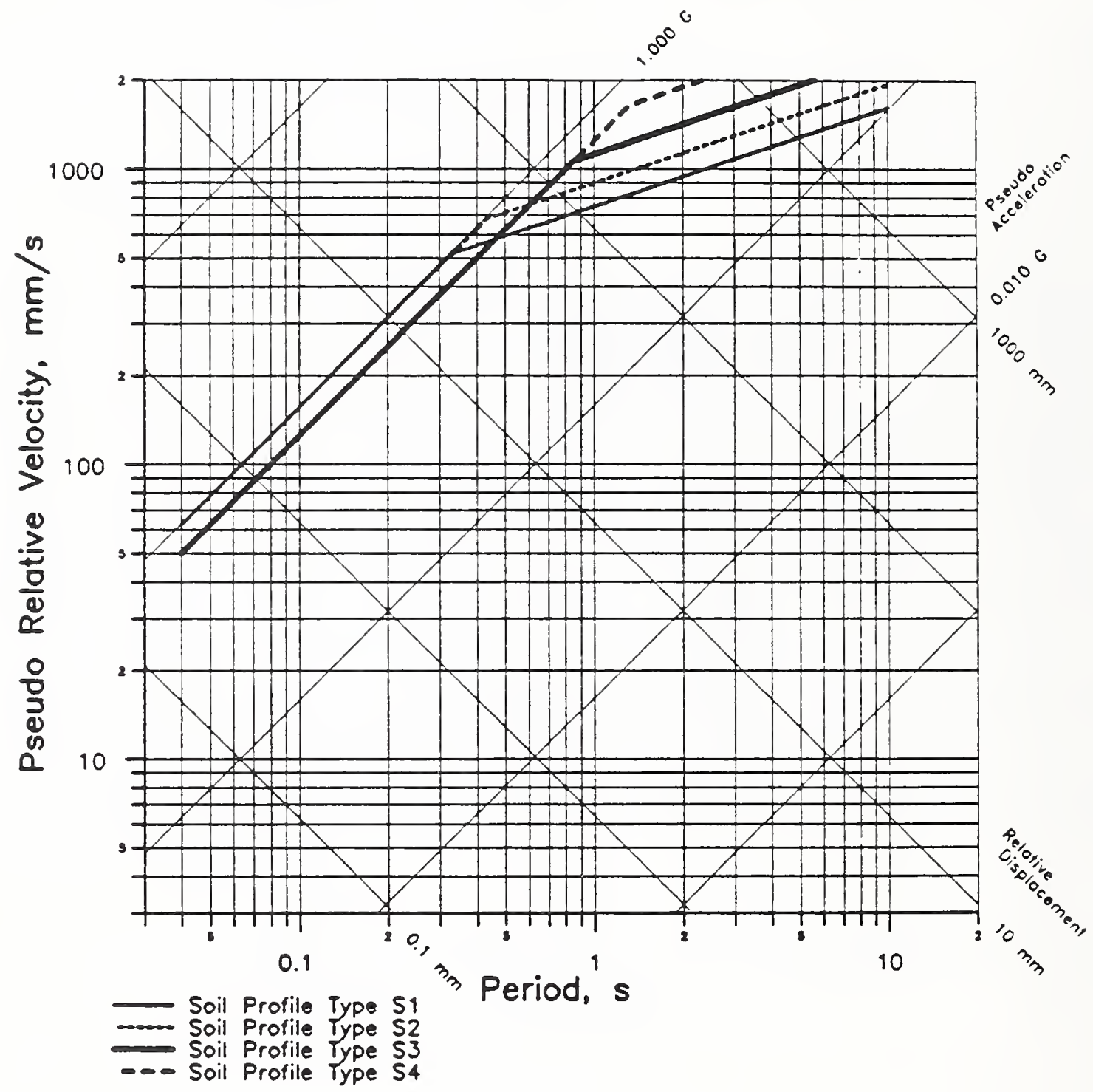

Figure 5.2: Design Spectra Specified by NEHRP, 1988, for the San Francisco Bay Region 


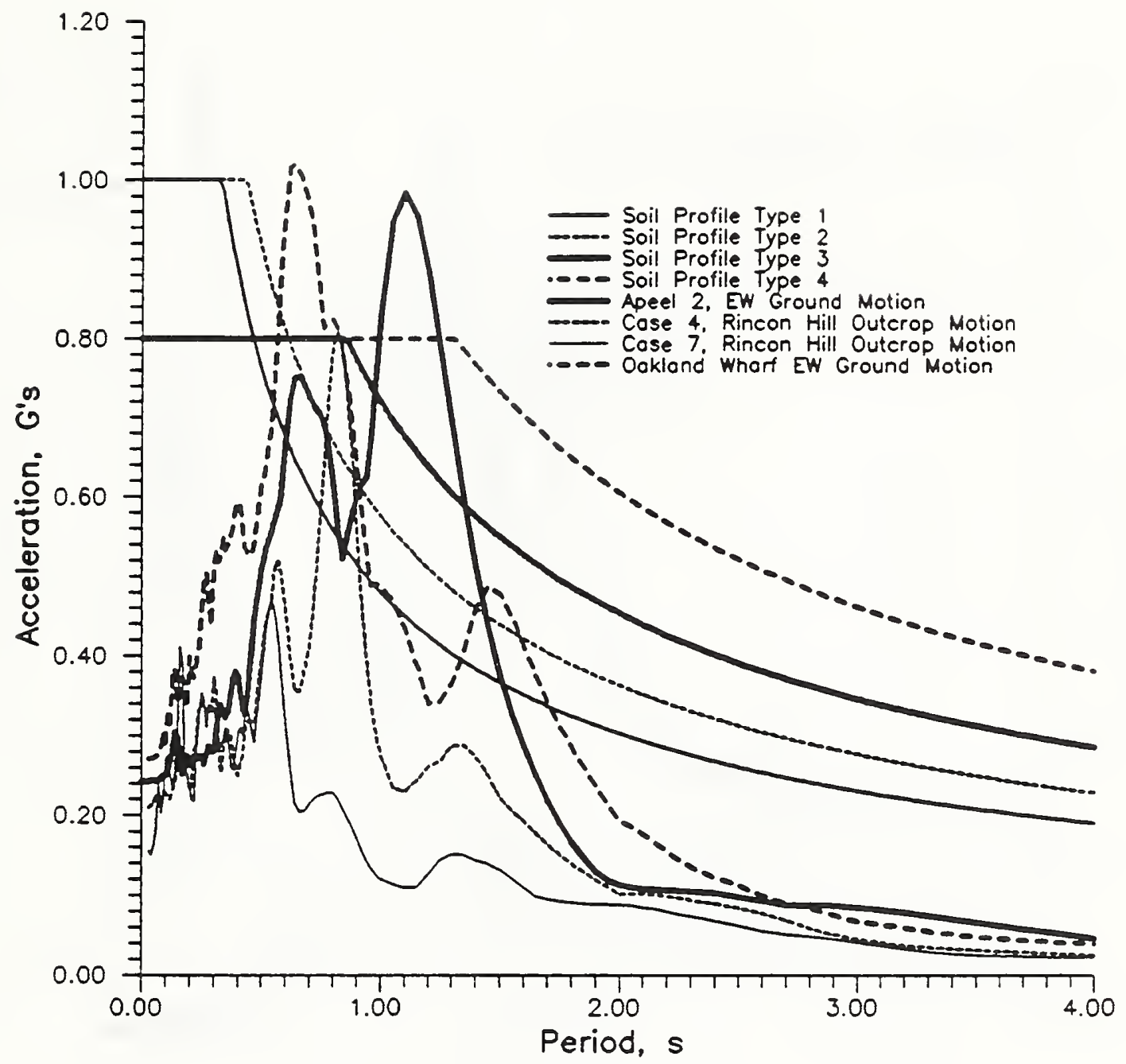

Figure 5.3: Comparison of the NEHRP Design Spectra for Acceleration for the San Francisco Region with Response Spectra for Recorded and Calculated Far Source Ground Motions. 


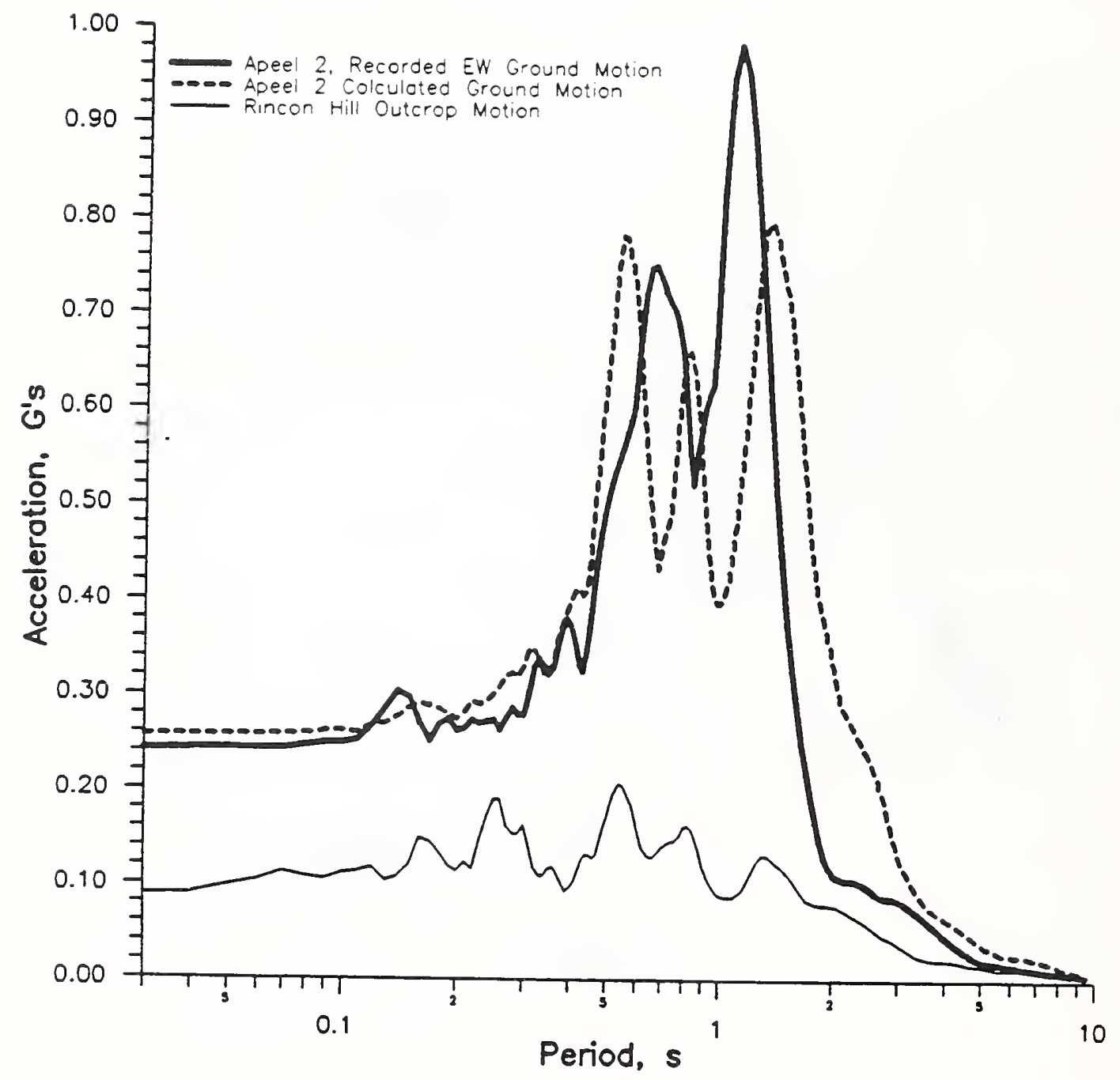

Figure 5.4: Comparison of Response Spectra for the Recorded and Calculated Ground Motions at the Apeel 2 array. 


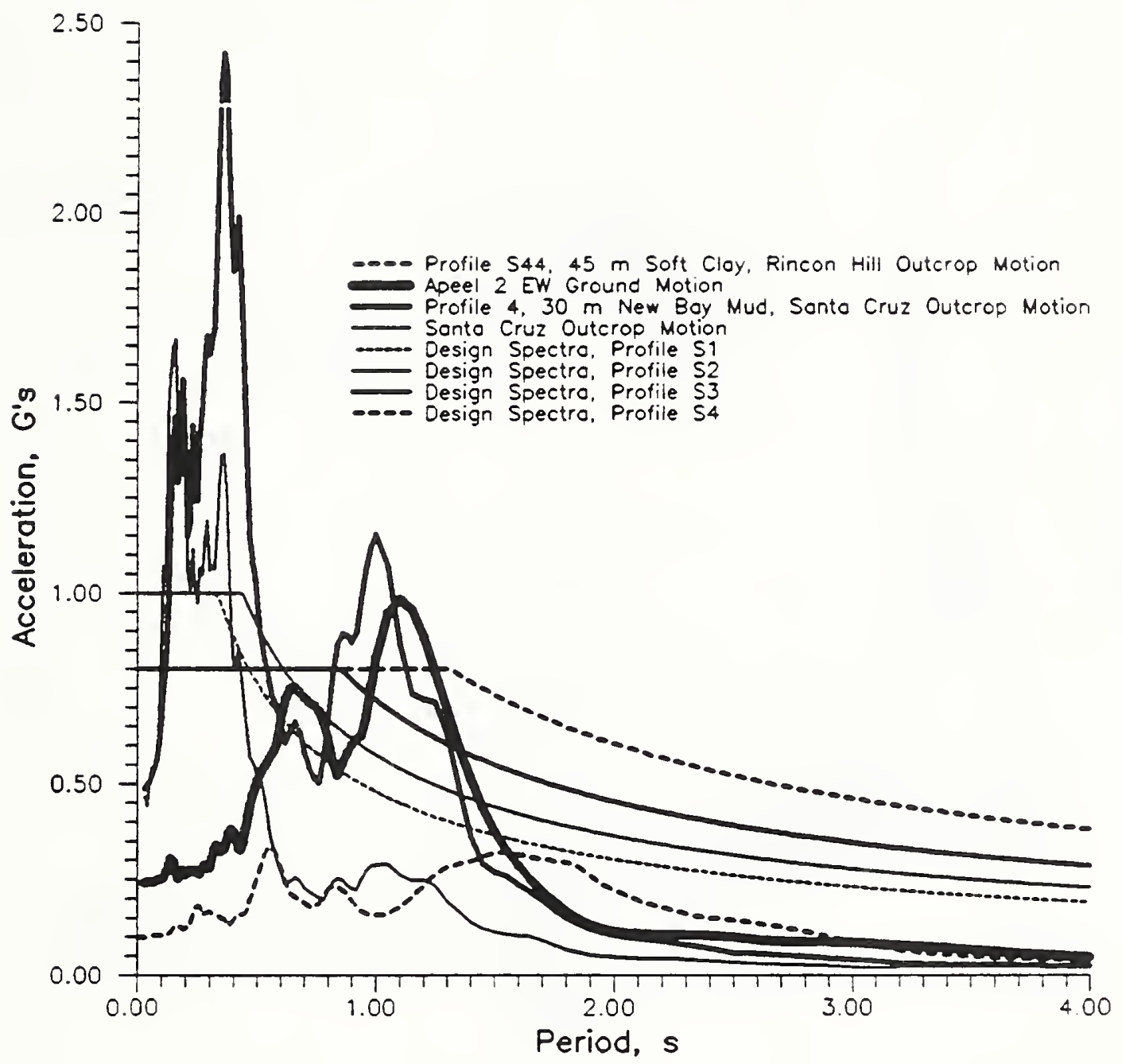

Figure 5.5: Comparison of the NEHRP Design Spectra for Acceleration for the San Francisco Region with Response Spectra for Recorded and Calculated Near Source Ground Motions. 


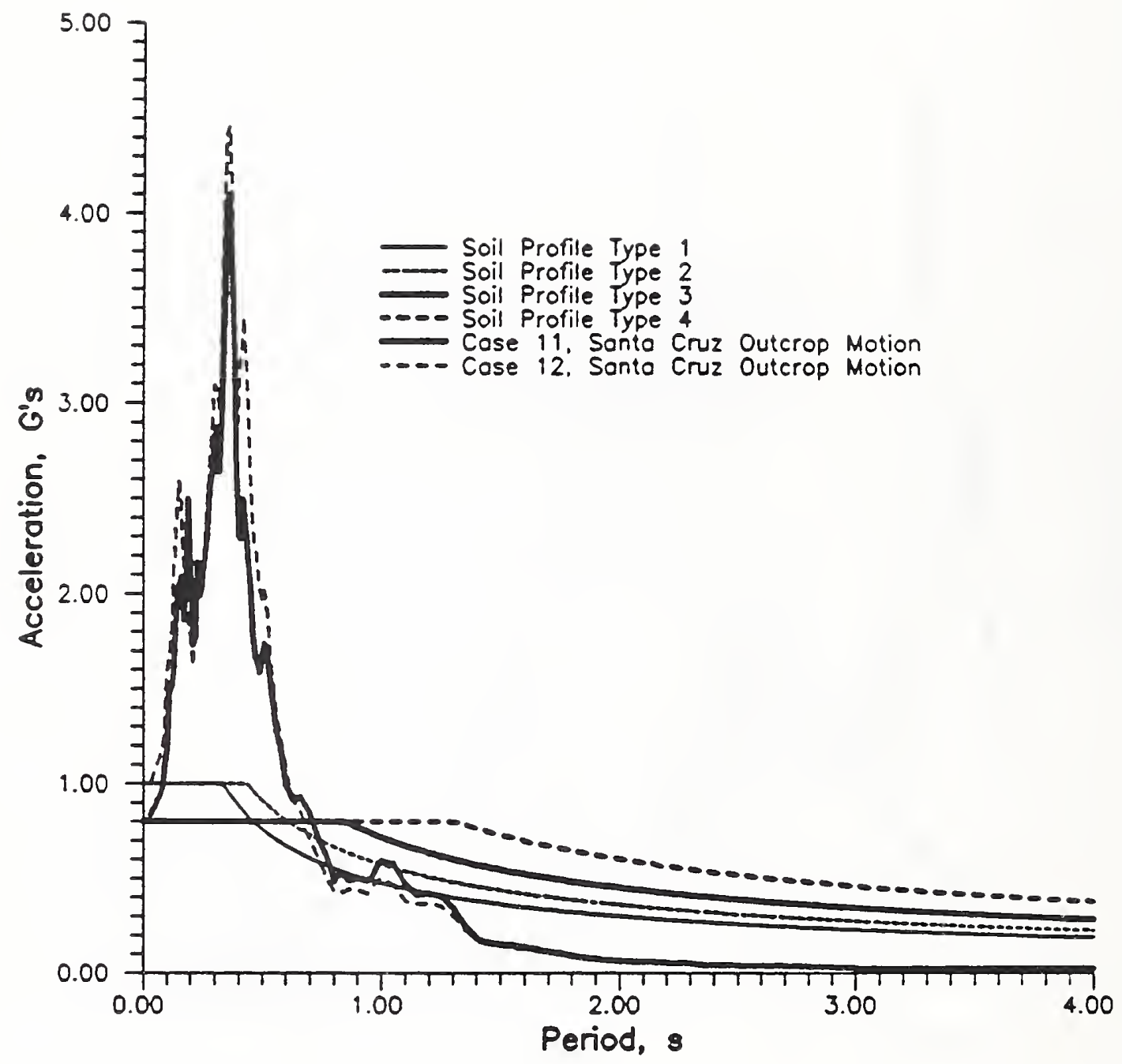

Figure 5.6: Comparison of the NEHRP Design Spectra for Acceleration for the San Francisco Region with Response Spectra for Calculated Near Source Ground Motions. 


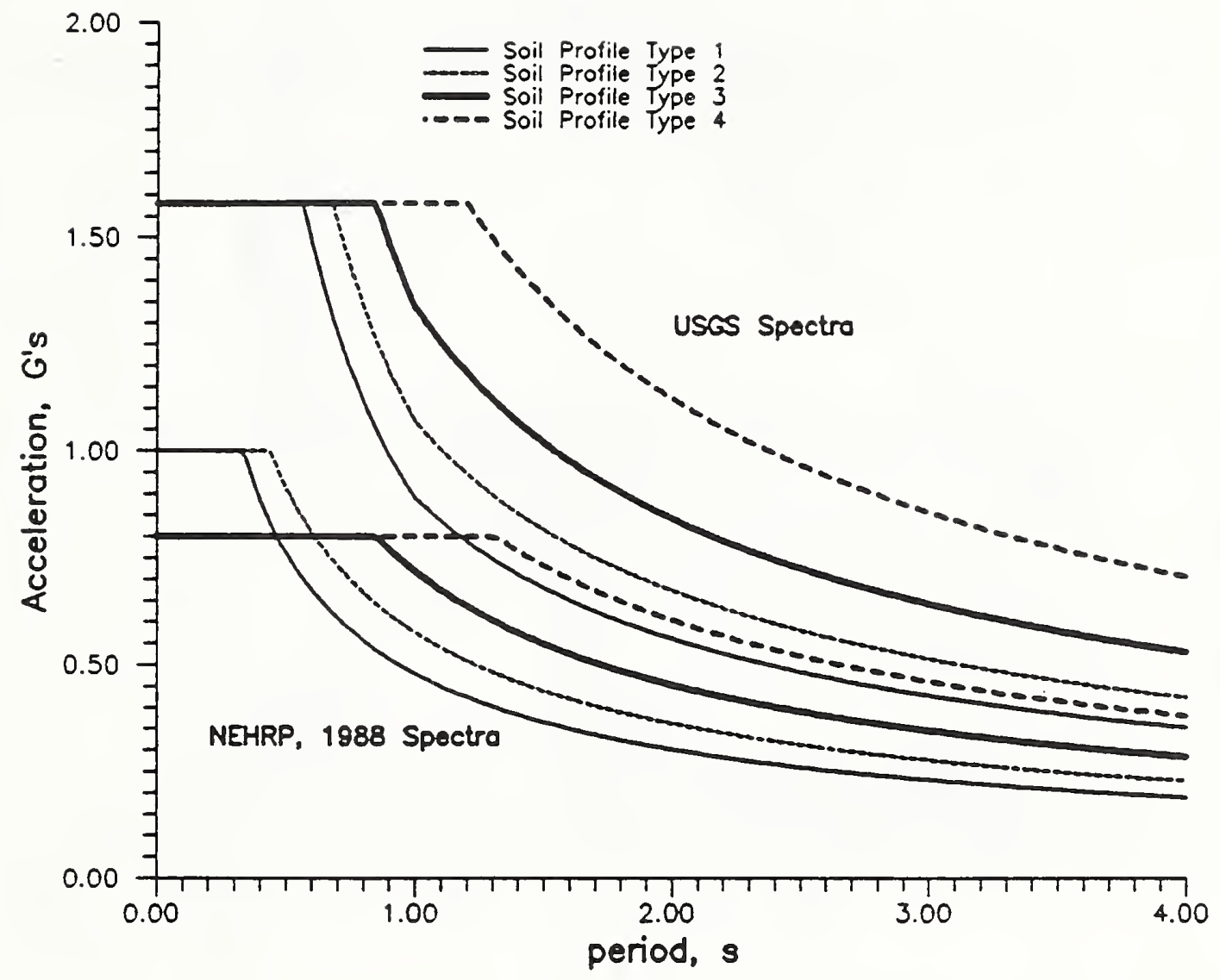

Figure 5.7: Comparison of Design Spectra for Acceleration for the San Francisco Region Recommended by Algermissen et al. 1991, with those recommended in NEHRP, 1988. 


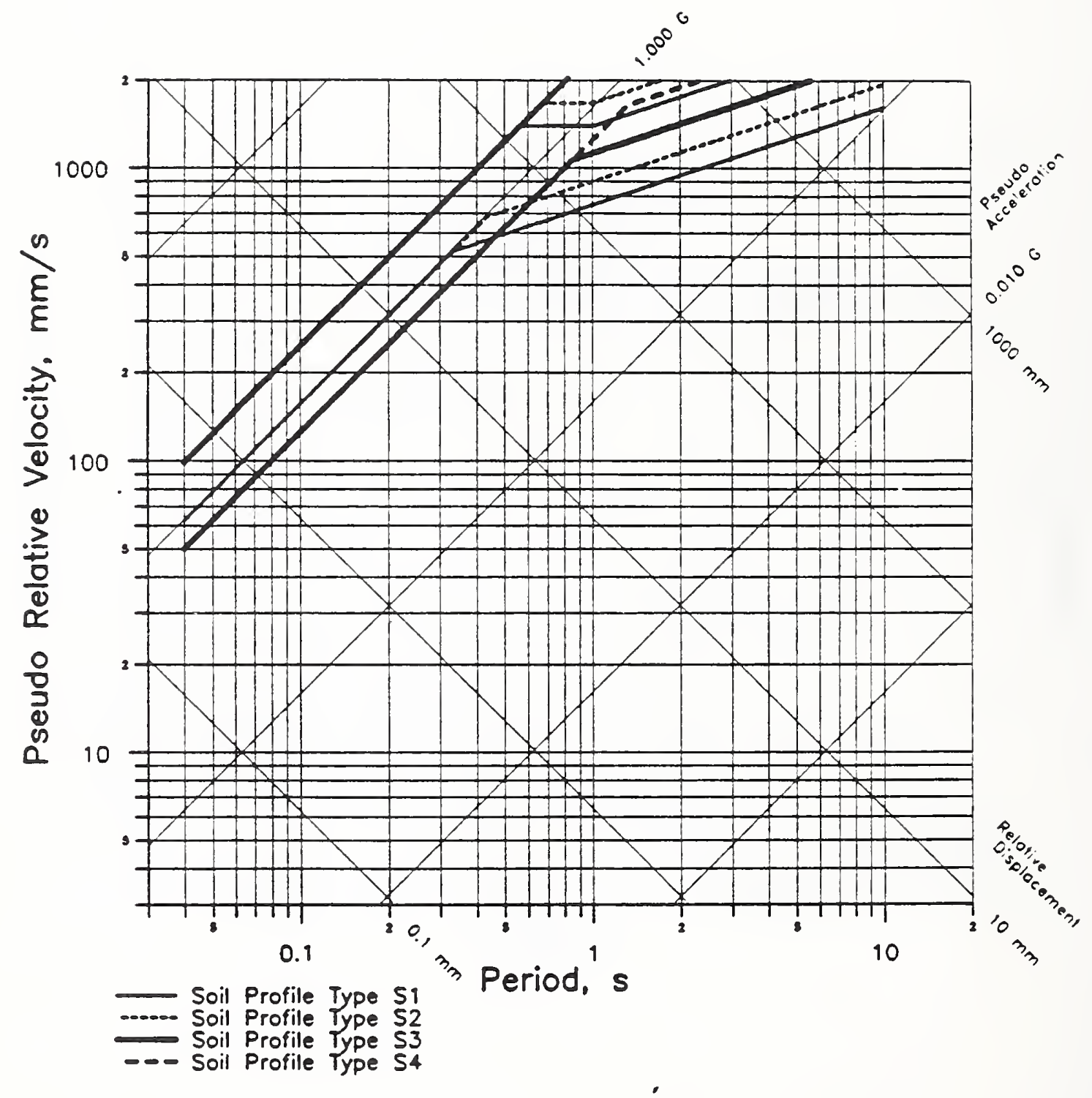

Figure 5.8: Comparison of Design Spectra for the San Francisco Region Recommended by Algermissen et al. 1991, with those recommended in NEHRP, 1988. 


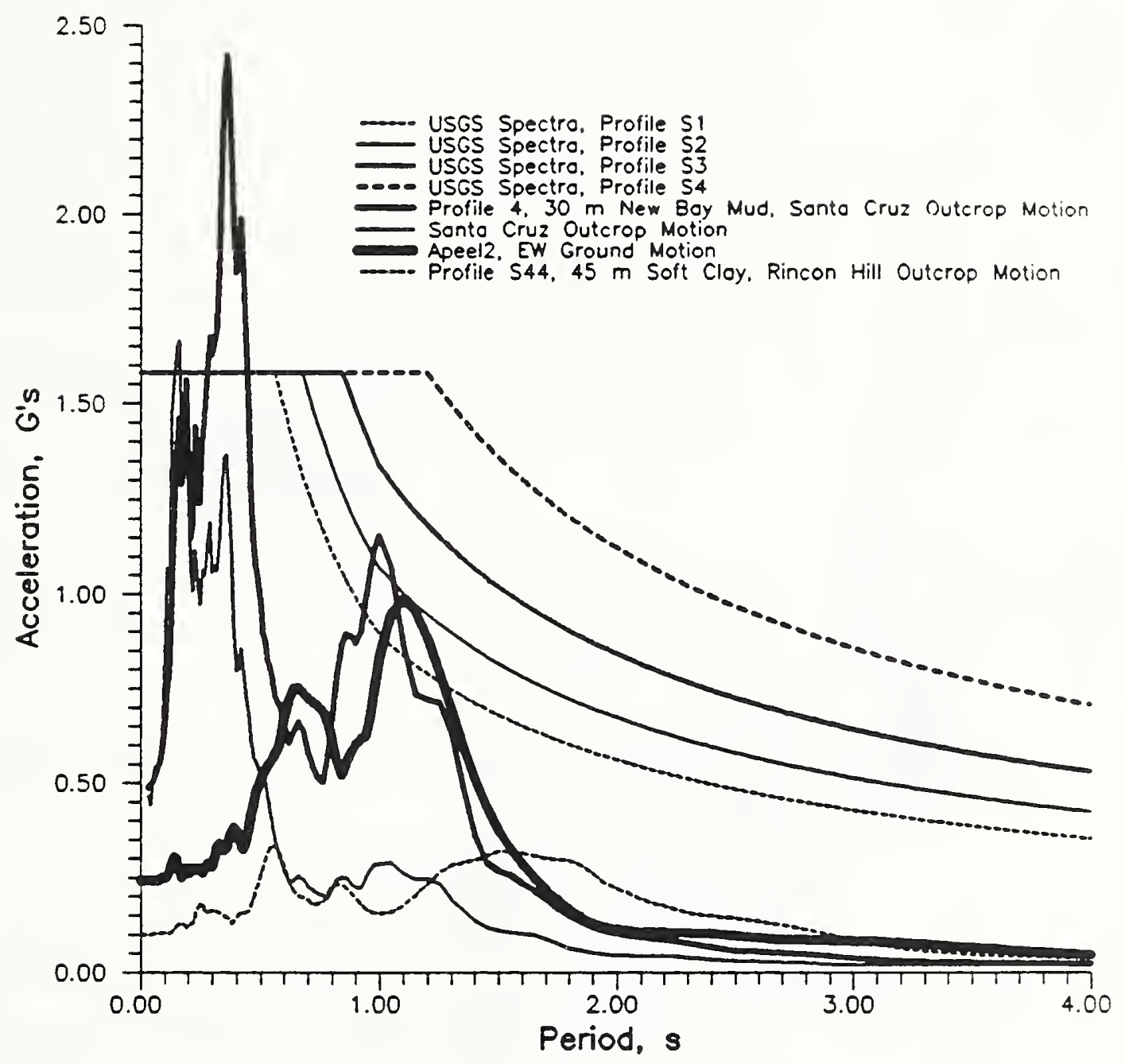

Figure 5.9: Comparison of the USGS Design Spectra for Acceleration for the San Francisco Region with Recorded and Calculated Response Spectra for Far and Near Source Earthquake Motions. 


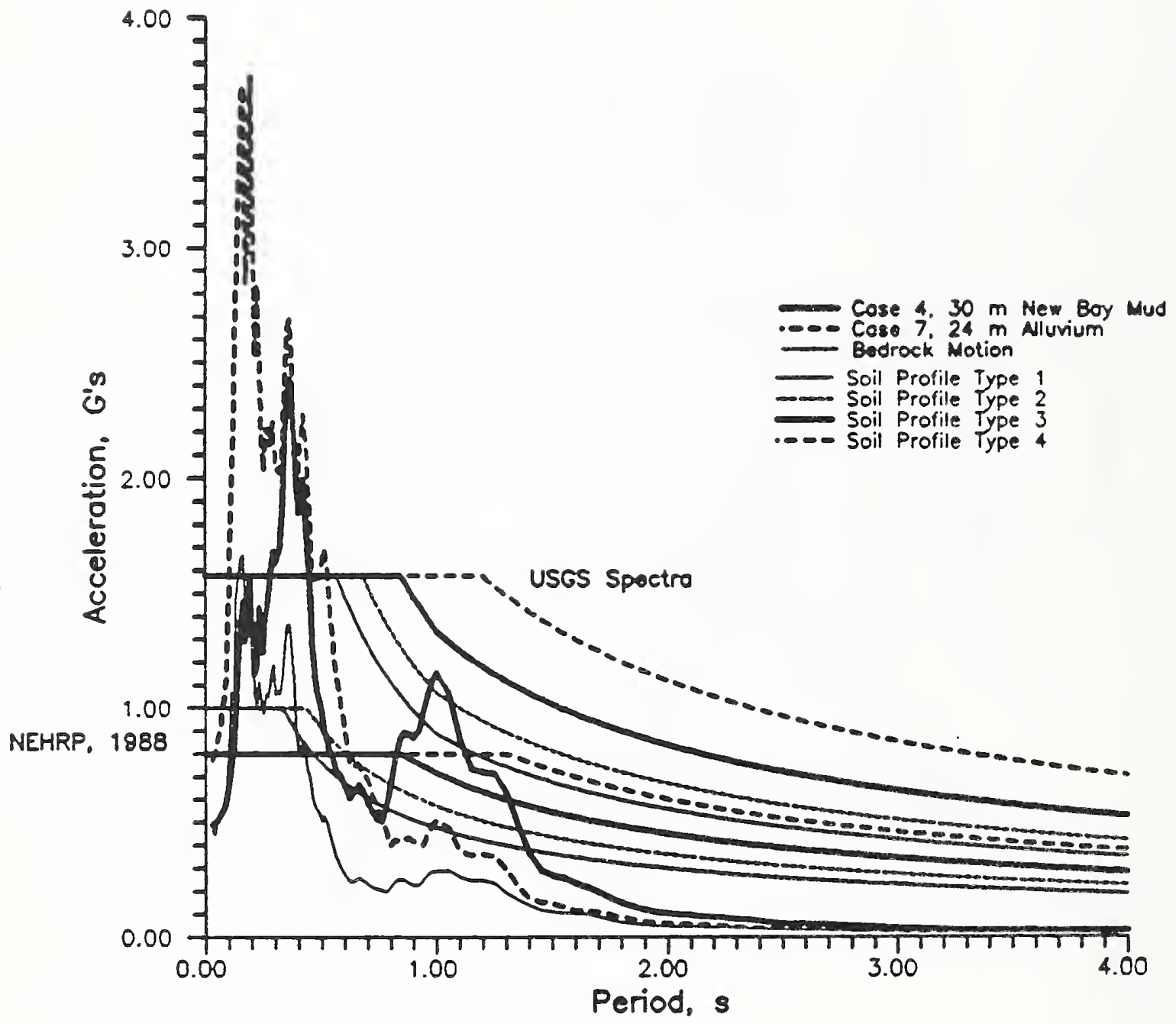

Figure 5.10: Comparison of the NEHRP and USGS Design Spectra for Acceleration for the San Francisco Region with Response Spectra for Far Source Earthquake Motions. 


\section{SUMMARY OF FINDINGS}

\subsection{Modeling of the Ground Motion}

A revised version of the SHAKE program, prepared as part of this study, was used to calculate ground surface motions at the Oakland Outer Harbor Wharf and the Apeel 2 USGS array, where strong motions caused by the Loma Prieta earthquake where recorded. In the calculations for the Oakland Outer Harbor Wharf, preliminary subsurface data were used, and it was assumed, that the bedrock motion corresponded to the recorded Yorba Buena rock outcrop motion. The calculations reasonably predicted the frequency content of the recorded ground motion, but underestimated the amplitude of the ground motion. Adjustment of the strain level at which dynamic soil properties are calculated, as well as the use of a range of dynamic soil properties did not materially affect the response amplitude. Increase in the assumed base rock stiffness, for which no field data were available, increased the amplitude of the calculated motion. But only when the base rock was assumed to be infinitely stiff, a hypothetical condition which gives an upper limit for the base rock stiffness effect but which cannot exist, did the amplitude of the calculated motion equal that of the recorded motion. Response spectra for a calculated ground motion at Apeel 2, using the Rincon Hill outcrop motion, amplified to account for source distance, were close to those obtained for the recorded motion. However, there is considerable uncertainty with regard to the subsurface conditions and the bedrock motion.

The capability of the revised SHAKE program to split the soil profile into 50 layers was used to determine the effect of reducing the thickness of soil layers used in the analysis to $1 / 4$ the wave length associated with the highest frequency component of the input motion utilized in the calculations.

Comparison of amplification functions calculated for soil profiles split into thin layers and identical profiles split into much thicker layers indicated that the layer thickness used in the analysis had no noticeable effect on the results of the calculations.

\subsection{Effect of Soil Profile Characteristics}

The effect of various soil profile types on the calculated ground surface motion was examined, using input motions at the base of the hypothetical profiles corresponding to the larger component of the horizontal rock outcrop motions recorded at the Rincon Hill, Yorba Buena and Santa Cruz strong motion stations. The recorded Rincon Hill and Yorba Buena motions were thought to be characteristic of a far source earthquake, and the Santa Cruz motion of a near source earthquake.

The effect of the far source earthquakes on the various profile types was as anticipated, with strong amplification in the vicinity of the characteristic period of the deposit. Addition of a 24 $\mathrm{m}$ layer of alluvium at the base of a $30 \mathrm{~m}$ deposit of New Bay mud did not significantly affect the predicted ground motion at the surface of the New Bay mud deposit.

All the soil profiles studied, but particularly the alluvial deposits, substantially amplified the near source outcrop motion for periods below 1.2s. For periods greater than $1.3 \mathrm{~s}$ there was 
no substantial difference between the response spectra for deep New Bay mud deposits calculated for the Santa Cruz motion, and those calculated for the Rincon Hill motion.

\subsection{Comparison With Recommended Design Spectra}

Comparison of response spectra for observed and calculated ground motions with the NEHRP design spectra indicates that, for a far source earthquake, the response spectra for observed ground motions at Oakland Outer Harbor Wharf and Apeel 2 significantly exceed the envelopes for type S2 and S3 profiles proposed in the NEHRP ' 88 recommended design spectra, as recently amended in committee.

For a near source earthquake, it appears that at least the Santa Cruz outcrop motion is reasonably within the envelope of the recommended design spectra. However, the spectra seem very unconservative for all calculated ground motions for the soil profiles studied. This is not inconsistent with the observation that in the Loma Prieta earthquake damage to buildings and lifelines was almost exclusively concentrated in areas of deeper soil deposits (Lew et al., 1990). While some of this latter damage can be attributable to liquefaction (not a topic of this study), much of it occurred in areas where liquefaction was not a contributing factor.

All the response spectra for calculated and observed ground motions are within the envelope of the recommended NEHRP ' 88 design spectra for periods greater than $1.5 \mathrm{~s}$.

Design spectra recently recommended in seismic risk maps prepared by USGS, as applied to the San Francisco Bay region, seem to reasonably predict the response spectra for near source earthquakes associated with the soil profiles studied for periods up to 1.0s. They seem conservative for rock outcrop motions, and conservative in the extreme in the longer period range. It is not clear whether these latter findings can be extrapolated to other regions in the U.S.

\section{ACKNOWLEDGEMENT}

The assistance and advice provided by professor I.M. Idriss is gratefully acknowledged. Dr Joseph I. Sun and Professor Mladen Vucetic provided information on dynamic soil properties. The revised version of SHAKE used in this study was developed by J.I. Sun, P. Dirrim, and I.M. Idriss.

\section{REFERENCES}

Algermissen, S.T. et al., "Probabilistic Ground-Motion Hazard Maps of Response Spectral Ordinates for the United States" ,Proc. 4th Int. Con. on Seismic Zonation,Stanford, CA., EERI, 1991., Vol.Il.

Cooley, J.W., and Tukey, J.W., "An Algorithm for the Machine Calculation of Complex Fourier Series", Mathematics of Computation, Vol. 19 No.90, pp 297, 1965.

Earthquake Eng. Res. Inst.and Nat. Res. Council,"Loma Prieta Earthquake, October 17, 1989, Preliminary Reconnaissance Report", EERI 89-03, 1989. 
Fumal, T.E., A Compilation of the Geology and Measured and Estimated Shear-Wave Velocity Profile at Strong-Motion Stations that Recorded the Loma Prieta, CA Earthquake. USGS Open File Report 91-311

Husid, R.L.,"Analysis de terremotos: Analysis general", Revista del IDIEM, Santiago, Chile, Vol. 8 No. 1, May, 1969, pp 21-42.

ICBO, "Uniform Building Code", International Conference of Building Officials, Whittier, CA, 1988.

Idriss, I.M., "Response of Soft Soil Sites During Earthquakes", Proc. H.B. Seed Memorial Symposium, Berkeley, CA, May, 1990.

Idriss, I.M., "Characteristics of Earthquake Ground Motions", Earthquake Engineering and Soil Mechanics, Proc. ASCE Geotechnical Division Specialty Conf. , Pasadena, CA, June, 1978, ASCE, 1979, Vol.III, pp 1151-1265.

Lew, H.S. et al., "Performance of Structures During the Loma Prieta Earthquake of October 17. 1989". NIST Special Publication 778, January, 1990.

National Earthquake Hazards Reduction Program (NEHRP), "NEHRP Recommended Provisions for the Development of Seismic Regulations for Buildings", FEMA 95, Part 1, Regulations, FEMA 96, Part 2, Commentary, FEMA 97, Part 3, Appendix.

SEAOC, Seismology Committee,"Recommended Lateral Force Requirements and Commentary", Sacramento, CA 1990.

Seed, H.B. and Idriss, I.M., "Soil Moduli and Damping Factors for Dynamic Response Analysis", EERC 70-10, University of California, Berkeley, December 1970.

Schnabel, P.B., Lysmer, J., Seed, H.B.,"SHAKE, a Computer Program for Earthquake Response Analysis of Horizontally Layered Sites", EERC California, Berkeley, CA, December, 1972.

72-12, University of

Sun, J.I. and Galesorkhi, R., "Addendum to Shake Manual", March, 1988.

Sun, J.I., Dirrim, P., Idriss, I.M., "Revision to SHAKE Program", February, 1991.

Udaka, T. and Lysmer, J.,"Supplement to Computer Program SHAKE", University of California, Berkeley, CA, September, 1973.

Vucetic, M. and Dobry, R.,"Effect of Soil Plasticity on Cyclic Response", J. Geotechnical Engineering, ASCE, Vol. 111, No.1, January, 1991. 


\section{APPENDIX: EQUATIONS USED IN THE SHAKE PROGRAM}

Equations used in the SHAKE program were derived by Schnabel et al., 1972, and amended by Udaka and Lysmer, 1973.

For the horizontal displacement:

$$
u=u(z, t)
$$

the 1-D wave equation must be satisfied:

$$
\rho \frac{\partial^{2} u}{\partial t^{2}}=G \frac{\partial^{2} u}{\partial z^{2}}+\eta \frac{\partial^{3} u}{\partial z^{2} \partial t}
$$

where: $\quad u=$ horizontal dynamic displacement

$$
\begin{aligned}
& z=\text { vertical position (in direction of wave propagation) } \\
& t=\text { time }
\end{aligned}
$$$$
\rho=\text { mass density }
$$$$
\eta=\text { viscosity }
$$

For a simple harmonic displacement with the circular frequency $\omega:$

$$
u(z, t)=U(z) \cdot e^{i \omega t}
$$

where: $\quad U=$ displacement amplitude

from (10) and (11):

$$
(G+i \omega u) \frac{\partial^{2} U}{\partial z^{2}}=\rho \omega^{2} U
$$

The general solution to $\mathrm{Eq}(12)$ is:

$$
U(z)=E e^{i k x}+F e^{-i k x}
$$




$$
\text { where: } \quad k^{2}=\frac{\rho \omega^{2}}{G+i \omega \eta}=\frac{\rho \omega^{2}}{G^{*}}
$$

$$
\begin{aligned}
& k=\text { complex wave number } \\
& G^{\circ}=\text { complex shear modulus }
\end{aligned}
$$

The critical damping ratio $\beta$ (see figure 1 ) is related to the viscosity, and $G^{*}$ has been defined by Udaka and Lysmer as:

$$
G^{*}=G\left[1-2 \beta^{2}+2 i \beta\left(1-\beta^{2}\right)^{0.5}\right]
$$

Within the frequency range under consideration $G$ and $\beta$ are assumed to be independent of frequency (refer to figure 1). Thus $G^{*}$ is frequency independent. From Eqs(11) and (13) the wave equation solution for a harmonic motion of frequency $\omega$ can be derived:

$$
u(z, t)=E e^{i(k z+\omega t)}+F e^{-i(k z-\omega t)}
$$

where $E$ and $F$ are displacement amplitudes.

The first term in (16) represents an upward (incident) travelling wave, and the second term a downward (reflected) travelling wave. If the downward direction of wave travel is taken as positive, then, for layer " $m$ " of thickness $h$, the relative displacement at the top and bottom of the layer are:

$$
\begin{gathered}
u(0)=\left(E_{m}+F_{m}\right) e^{i \omega t} \\
u(h)=\left(E_{m} e^{i k_{m} h_{m}}+F_{m} e^{-i k_{m} h_{m}}\right) e^{i \omega t}
\end{gathered}
$$

The shear stress in a horizontal plane is: 


$$
\tau(z, t)=G^{*} \frac{\partial u}{\partial z}=i k G^{*}\left(E e^{i k x}-F e^{-i k x}\right) e^{i \omega t}
$$

and at the top and bottom of layer $\mathrm{m}$ :

$$
\begin{gathered}
\tau(0)=i k_{m} G_{m}^{*}\left(E_{m}-F_{m}\right) e^{i \omega t} \\
\tau(h)=i k_{m} G_{m}^{*}\left(E_{m} e^{i k_{m} h_{m}}+F_{m} e^{-i k_{m} h_{m}}\right) e^{i \omega t}
\end{gathered}
$$

If stresses and displacements at layer boundaries are continuous, then:

$$
\begin{gathered}
E_{m+1}+F_{m+1}=E_{m} e^{i k_{m} h_{m}}+F_{m} e^{-i k_{m} h_{m}} \\
E_{m+1}-F_{m+1}=\frac{k_{m} G_{m}^{*}}{k_{m+1} G_{m+1}^{*}}\left(E_{m} e^{i k_{m} h_{m}}-F_{m} e^{-i k_{m} h_{m}}\right)
\end{gathered}
$$

From Eqs. (22) and (23) recursion formulas for amplitudes $E$ and $F$ can be derived for successive layers, starting with the top layer:

$$
\begin{aligned}
& E_{m+1}=0.5 E_{m}\left(1+\alpha_{m}\right) e^{i k_{m} h_{m}}+0.5 F_{m}\left(1-\alpha_{m}\right) e^{-i k_{m} h_{m}} \\
& F_{m+1}=0.5 E_{m}\left(1-\alpha_{m}\right) e^{i k_{m} h_{m}}+0.5 F_{m}\left(1+\alpha_{m}\right) e^{-i k_{m} h_{m}}
\end{aligned}
$$


where: $\quad \alpha_{m}=$ frequency independent complex impedance ratio:

$$
\alpha_{m}=\frac{k_{m} G_{m}^{*}}{k_{m+1} G_{m+1}^{*}}=\left(\frac{\rho_{m} G_{m}^{*}}{\rho_{m+1} G_{m+1}^{*}}\right)^{0.5}
$$

On the free surface $(m=1)$ the amplitudes of the incident and reflected waves are equal. Since the recursion equations (24 and 25) are directly proportional to $E$ and $F$, the relative amplitude of any layers can be calculated by assuming that $e_{1}=f_{1}=1$. Starting from layer $2, e_{m}(\omega)$ and $f_{m}(\omega)$ can be calculated for all layers.

Transfer functions between the displacements of any two layers can thus be calculated:

$$
A_{n, m}(\omega)=\frac{u_{m}}{u_{n}}=\frac{e_{m}(\omega)+f_{m}(\omega)}{e_{n}(\omega)+f_{n}(\omega)}
$$

Accelerations and strains in any layer can be obtained from displacements:

$$
\begin{gathered}
\ddot{u}(z, t)=-\omega^{2}\left(E e^{i(k z+\omega t)}=F e^{-i(k z-\omega t)}\right) \\
\gamma=i k\left(E e^{i(k z+\omega t)}-F e^{-i(k z-\omega t)}\right.
\end{gathered}
$$

The elasticity and confinement of the rock base is taken into consideration by assuming that the amplitude of the incident wave in the halfspace is independent of the properties of the overlying system. This assumption is applicable, if it is also assumed that the reflected wave is completely absorbed in the halfspace and therefore does not contribute to the incident wave. If the halfspace is Layer $\mathrm{N}$, and $\mathrm{N}^{\prime}$ is an outcropping rock layer for which an 
acceleration record is available, then:

$$
\begin{gathered}
A_{N^{\prime}}(\omega)=\frac{u_{N}}{u_{N^{\prime}}}=\frac{e_{N}(\omega)+f_{N}(\omega)}{2 e_{N}(\omega)} \\
A_{N^{\prime}, 1}(\omega)=\frac{1}{e_{N}(\omega)}
\end{gathered}
$$

Equations (30) and (31) permit consideration of the halfspace elasticity. If, on the other hand, it is assumed that the halfspace is infinitely rigid (an upper limit for response amplitude), a rock outcrop motion can be applied directly to the halfspace (this option is available in the program).

The latter derivation applies to the case of steady state harmonic displacements of circular frequency $\omega$. In the program, the ground motion is represented by a Fourier transform, and the recursion formulas, which are frequency dependent, are applied to each term of the transform. The inverse of these calculated terms represents the calculated ground motion.

The most important determination is the selection of the shear modulus and damping ratio. This is done for each layer for a strain level, specified as a fraction of the maximum strain in the layer produced by the time history. This requires iterative calculations, which are continued for a user specified number of iterations. The initial run is made for $G_{\max }$ and a specified damping ratio. In subsequent iterations dynamic soil properties are chosen from sets of specified soil-specific dynamic soil properties such as those shown in figure 1. Thanks to the efficiency of the Fast Fourier routine (Cooley and Tukey, 1965) and the fact that the curves in figure 1 are very flat (strains are on a logarithmic scale) and therefore convergence is rapid (convergence to within $2 \%$ of the correct value is usually achieved in 5 iterations), the routine is efficient and not very time consuming. 

